\title{
Estudo da interação entre pesticidas e polímeros condutores, visando a aplicação como sensores
}

\author{
Priscila Pizzolato
}

\section{USPNFSC/SBI}

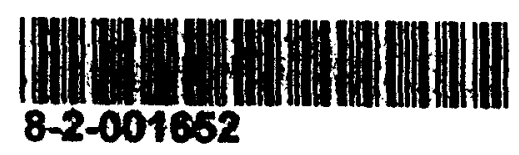

\begin{abstract}
Dissertação apresentada à Área . Interunidades em Clência e Engenharia de Materiais, da Universidade de São Paulo, para obtenção do título de Mestre em Ciências e Engenharia de Materiais.
\end{abstract}

Orientador: Dr. Carlos Manoel Pedro Vaz

São Carlos - 2005 
Pizzolato, Priscila

"Estudo da interação entre pesticidas e polímeros condutores, visando a aplicação como sensores" Priscila Pizzolato - São Carlos, 2005

Dissertação (Mestrado) - Interunidades Ciência e Engenharia de Materiais da Universidade de São Paulo, 2005 - páginas: 83

Área: Ciência e Engenharia de Materiais

Orientador: Dr. Carlos Manoel Pedro Vaz

1.Polímeros condutores, Pesticidas, Interação, POEA, Self-assembly.

1. Título 


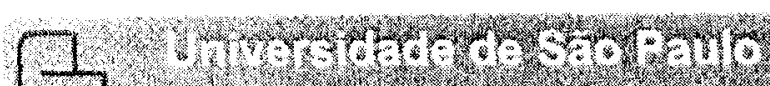

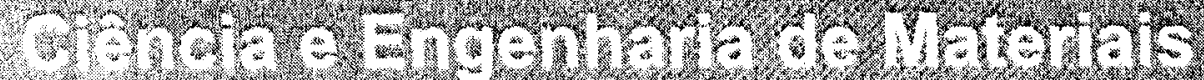

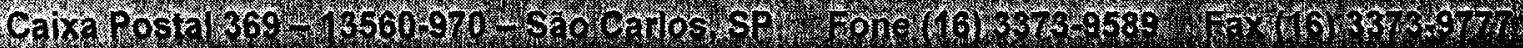

MEMBROS DA COMISSÃO JULGADORA DA DISSERTAÇÃO DE MESTRADO DE PRISCILA PIZZOLATO, APRESENTADA À ÁREA INTERUNIDADES CIÊNCIA E ENGENHARIA DE MATERIAIS, UNIVERSIDADE DE SÃO PAULO, EM 28/03/2005.

COMISSÃO JULGADORA:

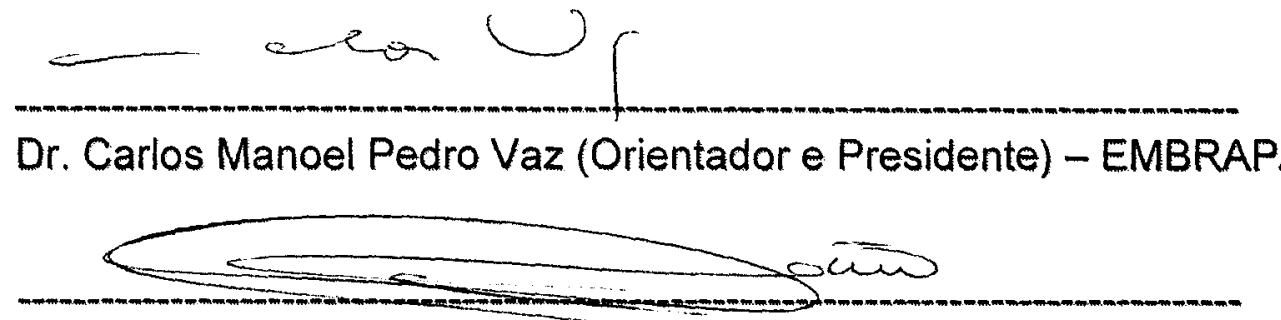

Prof. Dr. Artur de Jesus Motheo-IQSC/USP

Antrmo Riul Trimg

Dr. Antonio Riul Júnior - UNESP 
Aos meus pais e aos meus irmãos, por toda força, amizade e apoio durante todo o meu projeto de mestrado. 


\section{AGRADECIMENTOS}

- À DEUS.

- À minha família e ao Gustavo, pelo amor, compreensão, incentivo, e encorajamento em todos os momentos durante a realização deste trabalho.

- Ao Dr. Carlos Manoel Pedro Vaz, pela orientação deste trabalho.

- Ao Dr. Luiz Henrique Caparelli Mattoso, pela co-orientação e pelas discussões em grupo dos resultados obtidos.

- À FAPESP pela oportunidade, auxílio financeiro concedido ao meu projeto, e também pelas ótimas sugestões feitas pelos assessores.

- Ao Programa de Pós-Graduação em Ciência e Engenharia de Materiais, pela minha aceitação como aluna de mestrado.

- Ao Dr. Leonardo Paterno, Dr. Nelson Consolin Filho, Ms. Alessandra Firmino, Ms. Giuliane de Melo Castanho e Ms. Eduardo Borato pelas valiosas discussões e orientações durante este trabalho, incentivo e encorajamento nos momentos difíceis.

- Ao Ms. Fábio de Lima Leite pelo apoio na realização das análises de microscopia de força atômica (AFM).

- Ao Renato Iwamoto pela ajuda com os gráficos de capacitância.

- Ao Dr. Ernesto Pereira (UFSCAR) pela discussão sobre alguns resultados obtidos durante o mestrado.

- Às minhas amigas queridas: Aline, Giuliane, Nadja, Érica e Alessandra, pelos bons momentos compartilhados.

- Ao Renê de Oste e ao José Ferrazini pelo suporte técnico.

- À Ana pela ajuda nos acertos de contas com a FAPESP.

- Às secretárias da Pós-Graduação, pela eficiência dos serviços prestados.

- À todos meus colegas de trabalho da Embrapa Instrumentação Agropecuária, pela alegria, amizade e companheirismo. 


\section{PUBLICAÇÕES}

Priscila Pizzolato, Luiz Henrique Capparelli Mattoso e Carlos Manoel Pedro Vaz - Síntese e Caracterização de Polímeros Condutores para aplicação em sensores. VI Simpósio de Ciências e Engenharia de Materiais (SICEM). Outubro de 2003.

Priscila Pizzolato, Luiz Henrique Capparelli Mattoso e Carlos Manoel Pedro Vaz - Avaliação por Espectrofotometria de UV-Vis da Interação entre Diversos Pesticidas e a Poli(o-etoxianilina). XXVI Congresso Latinoamericano de Química (SBQ). Maio de 2004.

Priscila Pizzolato, Alessandra Firmino, Fábio de Lima Leite, Luiz Henrique Capparelli Mattoso e Carlos Manoel Pedro Vaz - Sintese e Caracterização de Polimeros Condutores para a Aplicação em Sensores. XVI Congresso Brasileiro de Engenharia e Ciência dos Materiais (CBECIMAT). Novembro de 2004.

Priscila Pizzolato, Luiz Henrique Capparelli Mattoso e Carlos Manoel Pedro Vaz - Estudo de Interação entre Pesticidas e Polímeros Condutores para a aplicação em sensores. VII Simpósio de Ciências e Engenharia de Materiais (SICEM). Novembro de 2004.

Alessandra Firmino, Priscila Pizzolato, Carlos Manoel Pedro Vaz, Luiz Henrique Capparelli Mattoso - Estudos de Caracterização de Filmes Finos Poliméricos de PEDOT Visando Aplicação em Sensores. VII Simpósio de Ciências e Engenharia de Materiais (SICEM). Novembro de 2004. 


\section{SUMÁRIO}

Resumo

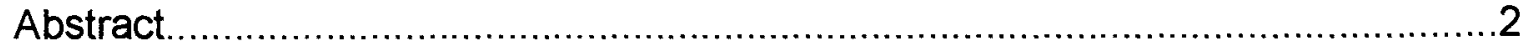

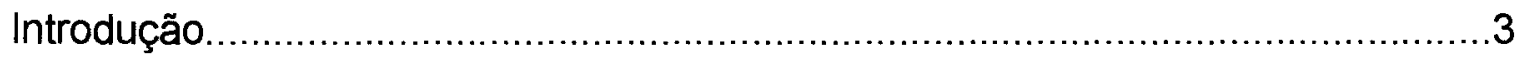

\section{CAPÍTULO I}

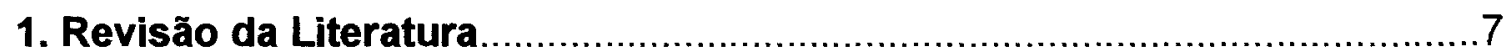

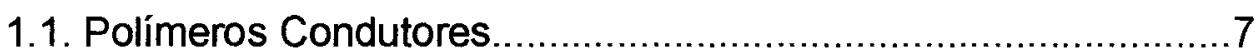

1.2. Filmes Poliméricos Ultra Finos ...........................................12

1.3 Língua Eletrônica.............................................................13

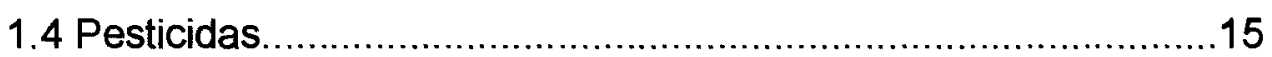

\section{CAPÍTULO II}

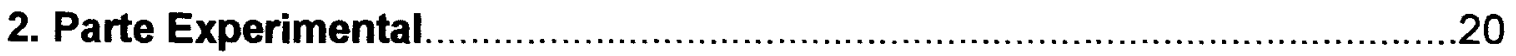

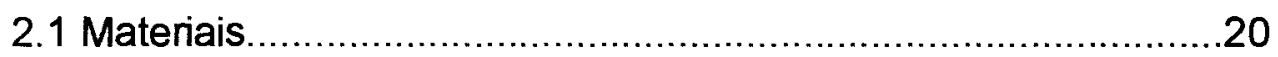

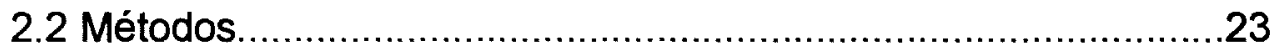

2.2.1 Síntese química dos Polímeros Condutores.................23

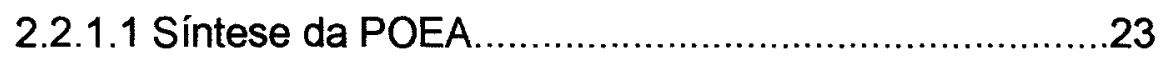

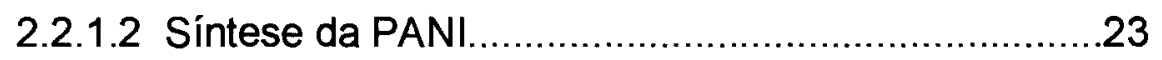

2.2.1.3 Desprotonação da PANI e POEA …………..............24

2.2.2 Caracterização dos Polímeros.....................................24

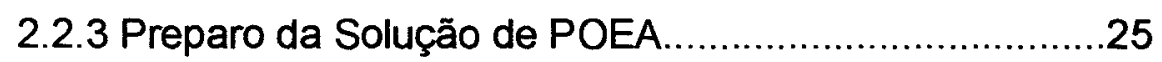

2.2.4 Caracterização de Filmes de POEA..............................25

2.2.5 Caracterização morfológica da POEA e da sua interação com pesticidas por MFA

2.2.6 Deposição "in situ" da PANI sobre substrato vitreo.......26

2.2.7 Determinação da Cinética de Adsorção dos pesticidas na

PANI por UV-Vis 
2.2.8 Estudo de soluções, deposição e caracterização de filmes de PEDOT/PSS.

2.2.9 Caracterização elétrica dos microeletrodos interdigitados. .29

2.2.10 Aplicação da "língua eletrônica" para a medida dos pesticidas. .29

2.2.11 Procedimento de preparação dos filmes poliméricos nos microeletrodos.

2.2.12 Análise do PEDOT/PSS e dos

Pesticidas. 32

\section{CAPÍTULO III}

3. Resultados e Discussões 32

3.1 Caracterização dos Polímeros Condutores 32

3.1.1 Análise dos Espectros de infravermelho com transformada de Fourier. 32

3.1.2 Espectro de UV-Vis das soluções poliméricas 34

3.1.3 Espectros de UV-Vis de filmes de POEA e PEDOT/PSS em lâminas vitreas 38

3.1.4 Espectrofotometria de UV-Vis das lâminas com PANI depositada "in situ". 41

3.1.5 Microscopia Óptica de filmes de PANI e PEDOT/PSS .............43

3.1.6 Microscopia de Força Atômica de filmes de PEDOT/PSS.......45

3.2 Interação POEA e pesticidas por MFA …………...................... 47

3.3 Espectroscopia de Impedância elétrica em filmes de PEDOT/PSS 50

3.4 Determinação das Cinéticas de Adsorção dos pesticidas na PANI por UV-Vis. .52

3.5 Caracterização elétrica dos microeletrodos interdigitados..........64

3.6 Análise dos pesticidas com a "língua eletrônica". 66 


\section{CAPÍTULO IV}

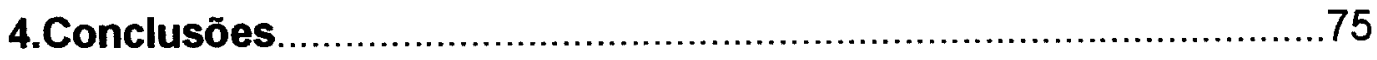

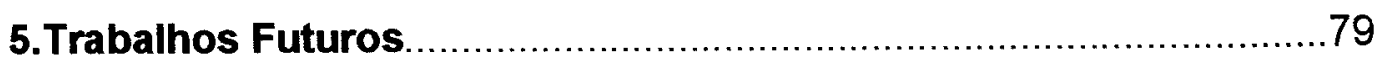

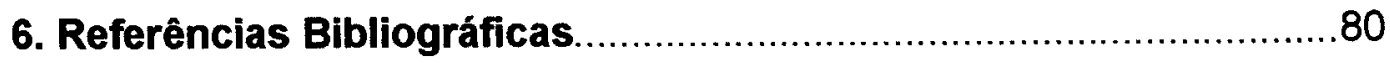




\section{Lista de Tabelas}

Tabela 1. Pesticidas e algumas de suas propriedades físico-químicas

Tabela 1. Pesticidas e algumas de suas propriedades físico-químicas

Tabela 2. Descrição dos sensores utilizados no arranjo da língua eletrônica para a análise dos pesticidas

Tabela 3. Rugosidades dos filmes de POEA e pesticidas, calculados das imagens de MFA apresentadas na Figura 22

Tabela 4. Adsorção do linuron na polianilina dopada. A concentração inicial do linuron na solução foi de $10 \mu \mathrm{g} \mathrm{mL}^{-1}$ e a de PANI $10^{-3} \mathrm{~mol}^{-1}$

Tabela 5. Adsonção do linuron na PANI desdopada. Concentração inicial do linuron $10 \mu \mathrm{g} \mathrm{mL}^{-1}$ e a de PANI $10^{-3} \mathrm{~mol} \mathrm{~L}^{-1}$.

Tabela 6. Adsorção do herbicida metribuzin na PANI dopada. A concentração inicial de metribuzin foi de $10 \mathrm{~g} \mathrm{~mL}^{-1}$ e a de PANI $10^{-3} \mathrm{~mol} \mathrm{~L}^{-1}$

Tabela 7. Adsorção do herbicida metribuzin na PANI desdopada. A 63 concentração inicial de metribuzin foi de $10 \mu \mathrm{g} \mathrm{mL}^{-1}$ e a de PANI $10^{-3} \mathrm{~mol} \mathrm{~L}^{-1}$......

Tabela 8. Melhores freqüências para as unidades sensoriais da "língua eletrônica", para a determinação de pesticidas..

Tabela 9. Dados de traços de metal em tecido sanguineos do coração............ II Tabela10. PC scores das concentrações de cromo e VI níquel.

Tabela 11. Resultados da Análise de Componente Principal nos logarítimos dos VII dados de concentração dos metais 


\section{Lista de Figuras}

Figura1. Estrutura química da polianilina....................................................... 9

Figura 2. Mecanismo de dopagem da PANI .................................................. $\quad 10$

Figura 3. Estrutura quimica da POEA ............................................................. 11

Figura 4. Estrutura química do PEDOT/PSS ${ }^{21} \quad 11$

Figura 5. a) Arranjo de sensores que compõem uma língua eletrônica e b) Um microeletrodo interdigitado de ouro ............................................................ 29

Figura 6. Espectros de FTIR da PANI dopada e desdopada............................. 33

Figura 7. Espectros de FTIR da POEA dopada e desdopada............................ 34

Figura 8. Espectro UV-VIS da PANI desdopada em meio NMP....................... $\quad 35$

Figura 9. Comparação de Espectros de UV-Vis da POEA dopada e desdopada 36

Figura 10. Estudo de UV-VIS de PEDOT/PSS- Baytron P®Bayer em vários pHs 37

Figura 11. Espectro de UV-Vis da POEA e do PEDOT, em pH $3,0 \ldots \ldots \ldots \ldots \ldots \ldots \ldots . . . . . . .38$

Figura 12. Espectros de UV-Vis do crescimento dos filmes de POEA por UV-

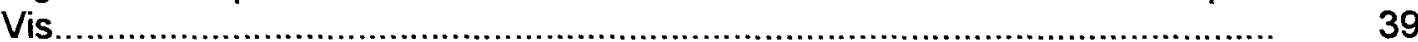

Figura 13. Espectro de crescimento de monocamadas de PEDOT/PSS.......... 40

Figura 14. Espectros de UV-Vis do crescimento do filme de POEA alternado 41 com PEDOT.

Figura 15. Espectro de UV-Vis das lâminas de PANI "in situ".

Figura 16. Imagem do filme de PANI obtido "in situ", com ampliação de $40 x \ldots . . \quad 43$

Figura 17. Imagem do filme de PANI obtido "in situ", com ampliação de $100 \mathrm{X} \ldots . .43$

Figura 18. Imagem do filme de PANI obtido "in situ", com ampliação de $400 X \ldots . .44$

Figura 19. Imagem de microscopia óptica de filme de PEDOT/PSS com 45 amplificação de $40 \mathrm{x}$.

Figura 20. (a) Imagem em 2-D de MFA do filme de PEDOT/PSS depositado por coating. (b) Imagem em 3- D de MFA do filme de PEDOT/PSS depositado por coating.

Figura 21. (a) Imagem em 2-D de MFA do filme de PEDOT/PSS, por 46 automontagem. (b) Imagem em 3-D de MFA do filme de PEDOT/PSS depositado por automontagem.

Figura 22. Imagens de AFM de lâminas de vidro com POEA depositada por automontagem e de lâminas de vidro com POEA depositada por automontagem em contato com diversos pesticidas

Figura 23. Rugosidade dos filmes de POEA antes e após o contato com vários pesticidas.

Figura 24. Curva de capacitância $(F)$ para o microeletrodo interdigitado de referência (sem filme), e para o microeletrodo interdigitado com uma camada de PEDOT/PSS-Baytron $\mathrm{P}^{\oplus}$ Bayer depositada por automontagem.

Figura 25. Curva de resistência (Ohm) para um microeletrodo interdigitado de referência (sem filme), e para o microeletrodo de PEDOT/PSS depositado com uma camada automontagem.

Figura 26. Espectro de Absorção do Linuron em diversas concentrações........... 52

Figura 27. Curva analítica do linuron, obtida por espectrofotometria de UV-Vis, 53 
com banda de absorção em $246 \mathrm{~nm}$

Figura 28. Espectros de UV-Vis do linuron em contato com a PANI dopada em função do tempo.

Figura 29. Cinética da concentração do sobrenadante do pesticida linuron com a PANI dopada.

Figura 30. Gráfico da concentração adsorvida do pesticida Linuron com PANI dopada em função do tempo.

Figura 31. Espectro de UV-Vis do linuron com a PANI desdopada em função do tempo de contato.

Figura 32. Variação da concentração do linuron em contato com a PANI desdopada no sobrenadante em função do tempo.

Figura 33. Variação da concentração do linuron adsorvido na PANI desdopada em função do tempo.

Figura 34. Espectros de UV-Vis do herbicida metribuzin em solução aquosa para várias concentrações

Figura 35. Curva analítica do herbicida metribuzin, obtida dos espectros da Figura 34 com a banda de absorção em $294 \mathrm{~nm}$

Figura 36. Espectro de UV-Vis do herbicida metribuzin na PANI dopada em função do tempo de contato.

Figura 37. Variação da concentração do metribuzin em contato com a PANI dopada no sobrenadante em função do tempo.

Figura 38. Cinética da concentração adsorvida do pesticida metribuzin com a PANI dopada.

Figura 39. Espectro de UV-Vis do herbicida metribuzin com a PANI desdopada em função do tempo de contato.

Figura 40. Variação da concentração do metribuzin em contato com a PANI desdopada em função do tempo.

Figura 41. Variação da concentração do metribuzin adsorvido na PANI desdopada em função do tempo.

Figura 42. Espectro da Capacitância versus Freqüência para os dez microeletrodos interdigitados de ouro.

- Figura 43. Espectro da Resistência versus Freqüência para os dez microeletrodos interdigitados de ouro.

Figura 44. Espectro da Capacitância versus Freqüência para os dez microeletrodos interdigitados de ouro após a deposição dos polímeros.

Figura 45. Espectro da Resistência versus Freqüência para os dez 67 microeletrodos interdigitados de ouro após a deposição dos polímeros.

Figura 46. Comparaçã̉o da variação das capacitâncias das águas antes da imersão na água contaminada com os pesticidas (A1) e após a lavagem realizada depois da imersão na solução dos pesticidas para os dez sensores....

Figura 47. Variação da capacitância em função da freqüência para os sensores - $1,2,8$ e 9

Figura 48. PCA de águas contaminadas e não contaminadas para os sensores na freqüência de $1 \mathrm{~K} \mathrm{~Hz}$.

Figura 49. Análise de Componentes Principais da capacitância dos sensores em água destilada (AA), no pesticida $\left(1 \mu \mathrm{g} \mathrm{mL}{ }^{-1}\right)$ e novamente na água (AD) utilizando-se $\circ$ procedimento de seleção da resposta na melhor freqüência (Tabela 11).

Figura 50. Elementos de uma matriz variância-covariância que definem uma elipse. 
Figura 51. Elementos de uma matriz variância-covariância que definem uma IV elipse

Figura 52. PCA dos dados de traços de metais nos tecidos do coração.

VIII 


\section{Resumo}

Atualmente a fabricação de sensores poliméricos tem sido de grande interesse tecnológico e científico, devido à grande demanda por sensores de diversos tipos em inúmeras aplicações. Nesse contexto, a Embrapa Instrumentação Agropecuária tem buscado o desenvolvimento de novas tecnologias, instrumentação, e sensores; visando a preservação do meio ambiente, tema de grande importância mundial. Muitos produtos comercializados nos países em desenvolvimento não atendem ao padrão de qualidade $\mathrm{FAO}$, e o seu mau uso leva a riscos de contaminação de solos, águas de rios, mananciais, e lençóis freáticos; prejudicando a vida aquática, e consequentemente a vida humana. Este trabalho teve um caráter exploratório, e os objetivos foram a preparação, caracterização e desenvolvimento de unidades sensoriais à base de polímeros, com o intuito de avaliar a qualidade da água através da detecção de vários pesticidas. Utilizou-se uma "língua eletrônica" constituida por diferentes unidades sensoriais, nas quais foram depositados filmes de polímeros condutores com composiçōes selecionadas e otimizadas a fim de se obter respostas elétricas caracteristicas para cada tipo de pesticida. Para tanto: i) sintetizou-se quimicamente os polimeros polianilina e poli(oetoxianilina) e caracterizou-se os mesmos; ii) depositou-se (através de automontagem) filmes ultrafinos dos polímeros condutores poli(o-etoxianilina), polianilina e poli(3,4-etilenodioxitiofeno) sobre microeletrodos interdigitados. Estes filmes foram investigados quanto à sensibilidade frente aos pesticidas; iii) Caracterizou-se espectroscopicamente por técnicas de ultra-violeta visivel (UVVIS), e microscopicamente (MEV) os filmes e as interações entre os pesticidas e os polimeros; iv) Caracterizou-se o conjunto de unidades sensoriais através de medidas elétricas de capacitância em corrente alternada através de espectroscopia de impedância e análise estatística de Componentes Principais (PCA). Resultados bastante interessantes foram obtidos, e a "língua eletrônica" foi capaz de distinguir águas contaminadas com $1 \mu \mathrm{g} \mathrm{mL}^{-1}$ de pesticidas, de águas não contaminadas. 


\section{Abstract}

Nowadays the manufacturing of polimeric sensors has been attracting technological and cientific interests, due to the demand for different sensors in a large number of applications. In this context, Embrapa Agriculturial Instrumentation has been looking for the development of new technologies, instrumentation and sensor, envisaging environment monitoring, theme of huge global importance. Many products that are in the market in developing countries do not follow the FAO quality standards and their use can cause risks of contamination to soil and water, damaging the acquatic life and consequently the human life.

The aim of this project was the preparation, characterization and development of sensing units made by thin layers of conducting polymers, in order to evaluate the water quality mainly due to contamination of pesticides. To achieve these aims, we made use of an "electronic tongue" designed with different sensing units in which conductor polymeric films with specific compositions were deposited, in order to have electric responses for each type of pesticide. For that, the following studies were carried out: i) The polymers PANI and POEA were synthesized and characterized ii) these films (PANI, POEA and PEDOT/PSS) were deposited by self-assembly on gold interdigited microelectrodes. The sensibility of these films to different pesticides was evaluated; iii) the interactions between pesticides and polymers were monitored by visible ultraviolet spectroscopic (UV-VIS) and microscopy techiques (SEM); iv) the sensing units were characterized by impedance measurements and by Principal Component Analysis (PCA). Using eight sensing units with PANI, POEA and PEDOT/PSS films it was demonstrated the possibility to detect some pesticides in concentration of $1 \mu \mathrm{g} \mathrm{ml}^{-1}$ and to distinguish contaminated samples from non contaminated water. 


\section{Introdução}

Desde os primórdios da nossa história, os seres humanos utilizam certos tipos de substâncias tóxicas para combater pragas que destroem as plantações. Durante o século XVII, por exemplo, era comum no mundo ocidental o uso de arsênio e tabaco para o controle de insetos ${ }^{1}$. Essas substâncias deram origem a era dos pesticidas, que são atualmente divididos em classes, como por exemplo, a dos organoclorados, organofosforados, carbamatos, entre outros ${ }^{2,3}$. Inclue substâncias que são altamente tóxicas e persistentes no meio ambiente ${ }^{4}$.

$\mathrm{Na}$ agricultura os pesticidas podem ser aplicados nas plantas, para o controle de insetos e pragas, para o controle de ervas daninhas ou pragas de solos. Entretanto, independentemente do alvo, esses produtos atingem, em última instância, o solo. A partir de então, eles podem ser transportados para a atmosfera por volatilização, ou para as fontes de água por drenagens, escoamento superficial ou erosão. Alguns pesticidas com alta solubilidade em água e baixa capacidade de interação com partículas minerais e material orgânico do solo podem vir a contaminar as fontes de água subterrânea por lixiviação, que corresponde ao transporte vertical de solutos no perfil do solo. O potencial de contaminação de águas subterrâneas ou superficiais por pesticidas pode ser avaliado por meio de modelos de previsão de destino, os quais utilizam informações das caracteristicas 
físico-químicas dos pesticidas, propriedades de degradação (meia vida) e sorção no solo, informações climatológicas, topográficas, propriedades do solo e outras ${ }^{5}$. Spadotto ${ }^{6}$ desenvolveu um modelo do movimento de herbicidas no solo, e validou-o para as condições de solos tropicais, sendo que a maioria tem sido desenvolvida para solos de áreas de clima temperado.

Ambientes terrestres e aquáticos contaminados por pesticidas podem causar problemas ambientais que prejudicam diversos tipos de organismos vivos, inclusive os seres humanos, que se alimentarão, por exemplo, de peixes contaminados.

No Estado de São Paulo a CETESB avalia diversos aspectos das águas para testar a qualidade das mesmas, inclusive através do índice de vida aquática (IVA), que fornece informações sobre a qualidade da água em termos ecotoxicológicos, bem como o seu grau de trofia. No relatório de qualidade das águas interiores do Estado de São Paulo de 2003 da CETESB $^{7}$, verificou-se para o IVA um elevado percentual para a classe ruim (que representa as piores condições de qualidade para a proteção da vida aquática), correspondendo a $37 \%$ dos pontos avaliados no Estado de São Paulo.

Do ponto de vista da contaminação das fontes de águas por pesticidas é essencial que haja monitoramento da qualidade das águas em regiões de uso agrícola intenso, onde o uso de insumos como fertilizantes e pesticidas é muito alto, comparando-se com os paises desenvolvidos. Desta forma vários tipos de estudo tem sido realizados com a finalidade de monitorar a quantidade de poluentes ambientais e pesticidas nas fontes de águas potáveis ${ }^{2,6,8-10}$.

Assim, este projeto faz parte de uma linha pioneira de pesquisa que vem sendo desenvolvida na Embrapa Instrumentação Agropecuária com o objetivo de desenvolver sensores para a avaliação da qualidade e nivel de contaminação de águas naturais, bem como a avaliação de bebidas. 
Para tanto, um conjunto de unidades sensoriais denominado "língua eletrônica", baseada em polimeros condutores depositados sobre microeletrodos interdigitados de ouro, foi desenvolvida e tem sido utilizada para a análise de bebidas, como cafés ${ }^{11}$, sucos, águas minerais e vinhos ${ }^{12,13}$, com resultados promissores. Além disso, têm sido realizado alguns estudos para avaliar o potencial da língua eletrônica para a avaliação de contaminantes de águas, como metais pesados, pesticidas e outros.

O objetivo deste trabalho foi o estudo da interação entre diferentes tipos de pesticidas e polímeros condutores, visando a confecção de uma "língua eletrônica" constituída por unidades sensoriais recobertas por filmes finos de polímeros condutores a fim de detectar, através de medidas elétricas, pesticidas em águas, avaliando a qualidade das mesmas com relação a este aspecto .

Neste trabalho foram realizados estudos com os seguintes pesticidas: atrazina, clorpirifos, glifosato, imazaquin, linuron, metribuzin, paraquat e pedimentalina, abrangendo diversas classes, e os polimeros condutores: polianilina (PANI), poli(oetoxianilina) (POEA) e poli(3,4-etilenodioxitiofeno)/ Ácido polistireno-sulfônico (PEDOT/PSS).

Para se atingir os objetivos propostos foram realizadas as seguintes atividades:

1. Síntese e caracterizaçäo dos polímeros condutores polianilina e poli(oetoxianilina) e poli(3,4-etilenodioxitiofeno)/ Ácido polistireno-sulfônico

2. Estudo da interação entre polímeros condutores e pesticidas por estudos de adsorção e microscopia de força atômica.

3. Caracterização elétrica de sensores interdigitados a fim de se selecionar um conjunto de unidades sensoriais para a "língua eletrônica".

4. Deposição dos filmes poliméricos sobre as unidades sensoriais por automontagem. 
5. Avaliação das unidades sensoriais em amostras de água contaminadas em laboratório com pesticidas, e tratamento matemático e estatístico dos dados por Análise de Componentes Principais. 


\section{CAPÍTULO I}

\section{REVISÃO DA LITERATURA}

\subsection{Polímeros Condutores}

Polímeros são macromoléculas compostas por entidades estruturais conhecidas por mero (mero vem do grego "meros" que significa parte) que são ligadas covalentemente ${ }^{14}$. Um monômero é constituído por um único mero, e um polímero por vários deles. O mero é a unidade repetitiva na cadeia polimérica. Quando todas as unidades repetidas ao longo de uma cadeia são do mesmo tipo, tem-se um homopolimero, caso contrário, se a cadeia for composta por duas ou mais unidades diferentes de mero tem-se um copolímero.

Polimeros com cadeias longas possuem elevados pesos moleculares, e a magnitude destes pode afetar várias características dos polímeros, como por exemplo, a temperatura de fusão. Materiais com pesos moleculares da ordem de $100 \mathrm{~g} \mathrm{~mol}^{-1}$, ou seja, com cadeias muito curtas, existem à temperatura ambiente como líquidos ou gases. Os com pesos moleculares de aproximadamente $1000 \mathrm{~g}$ $\mathrm{mol}^{-1}$ são sólidos pastosos e resinas moles. Já os que possuem pesos moleculares entre 10000 e vários milhões de $\mathrm{g} \mathrm{mol}^{-1}$ são polímeros sólidos ${ }^{15}$.

As diferenças na estrutura das cadeias moleculares, o peso molecular, a forma do polímero, e o grau de cristalinidade podem também afetar as 
caracteristicas físicas do mesmo. Os polimeros podem ser lineares (onde as unidades mero estão unidas ponta a ponta em cadeias únicas), ramificados (onde cadeias de ramificações laterais encontram-se conectadas às cadeias principais), com ligações cruzadas (onde as cadeias lineares adjacentes se unem umas às outras por ligações covalentes em várias posições), em rede (onde unidades meros trifuncionais formam redes tridimensionais), e em configurações isométricas (onde os átomos estão ligados uns aos outros na mesma ordem, mas diferem em seu arranjo espacial). Porém, os polímeros não são, em geral, de um único tipo estrutural, podendo ser predominantemente linear e possuir uma quantidade limitada de ramificações e ligações cruzadas, ou pode possuir outros tipos de combinações estruturais. Com relação à cristalinidade, como conseqüência do seu tamanho e complexidade, geralmente, as moléculas dos polímeros são semicristalinas. O grau de cristalinidade depende da taxa de resfriamento durante o processo de solidificação, e da configuração da cadeia.

Madeira, borracha, lã, seda, algodão, entre outros, são polimeros naturais que derivam de plantas e animais, e tem sido bastante utilizados. Outros exemplos de polímeros naturais, de suma importância nos processos biológicos e fisiológicos de animais e plantas, são as enzimas, as proteinas, os amidos e a celulose.

Desde o fim da Segunda Guerra Mundial, os polímeros sintéticos revolucionaram o campo dos materiais. Eles são produzidos de maneira mais acessivel economicamente, e ainda possuem a vantagem que suas propriedades podem ser manipuladas proporcionando uma gama muito variada de materiais com desempenho similar ou superior aos dos materiais naturais equivalentes. Um exemplo disso são os plásticos, que em algumas aplicações podem substituir peças metálicas e de madeira ${ }^{15}$.

As moléculas orgânicas têm recebido atenção por poderem ser aplicadas em sensores, recobrimentos para redução de fricção e agentes de superfície para 
orientação de camadas em dispositivos como diodos emissores de luz, e talvez possam, brevemente, competir com moléculas inorgânicas no setor eletrônico, por causa do baixo custo de produção e/ou disponibilidade e por sua ampla gama de propriedades e aplicações ${ }^{16,17}$. Atualmente, o desenvolvimento de novos materiais tem sido um desafio para químicos, físicos e engenheiros de materiais ${ }^{18}$. Uma motivação fundamental para o desenvolvimento de polímeros condutores é a possibilidade de interação entre estes e o meio ambiente, em nível molecular ${ }^{19}$. A seguir são descritas algumas características e propriedades de polímeros utilizados neste trabalho.

\section{- A Polianilina}

Polimeros condutores como a polianilina (PANI) têm sido muito utilizados devido às suas características e versatilidade. O eletrocromismo (propriedade do material em mudar de coloração em resposta a um potencial aplicado) é uma característica da polianilina que desperta grande interesse. Esse polimero, dependendo do potencial aplicado e do $\mathrm{pH}$, pode exibir a cor amarela, verde, azul ou violeta. A PANI pode ser sintetizada química ou eletroquimicamente ${ }^{18}$. Diferentes tipos de ácidos têm sido utilizados como dopantes, visando a melhoria de propriedades como a solubilidade e a condutividade elétrica em polianilinas sintetizadas quimicamente ${ }^{20}$.

A Polianilina na forma não dopada possui a fórmula geral mostrada na Figura 1, composta por y e (1-y) unidades repetitivas das espécies reduzidas e oxidadas, respectivamente :

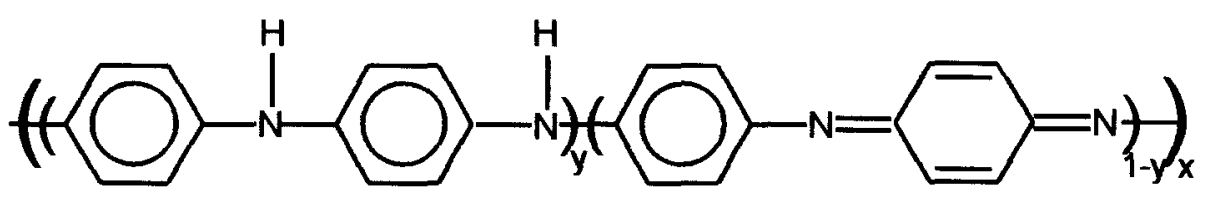

Figura 1. Estrutura química da polianilina 
Dependendo do valor de oxidação (y) tem-se diferentes estados da polianilina, designados por leucoesmeraldina $(y=1)$, protoesmeraldina $(y=0,75)$, esmeraldina $(y=0,5)$, nigranilina $(y=0,25)$ e pernigranilina $(y=0)$. $O$ estado de oxidação esmeraldina possui os maiores valores de condutividade após dopagem da PANI ${ }^{21}$.

O mecanismo de dopagem da PANI pode ser melhor visualizado com auxílio da Figura 2.

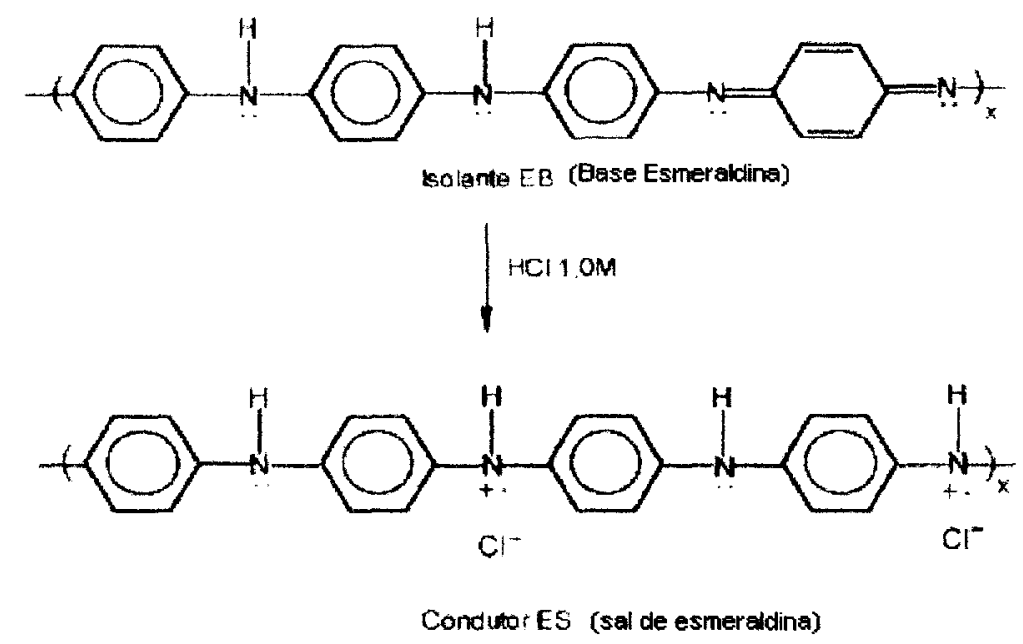

Figura 2. Mecanismo de dopagem da PANI ${ }^{21}$

A protonação da polianilina na forma de base esmeraldina (EB), de coloração azul, em solução de $\mathrm{HCl} 1 \mathrm{~mol} \mathrm{~L}^{-1}$ leva à formação do sal hidrocloreto de esmeraldina (ES), de coloração verde, na forma dopada, aumentando a condutividade em 10 vezes, mesmo quando o material fica em exposição ao ar durante longos periodos de tempo. Reversivelmente, por tratamento semelhante em solução de $\mathrm{NH}_{4} \mathrm{OH} 0,1 \mathrm{~mol} \mathrm{~L}^{-1}$, ocorre a desprotonação. Este método de sintese permite a obtenção de um polimero condutor completamente solúvel em solventes orgânicos, o que torna viável o processamento da polianilina na forma de filmes ${ }^{21}$. 
Devido à facilidade de dopagem, e outros fatores como a estabilidade química e a condutividade elétrica, a polianilina tem sido destaque em aplicações tecnológicas ${ }^{21,22}$.

- Poli(o-etoxianilina)

A poli(o-etoxianilina) (POEA), é um derivado da polianilina, e possui a estrutura química apresentada na Figura 3

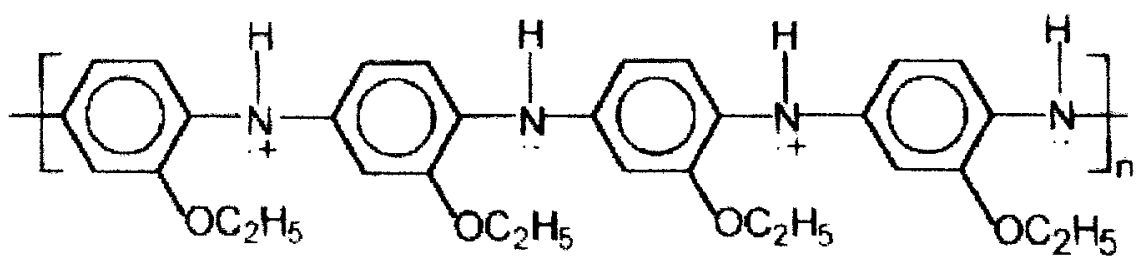

Figura 3. Estrutura química da POEA

A principal vantagem da POEA em relação à PANI é a presença do substituinte $-\mathrm{OC}_{2} \mathrm{H}_{5}$, o que a torna solúvel em vários solventes, incluindo a água, e isso facilita seu processamento sob a forma de filmes ${ }^{23}$.

- Poli(3,4- etilenodioxitiofeno)/ Ácido Poli-estireno-sulfônico

O poli(3,4-etilenodioxitiofeno)/ Ácido poli-estireno-sulfônico (PEDOT/PSS) tem a estrutura quimica mostrada na Figura 4.
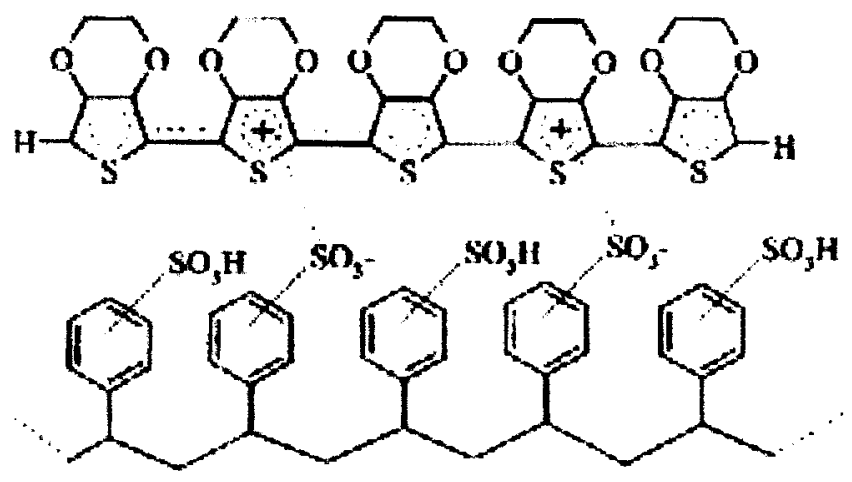

Figura 4. Estrutura química do PEDOT/PSS ${ }^{24}$ 
O PEDOT ou PEDT é um material com várias propriedades que despertam interesse quando comparado com outros polímeros, como o polipirrol e a polianilina, por exemplo, uma vez que combina um baixo potencial de oxidação e um band gap moderado com boa estabilidade no estado oxidado. Possui alta condutividade em torno de $400-600 \mathrm{~S} \mathrm{~cm}^{-1}$ para amostras preparadas química ou eletroquimicamente ${ }^{24}$, e propriedades muito boas de formar filmes ${ }^{19}$.

O PEDOT é um polímero insolúvel, porém o PEDOT/PSS é um polímero solúvel em água de coloração azul escuro, utilizado em diversas aplicações, como em lâmpadas eletroluminescentes ${ }^{24}$.

\subsection{Filmes Poliméricos Ultra Finos}

No começo do século passado, Langmuir ${ }^{25}$ e Blodgett $^{26}$ apresentaram as primeiras tentativas de produção de filmes finos de moléculas orgânica. Na técnica Langmuir-Blodgett (LB) ${ }^{16,27}$, camadas monomoleculares (geralmente de lipídios) são obtidas sobre uma sub-fase aquosa e transferidas para um substrato sólido, possibilitando a obtenção de filmes com uma organização em nivel nanométrico. Esses filmes podem ser obtidos com espessuras variadas, em função do número de camadas depositadas, tipo de material de depósito, condições laboratoriais e manuseio do pesquisador.

A técnica de automontagem LBL (layer by layer) (Self Assembly, SA) foi desenvolvida no começo da década de 90 , tendo como base a interação eletrostática entre polieletrólitos (moléculas orgânicas contendo vários grupos iônicos). Segundo o método proposto por Decher ${ }^{28}$, um substrato sólido previamente tratado é imerso em uma solução policatiônica, e após a lavagem e secagem, faz-se imersão em uma solução polianiônica, tendo como resultado uma bicamada de 10 a 100 ângstrons de espessura. $O$ procedimento pode ser obtido 
para a obtenção de diversas camadas, conforme a necessidade, a partir deste método. A deposição das camadas pode ser feita mecânica ou manualmente, utilizando-se soluções de policátions e poliânions. O crescimento das camadas pode ser observado por UV-Vis, já que há um aumento linear da absorbância do filme em um comprimento de onda característico, conforme o aumento de camadas depositadas ${ }^{28}$.

Filmes com diversos tipos de materiais tem sido estudados, como os filmes finos transparentes e condutores, que tem sido desenvolvidos atualmente para a deposição em substratos flexiveis que irão permitir a criação de displays de cristal líquido gerando um tipo de papel eletrônico, podendo, no futuro, substituir jornais e livros $^{29}$.

\subsection{Língua Eletrônica}

Sistemas artificiais "inteligentes" capazes de mostrar caracteristicas especificas de diferentes substâncias químicas ganharam destaque atualmente. Dentro desse contexto, podem ser encontrados os narizes eletrônicos e também as

- línguas eletrônicas, sendo utilizados em uma ampla gama de aplicações como em indústrias (alimentícia para o caso de vinhos, cafés, refrigerantes, etc.), biomédicas (como em análises de sangue, pele, urina, etc.), ambientais (para o controle de qualidade de ar e água), entre outras. O monitoramento ambiental de água é bastante complexo, devido à grande quantidade de substâncias orgânicas, inorgânicas e microorganismos encontrados em águas naturais (rios e lagos). Portanto, o método utilizado para a detecção deve ser bem sensível e seletivo ${ }^{10}$.

O conceito de uma língua eletrônica é de um conjunto de unidades sensoriais, em geral muito sensiveis e pouco seletivas, que funciona em conjunto com um programa de reconhecimento de padröes (rede neural, análise de componentes principais, entre outros). As "línguas eletrônicas" são instrumentos, 
nos quais as unidades sensoriais que fazem parte da mesma, podem classificar amostras líquidas e qualificar sabores da seguinte forma: as unidades sensoriais da "língua eletrônica" são imersas em uma determinada amostra, com certa concentração, e um sinal elétrico específico é gerado ${ }^{27,30}$. Esse sinal é analisado por um software de reconhecimento de padrões especificos ${ }^{10}$.

Toko et al. ${ }^{31}$ utilizam, em seu trabalho, uma "língua eletrônica" composta de membranas de filmes de polímeros/lipídios que possui um conceito de seletividade global, que implica na habilidade de classificação de vários tipos de substâncias em vários grupos. Essas membranas são conectadas a um eletrodo com vários canais, onde o eletrodo detector de cada canal é feito de fios de Ag cuja superfície é recoberta com $\mathrm{Ag} / \mathrm{AgCl}$. O eletrodo com vários canais é conectado a um analisador de impedância, e a diferença de voltagem entre o eletrodo de trabalho e o referência é medido. Em seu trabalho, Toko et al. ${ }^{31}$ utilizam as substâncias que representam os paladares básicos: azedo $(\mathrm{HCl})$, amargo (quinino), doce (sacarose) e salgado $(\mathrm{NaCl})$, além de um paladar conhecido por umami, representado por substâncias, como por exemplo, o glutamato monosódico (encontrado em algas marinhas). Outras bebidas como cerveja, café, água mineral e sake também são utilizadas ${ }^{31}$.

Krantz-Rülcker et al. ${ }^{10}$ utilizam uma "língua eletrônica" utilizando-se da voltametria cíclica pulsada. Para a confecção deste dispositivo, eletrodos de trabalho metálicos são inseridos em um disco cerâmico ao redor de um eletrodo de referência de $\mathrm{Ag} / \mathrm{AgCl}$, e são utilizados para a classificação de diferentes líquidos, como por exemplo sucos, leite e águas potáveis.

No Brasil, a Embrapa Instrumentação Agropecuária, vem sendo a pioneira no trabalho utilizando-se conjuntos de unidades sensoriais que compõem a "língua eletrônica"32. Para isso, filmes finos de polimeros condutores tem sido depositados por técnicas de automontagem e/ou Langmuir-Blodgett sobre microeletrodos 
interdigitados de ouro, que são conectados a um equipamento de Impedância elétrica. As respostas obtidas são analisadas por Análises de Componentes Principais, e já se mostraram bastante satisfatórias para diversos tipos de substâncias, como por exemplo, o café ${ }^{11}, 0$ vinho $^{12}$, edulcorantes ${ }^{33}$ e águas ${ }^{27}$. Atualmente, outros trabalhos estão sendo realizados pelo grupo, com sucos e águas contaminadas por pesticidas e metais pesados.

\subsection{Pesticidas}

Há uma competição entre espécies de plantas por espaço, água, luz e nutrientes, assim como há entre os animais e os humanos. Se um ser humano pode domesticar um ser animal, ele pode tirar proveito do mesmo, ou se o animal for caçado, ele pode servir como alimento ao humano. Entretanto, quando os animais são muito pequenos, apresentam-se em grandes quantidades, e ainda consomem o que os humanos usariam, eles são denominados de pragas, sendo estas inevitáveis e totalmente naturais ${ }^{34}$.

Desde o começo dos tempos agrícolas o homem pratica o controle de pragas. Os chineses utilizavam, há muito tempo, o arsênio para controlar insetos de jardim. No mundo ocidental, assim como o arsênio, o tabaco também foi utilizado como inseticida durante o século XVII ${ }^{1}$.

A palavra pesticida inclui os herbicidas, inseticidas, fungicidas, algicidas, repelentes animais e de insetos, entre outros. A maioria dos pesticidas é, propositalmente, tóxica aos organismos alvo ${ }^{35}$.

Um pesticida ideal deveria persistir tempo suficiente para executar sua função e depois degradar-se ${ }^{36}$. Porém, na realidade, vários pesticidas são persistentes e altamente tóxicos, como por exemplo, os pesticidas organoclorados ${ }^{4}$. Assim como os pesticidas organoclorados, existem outras classes de pesticidas como: os organofosforados, os carbamatos e os piretróides, cada um com um 
modo diferente de ação, e específico para determinados tipos de plantações. Além dos pesticidas químicos, há também os biopesticidas (que são certos tipos de substâncias derivadas de plantas, animais e certos minerais, como por exemplo o óleo de canola) e os antimicrobiais (que são substâncias usadas para a destruição de virus, bactérias e fungos em superficies) ${ }^{3}$.

O uso de pesticidas tem sido de suma importância para melhorar condições de cultivo na agricultura brasileira ${ }^{37}$, uma vez que a mesma ainda é bastante dependente de defensivos agricolas, utilizando-se aproximadamente $60 \%$ do total de pesticidas comercializados no Brasil em culturas como as de soja, milho, citros e cana-de-açúcar. O consumo de pesticidas no Brasil é de aproximadamente $3,2 \mathrm{Kg}$ de ingrediente ativo por hectare ${ }^{5}$.

O Conselho da Organização das Nações Unidas para a Agricultura e a Alimentação (FAO) já aprovou uma nova versão do Código de Conduta sobre Distribuição e Uso de Pesticidas, falando sobre a responsabilidade na regulamentação dessas substâncias por parte dos governos, da necessidade de ajudar os países com dificuldades técnicas em assumirem os riscos de sua utilização e também da importância de boas práticas de produção e comercialização. Segundo a Agência de Proteção Ambiental dos Estados Unidos existem 17 mil pesticidas registrados nos EUA, sendo que desse total $76 \%$ são utilizados nas zonas agricolas, e $23 \%$ em zonas urbanas ${ }^{37}$.

A maioria dos casos de envenenamento ocorre com os trabalhadores rurais devido às más condições de utilização dos defensivos agrícolas, e também à falta de informações relativas aos cuidados e segurança durante a aplicação dos mesmos, e em número menor, intoxicações residênciais devido ao contato de pessoas com inseticidas. Por isso, organizações como a FAO e a OMS (Organização Mundial da Saúde) insistem na necessidade de se adotarem precauções em sua manipulação e venda ${ }^{37}$. 
Devido ao uso intenso, e algumas vezes indiscriminado, substâncias tóxicas orgânicas e inorgânicas são introduzidas nos solos e em ambientes aquáticos. As dosagens de agrotóxicos são superestimadas durante as aplicações para que possam ser compensadas as perdas que ocorrem durante as mesmas. A Embrapa Meio Ambiente comprovou, em 1996, que $47 \%$ dos agrotóxicos não atinge o alvo, e os resultados disso são a resistência biológica a esses elementos, além de teores elevados de resíduos em águas e solos $^{38}$. Um grande desafio atual é conseguir selecionar e aplicar um determinado pesticida de maneira a controlar os organismos alvo, sem que haja interferência no meio ambiente, prejudicando outros tipos de organismos ${ }^{36}$.

Os processos de volatilização, lixiviação e escoamento superficial de pesticidas no solo dependem de processos de sorção, decomposição, degradação e interações entre os mesmos. Assim, além da diversidade de processos envolvidos nos destinos ambientais dos pesticidas, devem ser levados em consideração: diferenças nas estruturas químicas e propriedades dos pesticidas, condições climáticas, composição de populaçōes de microorganismos no solo, taxa e quantidade de águas que se movem através do perfil do solo ${ }^{6}$. Ultimamente, muitos esforços científicos tem sido feitos visando à melhor compreensão entre os sistemas pesticidas-planta-solo-água ${ }^{36}$.

Pesticidas com mobilidade alta no ambiente, e persistentes, têm sido encontrados em águas superficiais e subterrâneas. Devido a pouca solubilidade de vários pesticidas em água e aos efeitos de diluição, a concentração da maioria dos pesticidas em água é baixa, porém isso não exclui a possibilidade de que altas concentrações venham a ocorrer após, por exemplo, pesadas chuvas, especialmente quando áreas ao redor de córregos tenham sido tratadas com altas dosagens de agrotóxicos. Mesmo em ínfimas quantidades, os pesticidas podem 
prejudicar os organismos aquáticos, pois algumas espécies podem concentrar em até 1000 vezes esses produtos ${ }^{39}$.

Em todo o mundo, existe uma grande preocupação com a qualidade das águas, e vários estudos tem sido feito no sentido de detectar águas contaminadas. Zhang et al. ${ }^{8}$ estudaram a qualidade dos sedimentos e da água do rio Tonghui, em Beijing (China). Em seu trabalho, as concentrações totais encontradas variam de 192,5 à $2651 \mathrm{ng} \mathrm{L}^{-1}$ para hidrocarbonetos aromáticos policíclicos (PAHs), e 134,9 à $3788 \mathrm{ng} \mathrm{L}^{-1}$ para pesticidas organoclorados, na água. A concentração de poluentes orgânicos encontrada nos sedimentos foi maior que na superfície da água, devido à hidrofobicidade dos poluentes orgânicos. Entretanto, com relação aos pesticidas organoclorados encontrados na água, o autor conclui que a concentração encontrada apresenta-se abaixo, porém próxima, do valor critico proposto pela norma chinesa.

Turgut $^{40}$ em seu trabalho realizado de 2000 a 2002, demonstra que vários pesticidas organoclorados, além de alguns metais pesados, são detectados em amostras de águas superficiais do rio Küçük Menderes, na Turquia.

Filizola et al. ${ }^{41}$ utilizaram-se das águas na região de Guairá (São Paulo), para determinar niveis de ocorrência de pesticidas, que foram encontrados ocasionalmente nas águas superficiais devido à lavagens de tanques de aplicação e embalagens de pesticidas utilizadas na Fazenda Macaúba. Já no estado do Mato Grosso, Laabs et al..$^{42}$ demonstraram que as amostras de águas superficiais estudadas estavam contaminadas, em baixas concentrações, com pesticidas, tais como: metribuzin, metaclor entre outros.

No Brasil, a portaria $n^{\circ}$ 020/CONAMA, de 18/06/86, estabelece limites máximos de contaminantes em água dependendo do seu destino ${ }^{39}$. Estima-se que cerca de 10 milhões de pessoas são mortas anualmente devido à doenças associadas com a utilização de águas impróprias ${ }^{43}$. 
Levando em consideração que de toda a água existente no planeta, $3 \%$ são de água doce e está dividida na formas sólida, líquida e gasosa ${ }^{43}$, a preocupação é ainda maior quando a água é usada para o consumo humano. Foi estabelecido pela Comunidade Econômica Européia que a concentração máxima admissivel de qualquer pesticida em águas com destino ao consumo humano é de $0,1 \mu g \mathrm{~L}^{-1}$, sendo que esse limite provoca questionamentos, uma vez que há diferenças nas toxicidades de cada pesticida, e isso não é levado em conta. Já a Agência de Proteção Ambiental dos Estados Unidos (EPA) e a Organização Mundial da Saúde estabelecem niveis máximos de tolerância para cada pesticida individualmente em água destinada ao consumo humano ${ }^{39}$

O desenvolvimento de métodos alternativos de controle de pragas, como 0 controle biológico, a modificação da genética dos insetos e o desenvolvimento de animais e plantas resistentes, poderão, no futuro, diminuir a necessidade da utilização de pesticidas químicos. Porém, pesticidas continuarão a ser utilizados na produção de fibras e alimentos, e uma redução drástica dos mesmos em tempos atuais implicaria em baixa qualidade de produtos agricolas e aumento significativo de custos de produção, podendo-se concluir que nos dias de hoje, alguns tipos de pesticidas são essenciais ${ }^{36}$, e é de total importância que exista harmonia entre a agricultura e o meio ambiente.

Em vários trabalhos encontrados na literatura ${ }^{40,44-46}$ os estudos realizados a fim de detectar pesticidas utilizam-se de técnicas que são dispendiosas, como a cromatrografia. Tendo em vista que a contaminação do meio ambiente pode causar sérios problemas à população, toma-se imprescindivel o desenvolvimento de dispositivos práticos e baratos, e é por isso que este trabalho visa o estudo de interações entre pesticidas e polimeros, a fim de se desenvolver sensores para a detecção de poluentes ambientais. 


\section{CAPÍTULO II}

\section{PARTE EXPERIMENTAL}

\subsection{Materiais}

Os polímeros condutores polianilina e poli(o-etoxianilina) utilizados neste trabalho foram sintetizados e caracterizados segundo MacDiarmid e colaboradores $^{21,47-49}$, sendo sua preparação descrita no item 2.2 (métodos) ${ }^{50.51}$.

O polímero condutor PEDOT/PSS (Baytron P - Bayer) foi utilizado como recebido.

Os pesticidas atrazina, linuron, metribuzin, paraquat, foram obtidos da Riedel- de Haën. O pesticida clorpirifos foi obtido da Dow Agrosciences, o glifosato da Monsanto, e o imazaquin e a pedimentalina da Basf. 
Tabela 1. Pesticidas e algumas de suas propriedades físico-químicas.

\begin{tabular}{|c|c|c|c|c|c|}
\hline Fórmula Estrutural & $\begin{array}{c}\text { Peso } \\
\text { molecular } \\
(\mathrm{g} / \mathrm{mol})\end{array}$ & $\begin{array}{l}\text { Solubili dade } \\
\text { em água }\end{array}$ & Culturas & Kow & Forma \\
\hline${ }_{2} \mathrm{CH}_{3}$ & 215,7 & $33 \mathrm{mg} / \mathrm{L}$ à $20^{\circ} \mathrm{C}$ & $\begin{array}{l}\text { gramineas, } \\
\text { cana-de- } \\
\text { açúcar, café, } \\
\text { bananas }\end{array}$ & $\begin{array}{l}\log \\
P=2,5 \text { à } \\
25^{\circ} \mathrm{C}\end{array}$ & $\begin{array}{l}\text { Po } \\
\text { incolor }\end{array}$ \\
\hline $\begin{array}{l}\mathrm{S} \\
\mathrm{OP}\left(\mathrm{OCH}_{2} \mathrm{CH}_{3}\right)_{2} \\
\mathrm{C} \\
{ }_{9} \mathrm{H}_{11} \mathrm{Cl}_{3} \mathrm{NO}_{3} \mathrm{PS}\end{array}$ & 350,6 & $1,4 \mathrm{mg} / \mathrm{L}$ à $25^{\circ} \mathrm{C}$ & $\begin{array}{l}\text { Inseticida de } \\
\text { espécies em } \\
\text { culturas de } \\
\text { banana, } \\
\text { vegetais, } \\
\text { flores, } \\
\text { cereais, soja, } \\
\text { etc. }\end{array}$ & 50000 & $\begin{array}{l}\text { Cristais } \\
\text { incolo } \\
\text { res }\end{array}$ \\
\hline 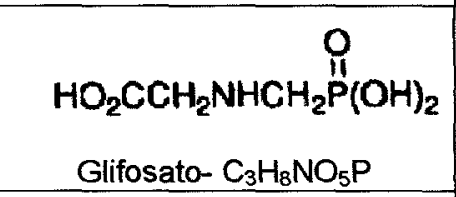 & 169,1 & $12 \mathrm{~g} / \mathrm{L}$ à $25^{\circ} \mathrm{C}$ & $\begin{array}{l}\text { bananas, } \\
\text { café, soja, } \\
\text { beterraba, } \\
\text { côco }\end{array}$ & - & $\begin{array}{l}\text { Cristais } \\
\text { incolo } \\
\text { res }\end{array}$ \\
\hline $\begin{array}{c}\mathrm{CO}_{2} \mathrm{H} \\
\text { in- } \mathrm{C}_{17} \mathrm{H}_{17} \mathrm{~N}_{3} \mathrm{O}_{3} \\
\end{array}$ & 311,3 & $\begin{array}{l}60-120 \mathrm{mg} / \mathrm{L} \text { à } \\
25^{\circ} \mathrm{C}\end{array}$ & soja & $\begin{array}{l}2,2 \mathrm{a} \\
22^{\circ} \mathrm{C}\end{array}$ & $\begin{array}{l}\text { Sólido } \\
\text { marrom }\end{array}$ \\
\hline 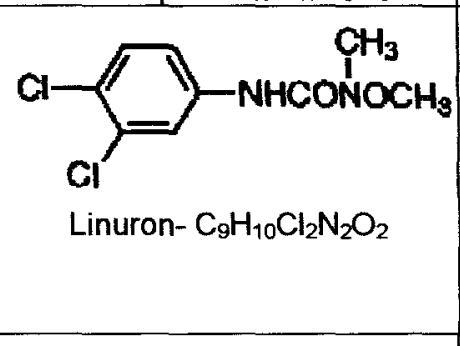 & 249,1 & $81 \mathrm{mg} / \mathrm{L}$ à $25^{\circ} \mathrm{C}$ & $\begin{array}{l}\text { cana-de- } \\
\text { açúcar, } \\
\text { batata, alho, } \\
\text { cebola, soja, } \\
\text { flores } \\
\text { ornamentais, } \\
\text { banana, café, } \\
\text { chá, } \\
\text { amendoim } \\
\end{array}$ & 1010 & $\begin{array}{l}\text { Cristais } \\
\text { incolo } \\
\text { res }\end{array}$ \\
\hline $\begin{array}{l}-\mathrm{SCH}_{3} \\
\mathrm{NH}_{2} \\
\mathrm{H}_{14} \mathrm{~N}_{4} \mathrm{O}_{5}\end{array}$ & 214,3 & $1,05 \mathrm{~g} / \mathrm{L}$ à $20^{\circ} \mathrm{C}$ & $\begin{array}{l}\text { morangos, } \\
\text { batatas doce, } \\
\text { alface, flores } \\
\text { de verão }\end{array}$ & $\begin{array}{l}37,6(\mathrm{pH} \\
5,6 \mathrm{a} \\
\left.20^{\circ} \mathrm{C}\right)\end{array}$ & $\begin{array}{l}\text { Cristais } \\
\text { incolo } \\
\text { res com } \\
\text { odor } \\
\text { fraco, } \\
\text { caracte } \\
\text { rístico }\end{array}$ \\
\hline
\end{tabular}


Tabela 1. Pesticidas e algumas de suas propriedades físico-químicas.

\begin{tabular}{|c|c|c|c|c|c|}
\hline $\mathrm{CH}_{\text {Paraquat- } \mathrm{C}_{12} \mathrm{H}_{14} \mathrm{~N}_{2}}+\mathrm{N}^{2+}$ & 186,3 & $700 \mathrm{~g} / \mathrm{L}$ à $20^{\circ} \mathrm{C}$ & $\begin{array}{l}\text { café, citrus, } \\
\text { árvores } \\
\text { ornamentais }\end{array}$ & - & $\begin{array}{l}\text { Cristais } \\
\text { incolo } \\
\text { res, } \\
\text { higros } \\
\text { cópicos }\end{array}$ \\
\hline$\sum_{\mathrm{NO}_{2}}^{\mathrm{NO}_{2}}$ & 281,3 & $\begin{array}{l}0,3 \mathrm{mg} / \mathrm{L} \text { aे } 20 \\
{ }^{\circ} \mathrm{C}, \text { e } 700 \mathrm{~g} / \mathrm{L} \\
\text { em acetona }\end{array}$ & $\begin{array}{l}\text { arroz, feijão, } \\
\text { soja, batata, } \\
\text { frutas, } \\
\text { cenoura }\end{array}$ & 152000 & $\begin{array}{l}\text { Cristais } \\
\text { alaran } \\
\text { jados }\end{array}$ \\
\hline
\end{tabular}

Os substratos empregados nesse trabalho foram lâminas de quartzo polidas

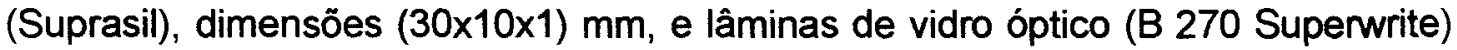
fornecidas pela Opto Eletrônica S.A., dimensões $(10 \times 10 \times 1) \mathrm{mm}$.

Os microeletrodos interdigitados de ouro que foram utilizados para avaliar a resposta elétrica do filme frente às soluções de águas contaminadas por pesticidas foram fornecidos pelo pesquisador Femando Fonseca da Escola Politécnica da Universidade de São Paulo. Os dispositivos contêm 25 pares de microeletrodos (dígitos) com $10 \mu \mathrm{m}$ de largura, $10 \mu \mathrm{m}$ de espaçamento e $0,1 \mu \mathrm{m}$ de espessura da camada de metal. 


\subsection{Métodos}

Neste item são descritos os procedimentos de síntese e caracterização dos polímeros, além dos procedimentos utilizados para os estudos de interação entre pesticidas e polímeros.

\subsection{1- Síntese química dos polímeros condutores}

A seguir são descritos os procedimentos utilizados para a sintese química da POEA e PANI, bem como a desprotonação destes polímeros.

\subsubsection{1- Síntese da Poli(o-etoxianilina) (POEA)}

Sintetizou-se o polímero condutor poli(o-etoxianilina) (POEA) através de sintese química ${ }^{48}$, via polimerização oxidativa do monômero o-etoxianilina (AldrichCo) em meio ácido clorídrico $1 \mathrm{~mol} \mathrm{~L}^{-1}$ e persulfato de amônio. Todos os reagentes foram levados à $0^{\circ} \mathrm{C}$. $\mathrm{O}$ persulfato de amônio foi o agente oxidante, e o mesmo foi adicionado em aproximadamente um minuto e meio, sendo a razão monômero/oxidante de (4:1).

\subsubsection{2- Sintese da Polianilina (PANI)}

Sintetizou-se a polianilina de acordo com o procedimento estabelecido em MacDiarmid ${ }^{47}$, obtendo-se ao final da sintese a polianilina na forma protonada. persulfato de amônio (agente oxidante) $(0,0126 \mathrm{~mol})$ foi dissolvido em $50 \mathrm{~mL}$ de $\mathrm{HCl}$ $1 \mathrm{~mol} \mathrm{~L}^{-1}$ e resfriado a uma temperatura de aproximadamente $0^{\circ} \mathrm{C}$. $\mathrm{O}$ monômero (anilina) em excesso $(0,0548 \mathrm{~mol})$ foi dissolvido em $75 \mathrm{~mL}$ de $\mathrm{HCl} 1 \mathrm{~mol} \mathrm{~L}^{-1}$ e também resfriado a uma temperatura próxima de $0^{\circ} \mathrm{C}$. A solução oxidante foi então adicionada àquela contendo o monômero, mantendo-se agitação durante $1 \mathrm{~min}$. Um pó de cor verde escura foi coletado em um funil de Büchner. Realizou-se a lavagem 
deste polímero com grandes quantidades de $\mathrm{HCl} 1 \mathrm{~mol} \mathrm{~L}^{-1}$, até que 0 filtrante apresentasse ausência de cor. Secou-se a polianilina em dessecador com vácuo continuo por um dia, e armazenou-se em frasco escuro.

\subsubsection{3 - Desprotonação da PANI e da POEA}

Para a desprotonação da polianilina dopada colocou-se 2 gramas da polianilina dopada em $1 \mathrm{~L}$ de solução de $\mathrm{NH}_{4} \mathrm{OH} 0,1 \mathrm{~mol} \mathrm{~L}^{-1}$, mantendo-se sob agitação constante por aproximadamente $16 \mathrm{~h}$ à temperatura ambiente (próxima de $25^{\circ} \mathrm{C}$ ). Filtrou-se a polianilina em funil de vidro sinterizado, lavou-se a mesma com água deionizada, secou-se em dessecador com vácuo contínuo durante $24 \mathrm{~h}$ e armazenou-se em frasco escuro. O mesmo procedimento foi adotado para a desprotonação do polímero condutor POEA.

\subsection{2- Caracterização dos Polimeros Condutores}

Caracterizou-se os polímeros condutores por meio das técnicas espectrofotométricas de UV-Vis, utilizando-se um espectrofotômetro modelo UV1601 PC da Shimadzu, e através de FTIR com um espectrofotômetro modelo Spectrum 1000 da Perkin Elmer, e comparou-se os resultados obtidos com dados da literatura.

Para as medidas de FTIR fez-se pastilhas de $\mathrm{KBr}$ na proporção de aproximadamente $1 \mathrm{mg}$ de polímero para $100 \mathrm{mg}$ de $\mathrm{KBr}$, sendo o material submetido a vácuo e pressão de 12 psi por aproximadamente 5 minutos.

Para as medidas de UV-Vis utilizaram-se duas cubetas, uma para a amostra de polímero e outra para referência (branco), e fez-se a varredura de 800 a $190 \mathrm{~nm}$. 


\subsection{3- Preparo da Solução de POEA}

A solução polimérica utilizada para a preparação dos filmes ultrafinos da POEA foi obtida pesando-se uma massa de $61,11 \mathrm{mg}$ de POEA seca, dopada em meio $\mathrm{HCl} 1 \mathrm{~mol} \mathrm{~L}^{-1}$. Umedeceu-se o pó com dez gotas de acetona e diluiu-se a 100 $\mathrm{mL}$ com água ultra pura obtida em um sistema milli-Q, da Milipore. A concentração final de POEA obtida foi de $10^{-3} \mathrm{~mol} \mathrm{~L}^{-1}$. Agitou-se a mistura durante 18 horas. A solução foi filtrada e conservada em geladeira.

\subsection{4-Caracterização dos filmes de POEA}

Fez-se o estudo do crescimento de filmes de POEA, concentração $10^{-3}$ mol $\mathrm{L}^{-1}, \mathrm{pH} 5,0^{48}$ em lâminas vitreas. Os filmes foram depositados pelo método de automontagem, sendo o substrato imerso na solução polimérica por três minutos e seco com nitrogênio logo em seguida. Foram depositadas seis camadas de POEA na lâmina de vidro. Após a deposição e secagem de cada camada, foram realizadas medidas espectrofométricas de UV-VIS.

\subsection{5-Caracterização morfológica da POEA e da sua interação com pesticidas, por MFA}

Lâminas vitreas foram lavadas abundantemente em uma solução de água ultrapura obtida de um sistema da Milipore e imersas em uma solução de POEA $10^{-}$ ${ }^{3} \mathrm{~mol} \mathrm{~L}^{-1}, \mathrm{pH}$ 5,0 por um periodo de 3 minutos. As lâminas foram retiradas da solução de POEA, secas à temperatura ambiente e novamente lavadas solução aquosa, em pH 5,0. As lâminas com a POEA foram imersas em soluções contendo os pesticidas atrazina, imazaquin, linuron, paraquat e metribuzin, também em $\mathrm{pH}$ 5,0 por 3 minutos. Fez-se imagens de microscopia de força atômica para essas 
lâminas no modo não-contato, e observou-se as mudanças nas rugosidades entre as amostras com os diferentes pesticidas.

\subsection{6- Deposição "in situ” de PANI sobre substrato vítreo}

Um substrato vitreo em forma de lâmina foi utilizado para a preparação do filme de PANI. As lâminas foram primeiramente lavadas em uma solução de $\mathrm{H}_{2} \mathrm{O}_{2}$ e $\mathrm{H}_{2} \mathrm{SO}_{4}$ na proporção 1:3, e posteriormente lavadas abundantemente com água destilada e água purificada em um sistema mili-Q $Q^{52}$.

$\mathrm{Na}$ síntese convencional da PANI ${ }^{16}, 20 \mathrm{~mL}$ da anilina previamente destilada são dissolvidas em $300 \mathrm{~mL}$ de $\mathrm{HCl} 1 \mathrm{~mol} \mathrm{~L}^{-1}$ e levados à $0^{\circ} \mathrm{C}$. Separadamente, $11,52 \mathrm{~g}$ do oxidante persulfato de amônio são dissolvidos em $200 \mathrm{~mL}$ de $\mathrm{HCl} 1 \mathrm{~mol}$ $\mathrm{L}^{-1}$, e também levados à $0^{\circ} \mathrm{C}$. Em seguida, a solução contendo $\mathrm{o}$ agente oxidante é adicionada lentamente à solução do monômero sob agitação contínua, em um minuto. As lâminas vítreas foram imersas no meio reacional da PANI. Durante a polimerização, um filme polimérico esverdeado é formado na superfície do substrato.

Observou-se o filme de PANI formado no substrato vítreo por microscopia óptica, e foram feitos espectros em UV-Vis de 1000 a $200 \mathrm{~nm}$ do filme de PANI "in situ". Foram realizados estudos de interações entre pesticidas e o filme de PANI. Para isso, três lâminas do filme de PANI foram imersas durante 15 minutos em uma solução aquosa dos pesticidas: clorpirifos, imazaquin e metribuzin, todos na concentração $10 \mu \mathrm{g} \mathrm{L}^{-1}$. Após a secagem das lâminas à temperatura ambiente, foram feitos espectros em UV-Vis de 1000 a $200 \mathrm{~nm}$. 


\subsection{7- Determinação da Cinética de Adsorção dos pesticidas na PANI por UV-Vis}

Realizou-se estudos de adsorção dos pesticidas na PANI, utilizando-se a técnica de espectrofotometria no UV-Vis para a quantificação da concentração dos pesticidas. Neste caso, a diminuição da concentração do pesticida em solução foi associada à adsorção no polímero (precipitado). Neste experimento $25 \mathrm{mg}$ da Polianilina em forma de pó, nos estado dopado e desdopado, foram colocados em erlenmeyers contendo $12,5 \mathrm{~mL}$ de soluções aquosas dos pesticidas linuron e metribuzin, em concentração $10 \mu \mathrm{g} \mathrm{L}^{-1}$. Foram obtidos espectros UV-Vis das soluções durante 96 horas. Após as medidas no espectrofotômetro de UV-Vis, as amostras eram retornadas ao erlenmeyer. As varreduras foram realizadas na faixa de 800 a $200 \mathrm{~nm}$. Adicionalmente foi realizado também um experimento de adição padrão dos pesticidas, possibilitando a obtenção de curvas analíticas dos pesticidas (absorbância máxima versus concentração), e conseqüentemente a determinação das concentrações dos pesticidas ao longo do tempo. Assim, foi possivel determinar-se a cinética de adsorção dos pesticidas.

\subsection{8- Estudo de soluções, deposição e caracterização de filmes de} PEDOT/PSS- Baytron P ${ }^{\circledR}$ Bayer

Fez-se um estudo utilizando-se solução do polímero PEDOT/PSS- Baytron P Bayer, juntamente com água ultra pura na razão 1:3, em diversos pHs, obtidos com $\mathrm{NH}_{4} \mathrm{OH} \mathrm{0,1} \mathrm{mol} \mathrm{L}^{-1}$ e $\mathrm{HCl} \mathrm{0,1} \mathrm{mol} \mathrm{L}^{-1}$.

A solução polimérica utilizada para estudos de caracterizaçăo dos filmes ultrafinos através de automontagem "self-assembly" e "coating" foi preparada adicionando-se uma gota de ácido dodecilbenzenosulfônico $\left(\mathrm{CH}_{3}\left(\mathrm{CH}_{2}\right)_{11} \mathrm{C}_{6} \mathrm{H}_{4} \mathrm{SO}_{3}^{-}\right.$ 
$\mathrm{H}^{+}$)-DBSA em $10 \mathrm{~mL}$ de etilenoglicol, agitando-se a mistura manualmente. Adicionou-se $2 \mathrm{~mL}$ dessa solução a $10 \mathrm{~mL}$ da dispersão de PEDOT/PSS-Baytron $\mathrm{P}$, e agitou-se manualmente. Essa solução resultante apresentou pH 3,0 ${ }^{48}$. Utilizou-se também o PEDOT/PSS-Baytron $\mathrm{P}$ diluído em água destilada na razão 1:5 para a fabricação de sensores, devido à alta capacitância da solução utilizada para os estudos de caracterização do polímero.

Através da espectrofotometria de UV-Vis realizou-se o estudo do crescimento dos filmes poliméricos de PEDOT/PSS diluído por automontagem, 0 estudo do crescimento do filme alternado com POEA e o estudo da influência do pH na solução de PEDOT/PSS.

A técnica de automontagem utilizada para fabricação dos filmes consiste na imersão do substrato na solução de PEDOT/PSS e secagem com ar quente. A repetição dos itens anteriores foi realizada para a obtenção várias camadas de filmes. Decher et al. ${ }^{28}$ propuseram um princípio de preparação de multicamadas moleculares, sendo assim, um substrato sólido com superfície de carga negativa é imerso em uma solução contendo um polieletrólito catiônico, e a camada do policátion é adsorvida via atrações eletrostáticas ${ }^{53}$. Assim, estudou-se filmes de um poliânion (PEDOT/PSS) intercalado com um policátion (POEA).

A técnica de "coating" utilizada consistiu no recobrimento do substrato (lâmina de vidro) com a solução de PEDOT/PSS com auxilio de uma pipeta Pasteur e um bastão de vidro, e secagem com ar quente durante três minutos.

As técnicas de microscopia óptica e de força atômica foram utilizadas para caracterizar as diferenças morfológicas dos filmes nos dois procedimentos de deposição dos filmes de PEDOT/PSS. 


\subsection{9- Caracterização elétrica dos microeletrodos interdigitados}

Foram selecionados dez microeletrodos interdigitados para a utilização como unidades sensoriais no arranjo "língua eletrônica" (Figura 5a), que foi utilizada para a detecção dos pesticidas em água. A caracterização dos 10 microeletrodos interdigitados foi obtida com os mesmos imersos em água destilada. Foram realizadas medidas elétricas de capacitância e resistência na freqüência de $1 \mathrm{~Hz}$ e $1 \mathrm{MHz}$ em corrente alternada (AC) em um medidor de impedância Solartron SI 1260 Impedance/Gain - Phase Analyser .

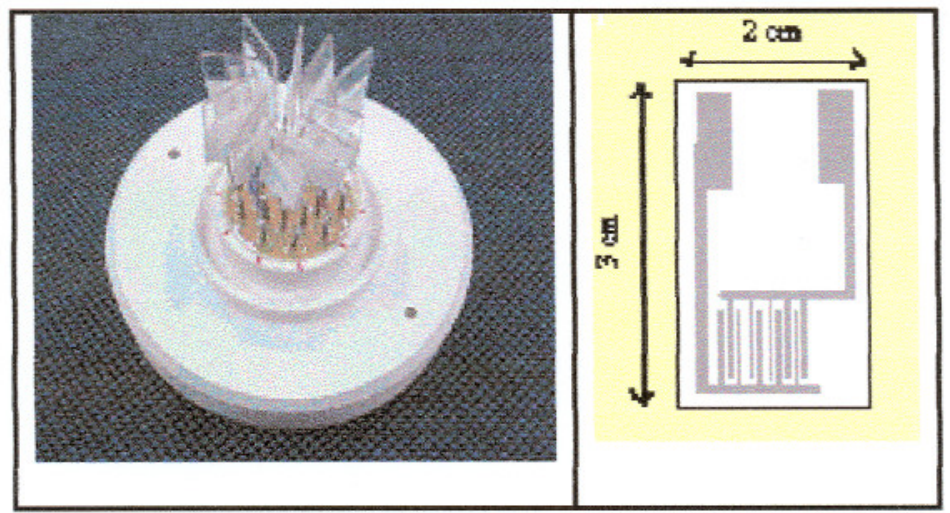

(a)

(b)

Figura 5. a) Arranjo de sensores que compõem uma língua eletrônica e b) Um microeletrodo interdigitado de ouro.

\subsubsection{0- Aplicação da língua eletrônica para a medida dos pesticidas}

Após a realização dos estudos de caracterização dos polímeros e interação dos pesticidas com os polímeros, efetuou-se a seleção dos polímeros e as combinações de camadas para compor as dez unidades sensoriais a serem utilizadas na "língua eletrônica". A Tabela 2 apresenta uma descrição dos filmes de polímeros utilizados em cada uma das unidades sensoriais. $O$ objetivo desta escolha foi obter um arranjo onde se pudesse avaliar o efeito dos três polímeros 
anteriormente estudados (POEA, PEDOT/PSS e PANI), bem como o número de camadas depositadas e a repetibilidade de sensores com o mesmo tipo de polímero e mesmo número de camadas. A seguir serão descritos os procedimentos de preparo, caracterização e análise utilizados.

Tabela 2. Descrição dos sensores utilizados no arranjo da língua eletrônica para a análise dos pesticidas.

\begin{tabular}{|c|c|}
\hline $\begin{array}{c}\text { Microeletrodos } \\
\text { Interdigitados de ouro }\end{array}$ & $\begin{array}{c}\text { Filmes depositados } \\
\text { por automontagem }\end{array}$ \\
\hline Sensor 1 & Sem filme (SF) \\
\hline Sensor $\mathbf{2}$ & POEA (1 camada) \\
\hline Sensor 3 & POEA (2 camadas) \\
\hline Sensor 4 & POEA (2 camadas) \\
\hline Sensor 5 & POEA (2 camadas) \\
\hline Sensor 6 & POEA (3 camadas) \\
\hline Sensor 7 & POEA (4 camadas) \\
\hline Sensor $\mathbf{8}$ & PEDOT/PSS alternado \\
& com POEA \\
& (1 bicamada) \\
\hline Sensor 9 & PANI (1 camada) \\
\hline Sensor 10 & PANI (1 camada) \\
\hline
\end{tabular}

\subsubsection{1- Procedimento de preparação dos filmes poliméricos nos microeletrodos}

As dez unidades sensoriais foram recobertas com os polímero condutores depositados por automontagem. Os filmes automontados foram fabricados através da imersão do substrato na solução de policátion de concentração $10^{-3} \mathrm{~mol} \mathrm{~L}^{-1}$, lavagem do substrato em água milli-Q no em $\mathrm{pH}$ 5,0 e secagem a temperatura ambiente. Para o filme de PEDOT/PSS alternado com POEA, utilizou-se o mesmo 
processo, fazendo-se, primeiramente, a imersão do substrato em solução aquosa de poliânion na razão 1:5, e depois a imersão do substrato na solução de policátion de concentração $10^{-3} \mathrm{~mol} \mathrm{~L}^{-1}$.

Todos os microeletrodos foram lavados com água ultra-pura milli-Q em abundância antes da deposição dos filmes poliméricos.

\subsubsection{2- Análise do PEDOT/PSS e dos Pesticidas}

Para caracterizar os filmes de PEDOT/PSS depositados por "coating" e automontagem, foram realizadas medidas de capacitância (C) e resistência (R) na freqüência de $1 \mathrm{kHz}$ e $10 \mathrm{kHz}$ com os filmes imersos em amostras de água ultrapura Milli-Q.

A análise dos pesticidas foi feita utilizando-se soluções dos pesticidas nas

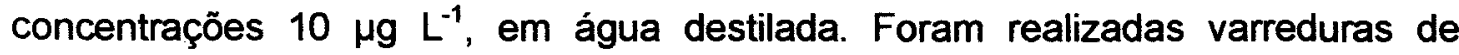
capacitância na freqüência de $100 \mathrm{~Hz}$ à $10 \mathrm{kHz}$ com os filmes imersos em amostras de água destilada e água contaminada com os pesticidas.

Para essas análises, utilizou-se um medidor de impedância Solartron SI 1260 Impedance/Gain - Phase Analyser, aplicando-se um potencial com uma amplitude de $50 \mathrm{mV}$ pico a pico em corrente alternada (AC) em e um banho termostático. Todas as medidas foram realizadas em triplicatas, após um periodo de estabilização de 20 minutos e em banho termostático à $25^{\circ} \mathrm{C}$. Os resultados obtidos foram analisados através de Análise de Componente Principal. 


\section{CAPÍTULO III}

\section{RESULTADOS E DISCUSSÕES}

\section{1- Caracterização dos Polímeros Condutores}

A seguir são apresentadas as caracterizações da PANI, POEA e PEDOT/PSS, por meio das técnicas de FTIR, UV-Visível, microscopia óptica, microscopia de força atômica e impedância elétrica.

\subsection{1-Análise dos Espectros de Infravermelho com}

\section{transformada de Fourier}

- PANI

Os espectros da PANI dopada e desdopada são apresentados na Figura 6, com a indicação dos principais números de onda dos picos, os quais são descritos a seguir:

-3500 à 3300- região correspondente ao estiramento $\mathrm{N}-\mathrm{H}$, com absorção média -3100 à 2800- corresponde às deformações axiais de $\mathrm{C}-\mathrm{H}$ dos aromáticos -2800 à 2000- deformações axiais de N-H de aminas secundárias protonadas -1689 à 1471- deformações axiais do $\mathrm{C}=\mathrm{N}$ -1600 à 1585 e 1500 à 1400 - bandas de vibrações de esqueleto envolvendo a deformações axiais das ligações carbono-carbono no anel aromático 
-1400 à 1240- estiramento C-N de aminas aromáticas secundárias

- 1300 à 1000- bandas de deformações angulares no plano das ligações C-H dos hidrocarbonetos aromáticos ${ }^{54,55}$.

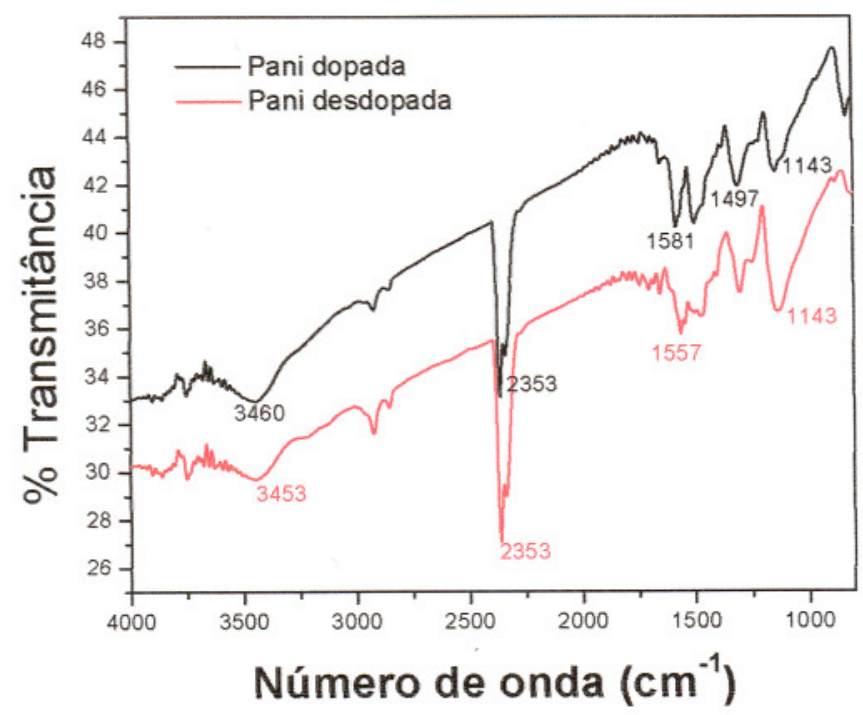

Figura 6. Espectros de FTIR da PANI dopada e desdopada.

Depois da dopagem, as bandas quinóides e benzenóides ficam em aproximadamente $1581 \mathrm{~cm}^{-1}$ e $1497 \mathrm{~cm}^{-1}$, respectivamente ${ }^{56}$.

\section{- POEA}

A Figura 7 mostra os espectros da POEA dopada em meio $\mathrm{HCl}$ e em $\mathrm{NH}_{4} \mathrm{OH}$. 


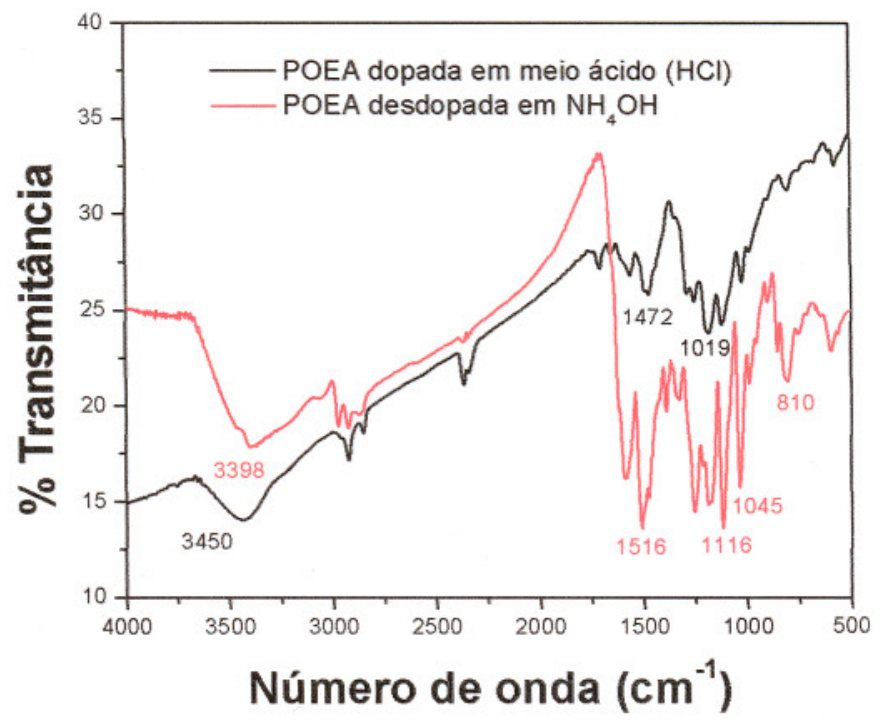

Figura 7. Espectros de FTIR da POEA dopada e desdopada.

Os espectros apresentam regiões de bandas características similares aos da PANI, já que a POEA é um derivado da PANI, com a diferença da ocorrência de deformações axiais simétricas e assimétricas do C-O-C nas regiões de 1075-1020 $\mathrm{cm}^{-1}$ e $1275-1200 \mathrm{~cm}^{-1}$, respectivamente.

\subsection{2- Espectros de UV-Vis das soluções poliméricas}

\section{- PANI}

A Figura 8 mostra um espectro de UV-vis do polímero condutor Polianilina em sua forma desdopada, em meio NMP, uma vez que a PANI é insolúvel em meio aquoso. 


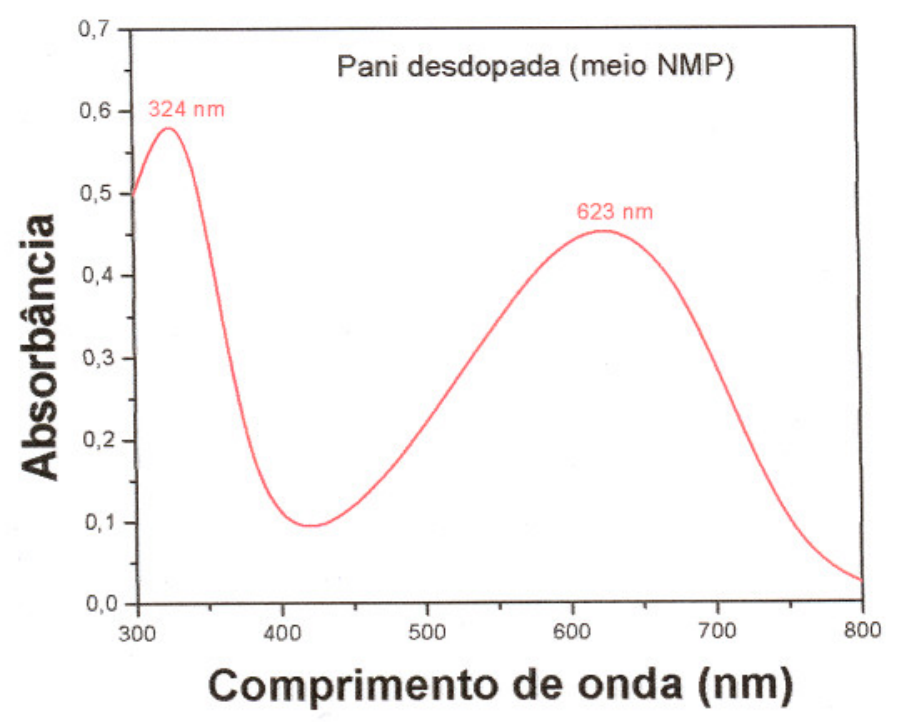

Figura 8. Espectro UV-VIS da PANI desdopada em meio NMP

Transições $\pi \rightarrow \pi^{\star}$ (bandas K) aparecem nos espectros de moléculas que contém sistemas $\pi$ conjugados, e em moléculas aromáticas que possuem substituição cromófora ( grupo insaturado covalente, como por exemplo $\mathrm{C}=\mathrm{C}$ ) ${ }^{54}$. Bandas benzenóides são características dos espectros de moléculas aromáticas e heteroaromáticas ${ }^{54}$. A banda em $623 \mathrm{~nm}$ está relacionada à transferência de carga entre os anéis benzenóides e quinóides ${ }^{11}$.

\section{- POEA}

A Figura 9 mostra uma comparação dos espectros de UV-Vis da POEA (derivado da PANI) quando o polímero encontra-se dopado em meio ácido, e desdopado em meio básico. 


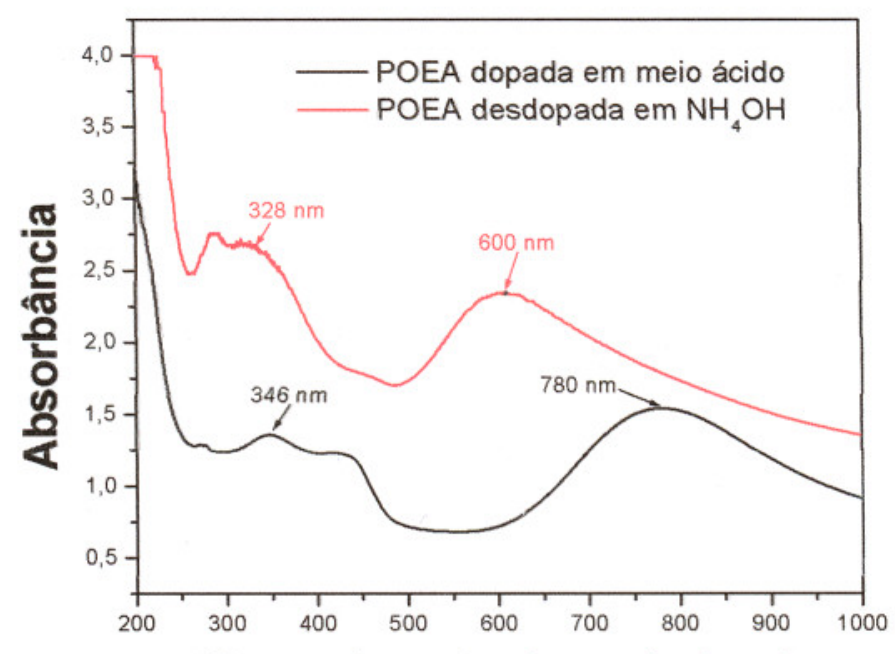

Comprimento de onda $(\mathrm{nm})$

Figura 9. Comparação de Espectros de UV-Vis da POEA dopada e desdopada.

A banda em aproximadamente $346 \mathrm{~nm}$ da POEA dopada é devida à transição $\pi \rightarrow \pi^{*}$ dos anéis benzênicos, e a banda em aproximadamente $780 \mathrm{~nm}$ corresponde à formação de pólarons na cadeia polimérica ${ }^{54}$.

Nota-se que a banda do polímero na forma desdopada em aproximadamente $600 \mathrm{~nm}$ desloca-se para $780 \mathrm{~nm}$ quando o mesmo encontra-se na forma dopada. Isso ocorre devido à transferência de carga dos anéis benzenóides e quinóides. Essa banda corresponde à formação de pólarons na cadeia polimérica e está relacionada ao aumento de condutividade do processo de dopagem ${ }^{11}$.

\section{- PEDOT/PSS- Baytron P ${ }^{\circledR}$ Bayer}

A Figura 10 apresenta os espectros de UV-Vis para as soluções do polímero PEDOT/PSS- Baytron $\mathrm{P}{ }^{\circledR}$ Bayer em água na razão de 1:3 em diversos pHs. 


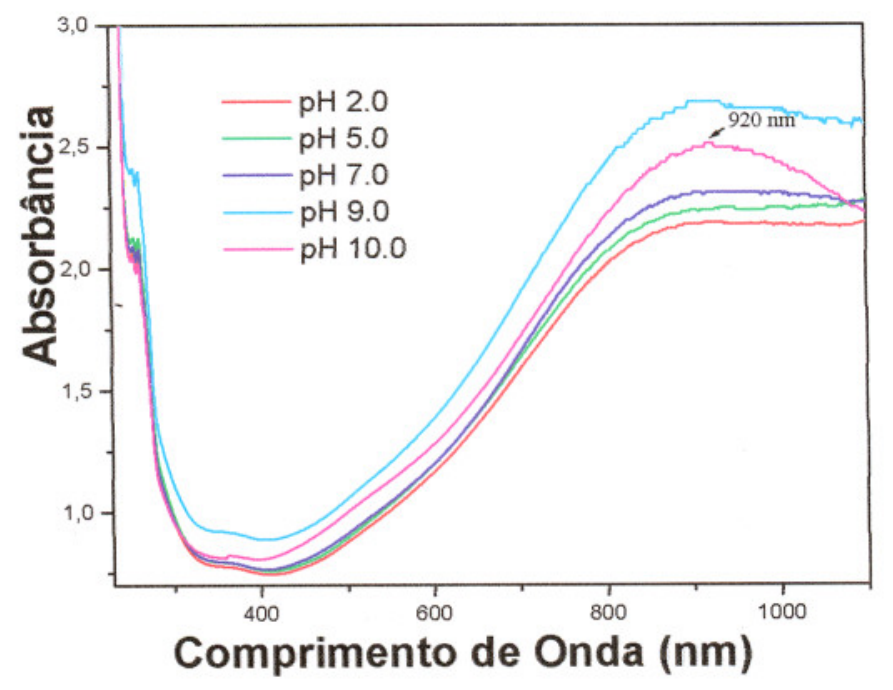

Figura 10. Estudo de UV-VIS de PEDOT/PSS- Baytron $\mathrm{P} \circledast$ Bayer em vários pHs.

Nota-se uma banda característica do polímero no comprimento de onda de $920 \mathrm{~nm}$. Essa mesma banda aparece independentemente do $\mathrm{pH}$ utilizado, mas observa-se que para pH 10,0 a banda é melhor visualizada. Estudos de crescimentos de filmes finos em lâminas poderiam ser, portanto, realizados em qualquer $\mathrm{pH}$, tendo apenas a vantagem da melhor definição do pico se $\circ \mathrm{pH} 10,0$ for utilizado. A absorbância em aproximadamente $900 \mathrm{~nm}$ representa a banda polarônica característica para o polímero PEDOT/PSS. A banda em maiores comprimentos de onda pode ocorrer devido à presença do grupo $=\mathrm{C}-\mathrm{S}$, para os tiofenos, ligado a.um grupamento doador de elétrons. A transição $n \rightarrow \pi^{\star}$ neste grupo ocorre em comprimentos de onda maiores que do grupo $\mathrm{C}=\mathrm{O}$ e é atribuído à energia mais alta dos orbitais não ligantes do enxofre em relação aos do oxigênio. A transição $\pi \rightarrow \pi^{*}$ e $n \rightarrow \sigma^{*}$ do grupamento $=C-S$ é visualizada na região de 250$320 \mathrm{~nm}^{54,57}$. 
A Figura 11 mostra o espectro de UV-Vis da POEA em seu estado dopado, na concentração $10^{-3} \mathrm{~mol}^{-\mathrm{L}^{-1}}$, em pH 3,0 , e do PEDOT/PSS- Baytron P ${ }^{\circledR}$ Bayer em $\mathrm{pH} 3,0$, ambas as soluções foram utilizadas para a deposição por automontagem em lâminas de vidro. Observa-se a banda característica de absorção da POEA dopada em cerca de $700 \mathrm{~nm}$ e do PEDOT/PSS-Baytron $\mathrm{P}{ }^{\circledR}$ Bayer em torno de 870 $\mathrm{nm}$.

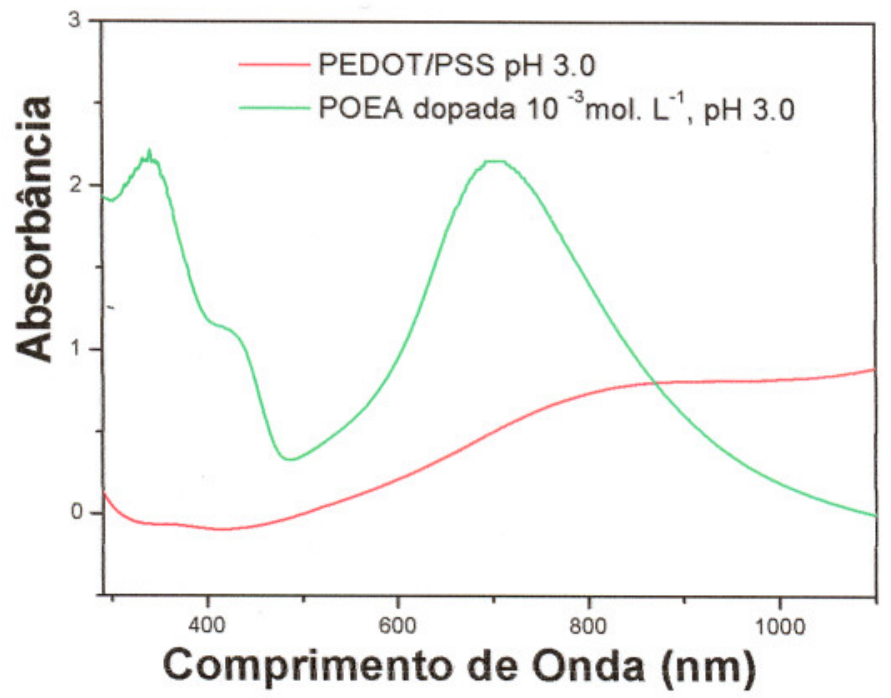

Figura 11. Espectro de UV-Vis da POEA e do PEDOT, em $\mathrm{pH} 3,0$.

3.1.3- Espectros de UV-Vis de filmes de POEA e PEDOT/PSS- Baytron $\mathrm{P}^{\circledR}$ Bayer em lâminas vítreas

\section{- POEA}

Na Figura 12 apresenta-se os espectros de UV-Vis para o crescimento de monocamadas de POEA dopada em $\mathrm{pH} 5,0$, na concentração $10^{-3} \mathrm{~mol} \mathrm{~L}^{-1}$. O espectro $\mathrm{O} \mathrm{pH} 5,0$ foi escolhido porque aumenta-se a quantidade de material 
adsorvido com o aumento do $\mathrm{pH}$ da solução polimérica, devido a uma diminuição da repulsão eletrostática intramolecular. Conseqüentemente, uma interação maior com o substrato é ocasionada ${ }^{58}$. O aumento linear da absorbância confirma a deposição do polímero na lâmina.

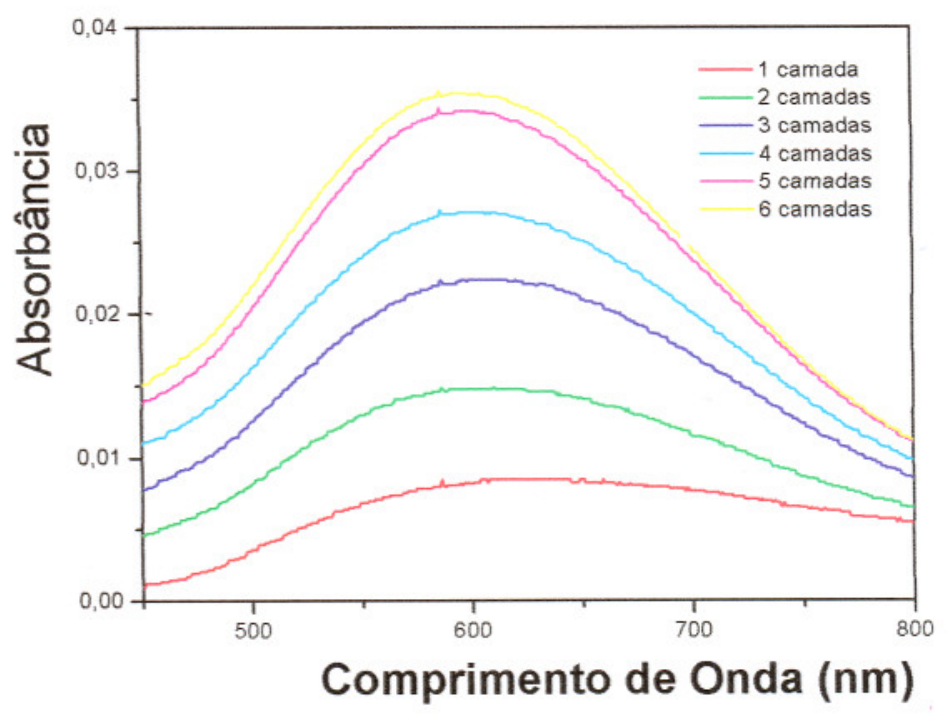

Figura 12. Espectros de UV-Vis do crescimento dos filmes de POEA por UV-Vis.

\section{- PEDOT/PSS- Baytron P ${ }^{\circledR}$ Bayer}

Foi realizada a caracterização dos filmes de PEDOT/PSS- Baytron P ®Bayer através de UV-Vis em sete monocamadas e da combinação de bicamadas de POEA/PEDOT. A Figura 13 apresenta os espectros de UV-Vis dos filmes de PEDOT/PSS- Baytron $\mathrm{P}{ }^{\circledR}$ Bayer com deposição de uma a sete monocamadas em lâminas de vidro por automontagem. 


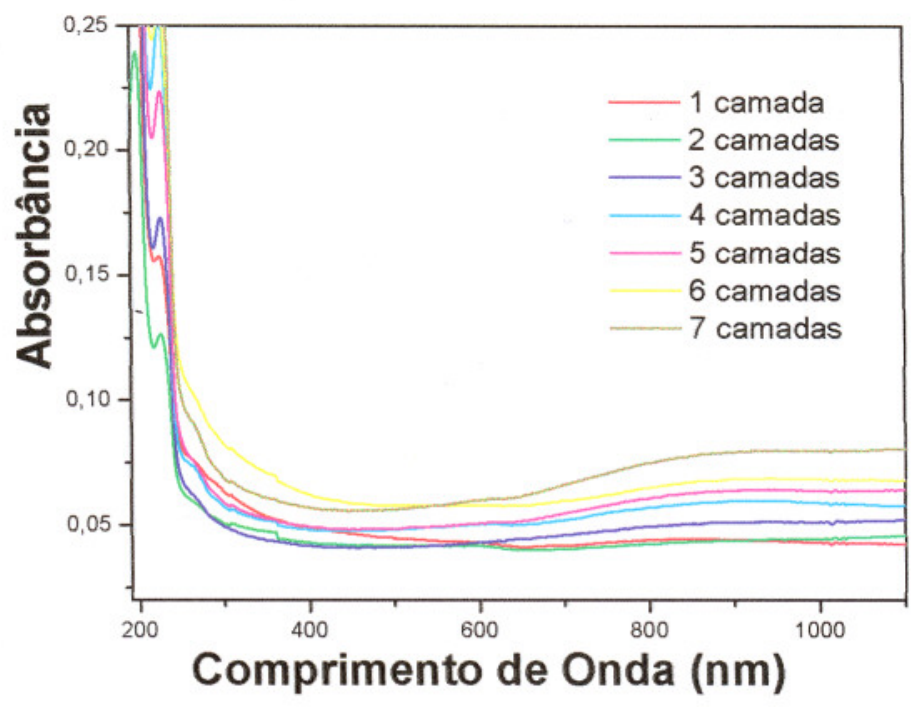

Figura 13. Espectro de crescimento de monocamadas de PEDOT/PSS.

Observa-se através das Figura 13, o aumento da absorbância conforme o crescimento de camadas depositadas, comprovando a deposição de material sobre o substrato. Quanto maior o número de camadas depositadas, maior a quantidade de material adsorvido, e portanto, maior a absorbância' ${ }^{11,12,58}$.

$O$ resultado do estudo de bicamadas de POEA e PEDOT/PSS- Baytron P ${ }^{\circledR}$ Bayer é apresentado na Figura 14. Este espectro apresenta o mesmo comportamento do espectro da Figura 13, mostrando que há deposição de PEDOT/PSS. O espectro deixa de apresentar a banda polarônica característica da POEA devido a última camada depositada ser de PEDOT/PSS. 


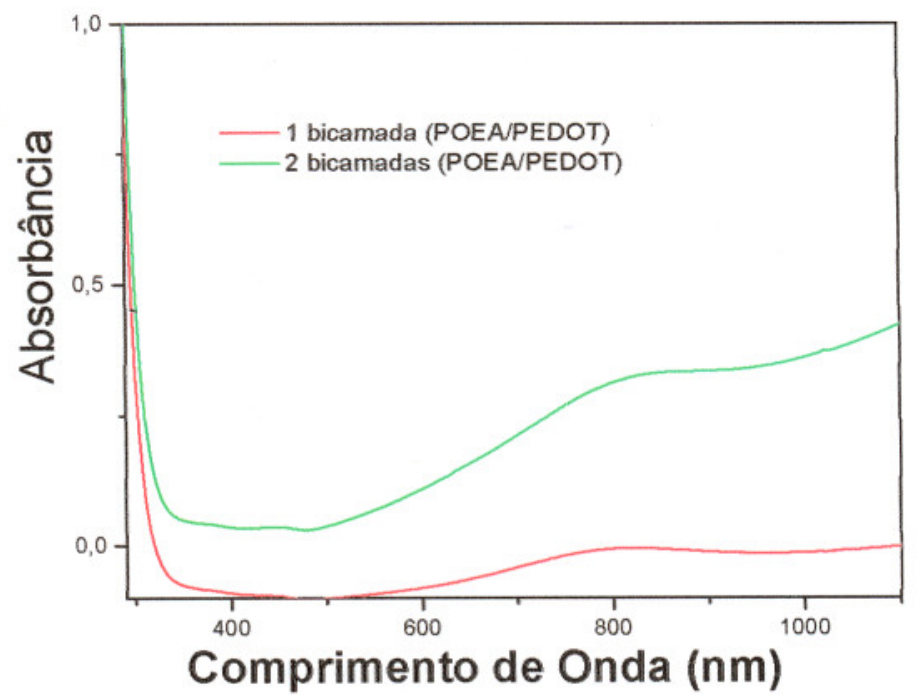

Figura 14. Espectros de UV-Vis do crescimento do filme de POEA alternado com PEDOT.

\subsection{4- Espectrofotometria de UV-Vis das lâminas com}

\section{PANI depositadas "in situ"}

Os espectros de UV-Vis das lâminas de vidro obtidas da polimerização da PANI "in situ" 59 , antes e após o contato por 15 minutos em solução de $10 \mu \mathrm{gL} \mathrm{L}^{-1}$ com os pesticidas clorpirifos, imazaquin e metribuzin, são apresentados na Figura 15. 


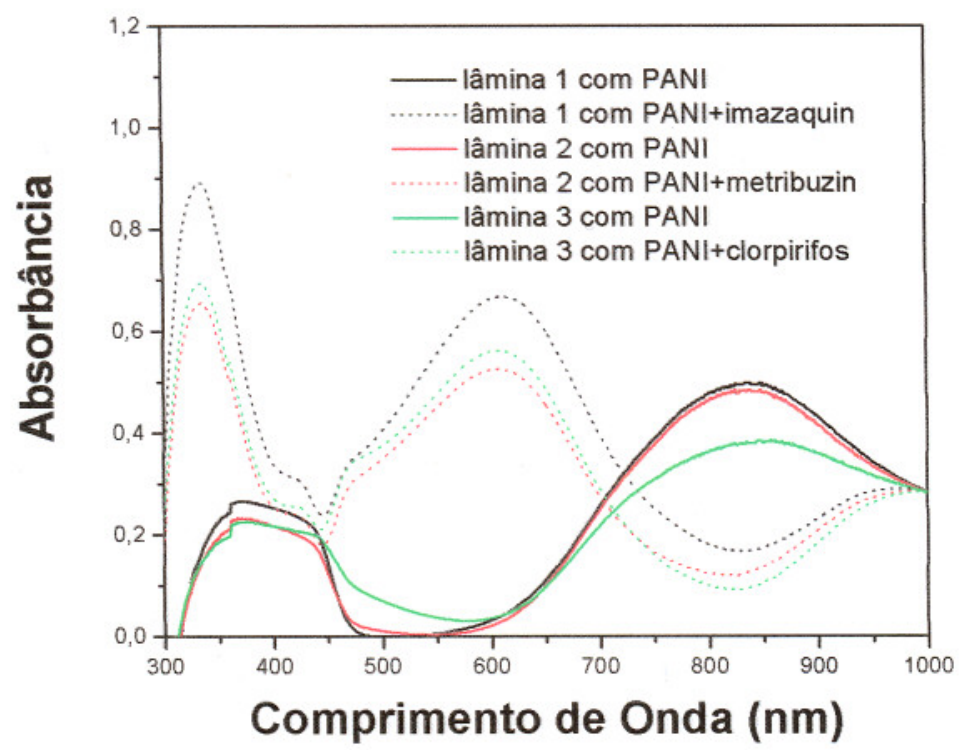

Figura 15. Espectro de UV-Vis das lâminas de PANI "in situ".

Observa-se que as lâminas com filme de PANI absorvem em comprimentos de onda de aproximadamente $800 \mathrm{~nm}$. Após a imersão das lâminas nos pesticidas ocorre um deslocamento da banda de absorção para comprimentos de onda de aproximadamente $600 \mathrm{~nm}$, indicando que houve uma mudança no estado de oxidação do polímero (desdopagem), o que foi comprovado visualmente através da mudança de coloração de verde para azul, após o contato da lâmina com os pesticidas. Também pode-se notar um aumento da absorbância do filme após o contato com os pesticidas, indicando que pode estar se formando um filme fino de pesticidas sobre o filme de PANI "in situ". Esse aumento foi mais intenso para o imazaquin, como pode ser observado na Figura 15. Observa-se também uma banda de absorção em torno de $320 \mathrm{~nm}$, que pode estar associada ao excesso de pesticida na superfície do polímero, uma vez que não houve lavagem da lâmina após a imersão na solução contendo os pesticidas. 


\subsection{5- Microscopia Óptica de filmes de PANI e}

\section{PEDOT/PSS- Baytron $\mathbf{P}^{\circledR}$ Bayer}

- PANI "in situ"

Nas Figuras 16, 17 e 18 são apresentadas imagens de microscopia óptica de lâminas vítreas contendo o filme de PANI, com amplificação de 40, 100 e 400 vezes, respectivamente. A deposição foi realizada "in situ", via síntese química da PANI.

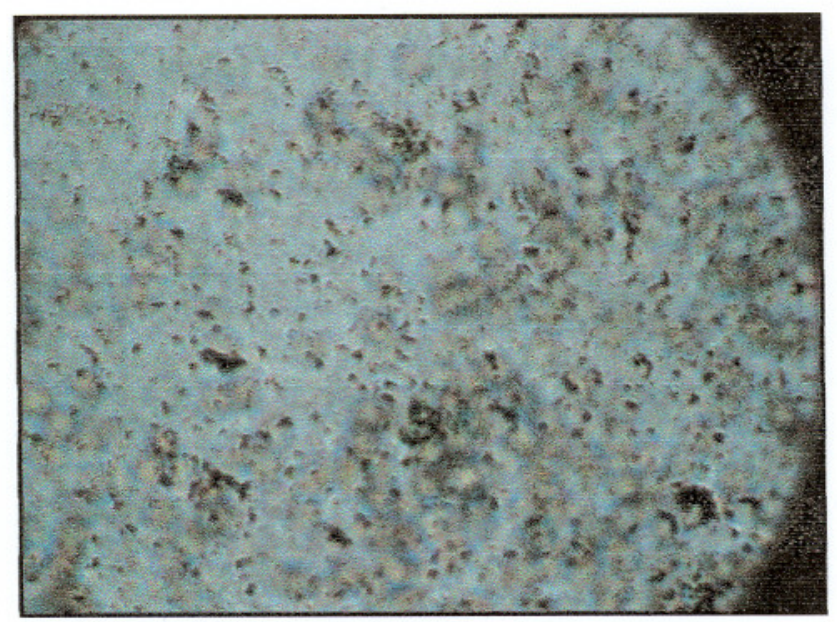

Figura 16. Imagem do filme de PANI obtido "in situ", com ampliação de 40x.

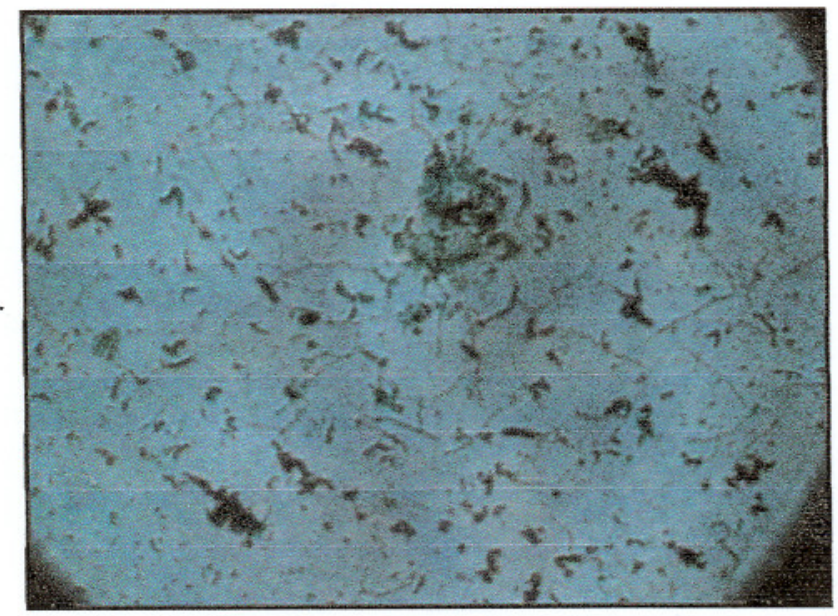

Figura 17. Imagem do filme de PANI obtido "in situ", com ampliação de 100X. 


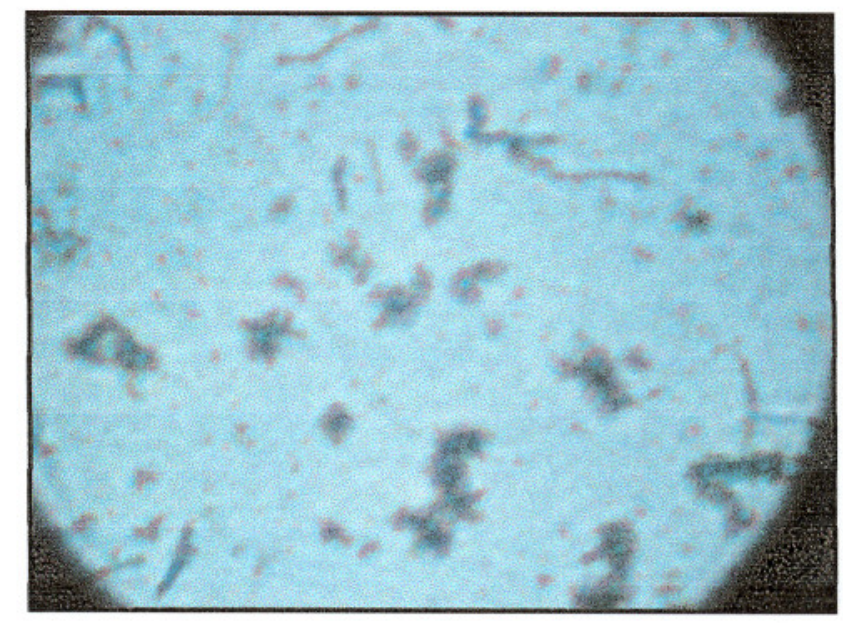
$400 X$

Figura 18. Imagem do filme de PANI obtido "in situ", com ampliação de

Observa-se, nos três graus de magnificação (Figuras 16, 17 e 18) a formação de grãos poliméricos típicos da estrutura molecular da PANI ${ }^{60}$ e a formação de ilhas com acúmulo de material em forma de agregados, pequenos pontos e estruturas mais retilíneas, bem como a coloração esverdeada, característica da PANI em seu estado dopado (sal de esmeraldina).

\section{- PEDOT/PSS}

Após a deposição do filme de PEDOT/PSS em lâminas de vidro, de acordo com o procedimento sugerido por Lu et al. ${ }^{61}$, observou-se, visualmente, uma coloração azulada na lâmina. A Figura 19 apresenta uma imagem com amplificação de 40 vezes. Verifica-se a presença de pequenos agregados e pontos, o que indica que a formação do filme de PEDOT/PSS é não homogênea. 


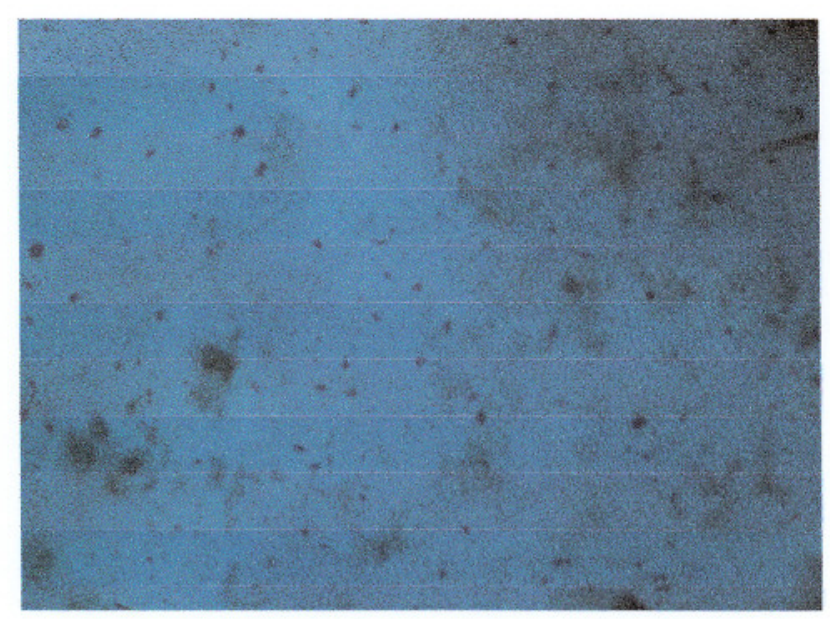

Figura 19. Imagem de microscopia óptica de filme de PEDOT/PSS com amplificação de $40 \mathrm{x}$.

\subsection{6- Microscopia de Força Atômica de filmes de}

\section{PEDOT/PSS- Baytron $\mathrm{P}^{\circledR}$ Bayer}

Foram utilizados dois procedimentos de deposição para a obtenção dos

filmes de PEDOT/PSS- Baytron $\mathrm{P}^{\circledR}$ Bayer e a avaliação da morfologia por MFA : o "coating" e a automontagem .

A Figura 20 mostra imagens de microscopia de força atômica para filmes de PEDOT/PSS depositados em lâminas vítreas pelo método "coating", em duas e três dimensões, Figura 20(a) e Figura 20(b), respectivamente. Observa-se uma estrutura bastante rugosa formada por grânulos, similar a resultados verificados por outros autores ${ }^{62}$. 


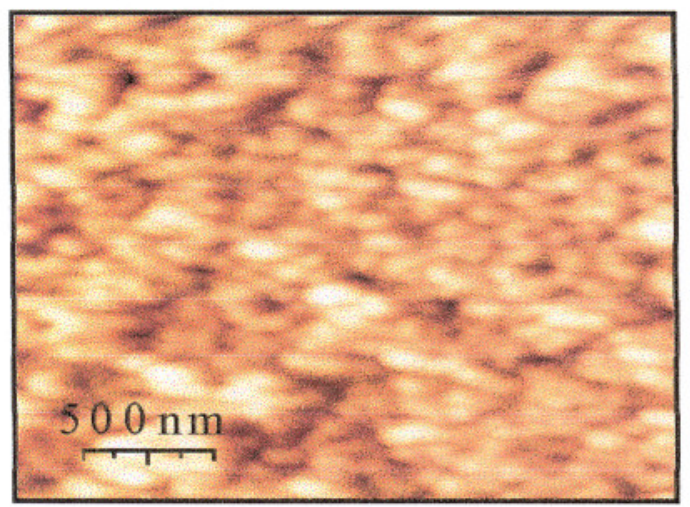

(a)

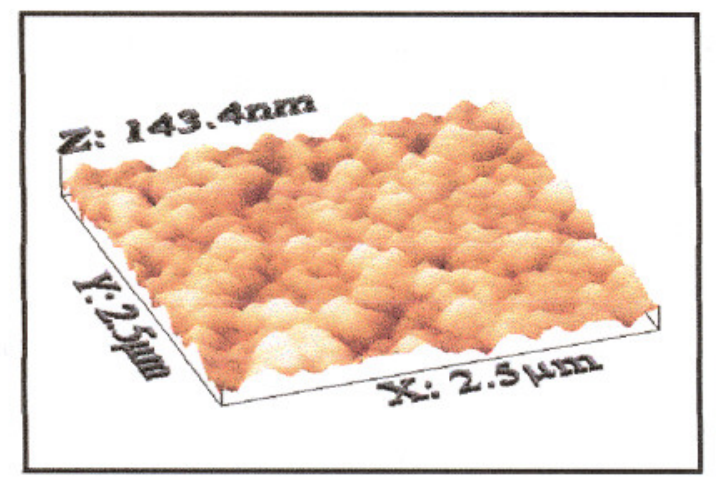

(b)

Figura 20. (a) Imagem em 2-D de MFA do filme de PEDOT/PSS depositado por coating. (b) Imagem em 3-D de MFA do filme de PEDOT/PSS depositado por coating.

A Figura 21 mostra imagens de MFA do filme de PEDOT/PSS Baytron $\mathrm{P}^{\oplus}$ Bayer depositado por automontagem.

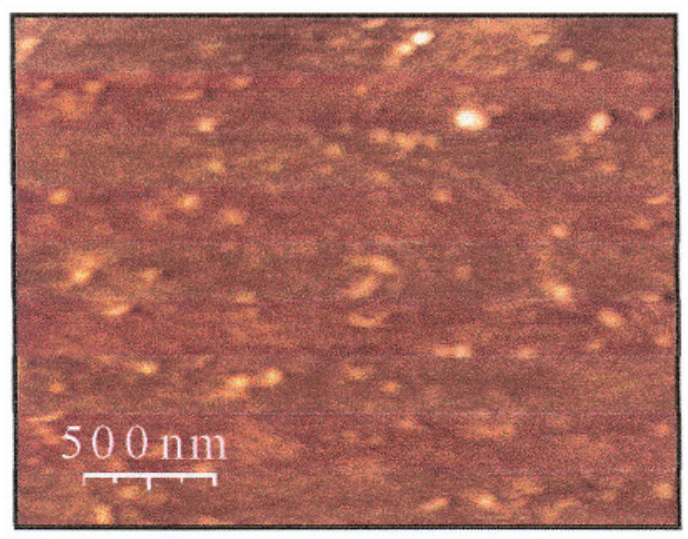

(a)

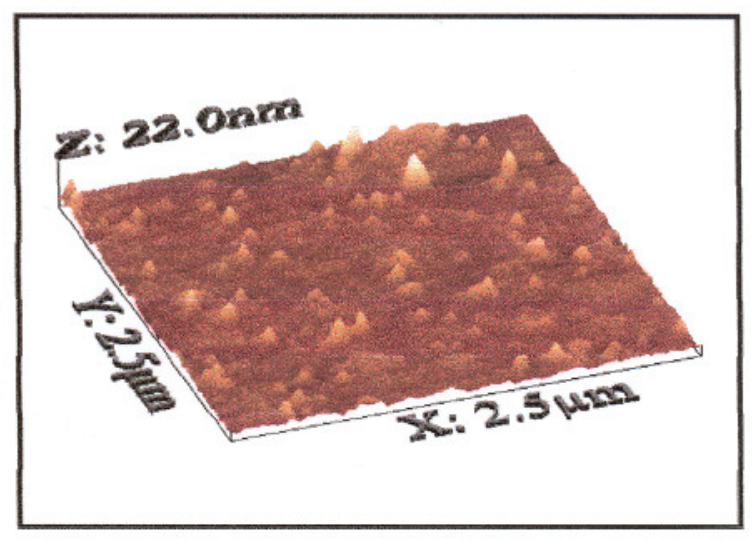

(b)

Figura 21. (a) Imagem em 2-D de MFA do filme de PEDOT/PSS, por automontagem. (b) Imagem em 3-D de MFA do filme de PEDOT/PSS depositado por automontagem.

Comparativamente, pode-se verificar que o filme formado pelo método de automontagem é mais homogêneo e menos rugoso que o formado por "coating", como verificado pelas imagens de MFA e também visualmente.

As imagens obtidas por microscopia de força atômica de filmes de PEDOT /PSS - Baytron $\mathrm{P}^{\circledR}$ Bayer mostram que a topografia destes filmes consiste de 
glóbulos conectados através de redes formadas por grãos pequenos. Os grãos apresentam perfil alongado, embora essa característica não tenha sido uma constante em outras regiões da amostra. A formação de um contorno globular pode ter sido influenciada pelo processo de secagem e adsorção no substrato.

\section{2 - Interação POEA e pesticidas por MFA}

Na Figura 22 são apresentadas imagens de microscopia de força atômica do polímero condutor POEA, sozinho e após o contato com os pesticidas: atrazina, imazaquin, linuron, paraquat e metribuzin. Observa-se a diferença na topografia dos filmes. 


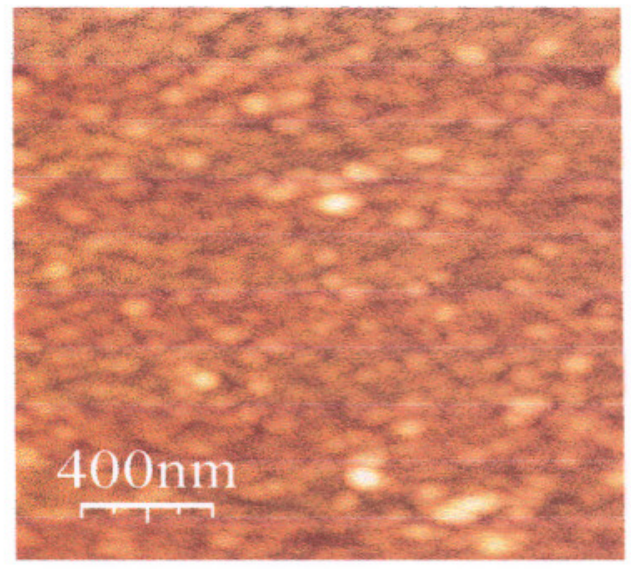

\section{POEA}

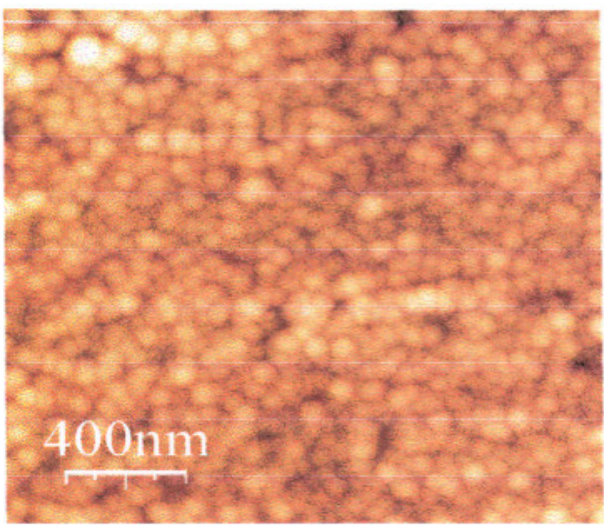

POEA/lmazaquin

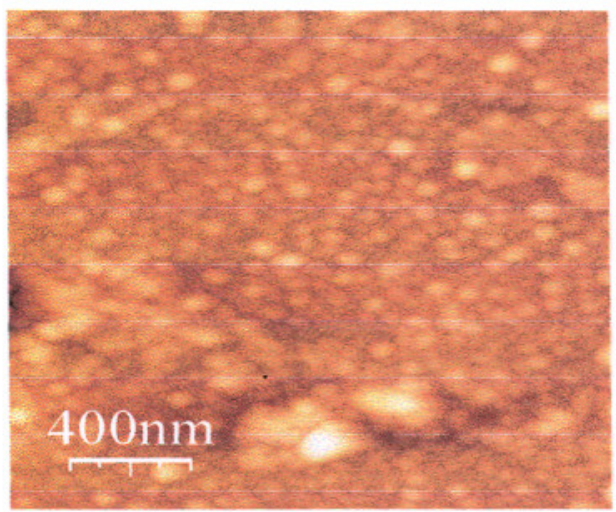

POEA/Metribuzin

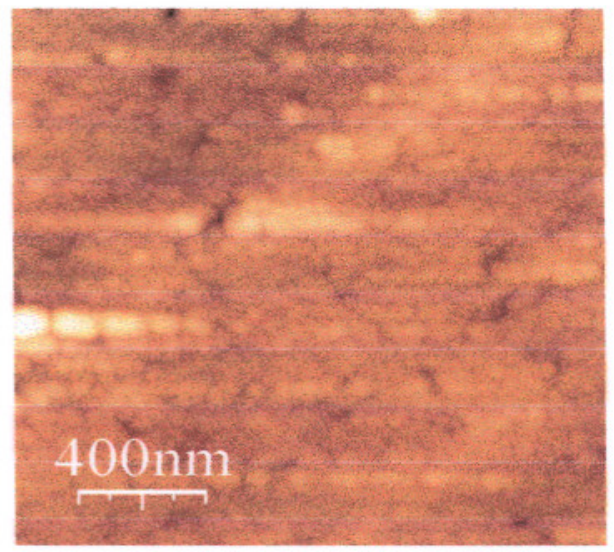

POEA/Atrazina

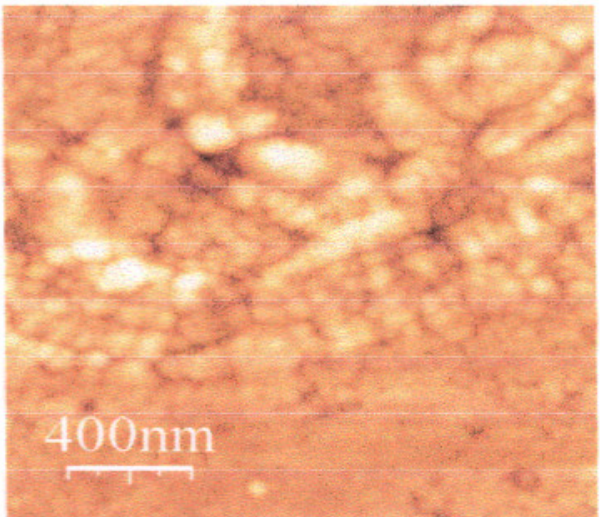

POEA/Linuron

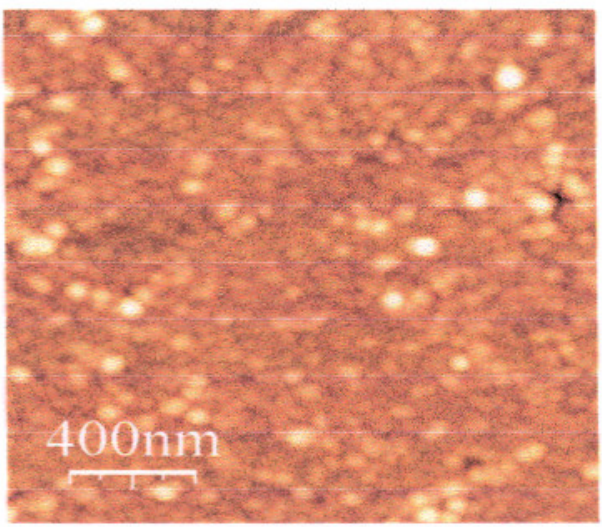

POEA/Paraquat

Figura 22. Imagens de MFA de lâminas de vidro com POEA depositada por automontagem e de lâminas de vidro com POEA depositada por automontagem em contato com diversos pesticidas. 


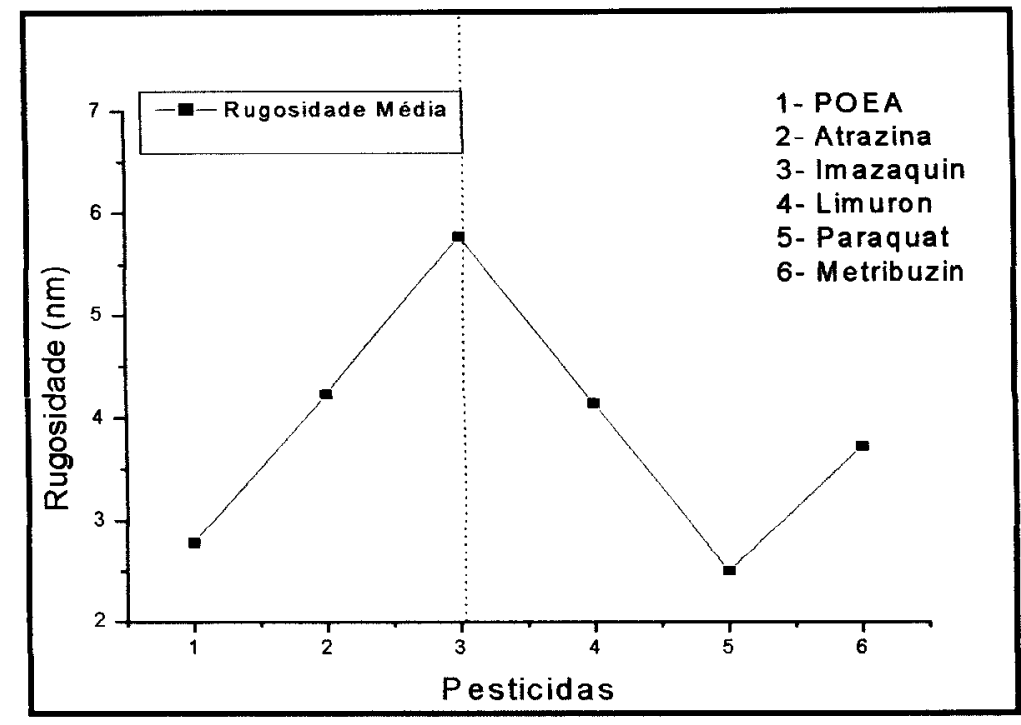

Figura 23. Rugosidade dos filmes de POEA antes e após o contato com vários pesticidas.

A Figura 23 mostra que a topografia do filme de POEA muda quando o polimero entra em contato com os pesticidas. Nota-se que quando a POEA entra em contato com o imazaquin, a superfície do filme torna-se bem mais rugosa, como observado na Tabela 3, indicando uma possível interação entre o pesticida imazaquin e o filme polimérico de POEA. Para o pesticida Paraquat, nota-se que a rugosidade não é afetada. 
Tabela 3. Rugosidades dos filmes de POEA e pesticidas, calculados das imagens de MFA apresentadas na Figura 22.

\begin{tabular}{|c|c|}
\hline $\begin{array}{c}\text { Pesticidas } \\
\text { (nm) }\end{array}$ & $\begin{array}{c}\text { Rugosidade } \\
2,8 \pm 0.6\end{array}$ \\
\hline POEA & $4,2 \pm 0.6$ \\
\hline POEA/Atrazina & $5,8 \pm 0.8$ \\
\hline POEA/Imazaquin & $4,1 \pm 0.6$ \\
\hline POEA/Linuron & $2,5 \pm 0.7$ \\
\hline POEA/Paraquat & $3,7 \pm 0.7$ \\
\hline POEA/Metribuzin & \\
\hline
\end{tabular}

3.3- Espectroscopia de Impedância elétrica de filmes de PEDOT/PSS- Baytron $\mathrm{P}^{\circledR}$ Bayer

Os resultados da caracterização elétrica do filme de PEDOT/PSS-Baytron $\mathrm{P}^{\circledR}$ Bayer com a técnica de impedância são apresentados nas Figuras 24 e 25. Aplicou-se a freqüência de $1 \mathrm{~Hz}$ a $1 \mathrm{MHz}$, em água destilada. 


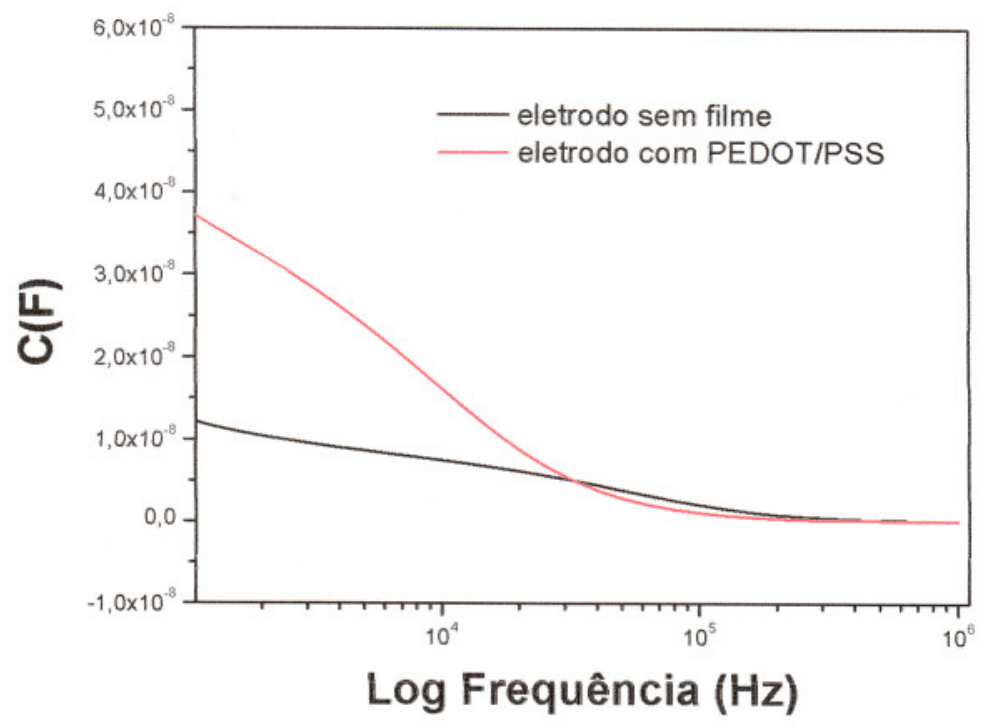

Figura 24. Curva de capacitância para o microeletrodo interdigitado sem filme, e para o microeletrodo interdigitado com uma camada de PEDOT/PSS-Baytron $\mathrm{P}^{\circledR}$ Bayer depositada por automontagem.

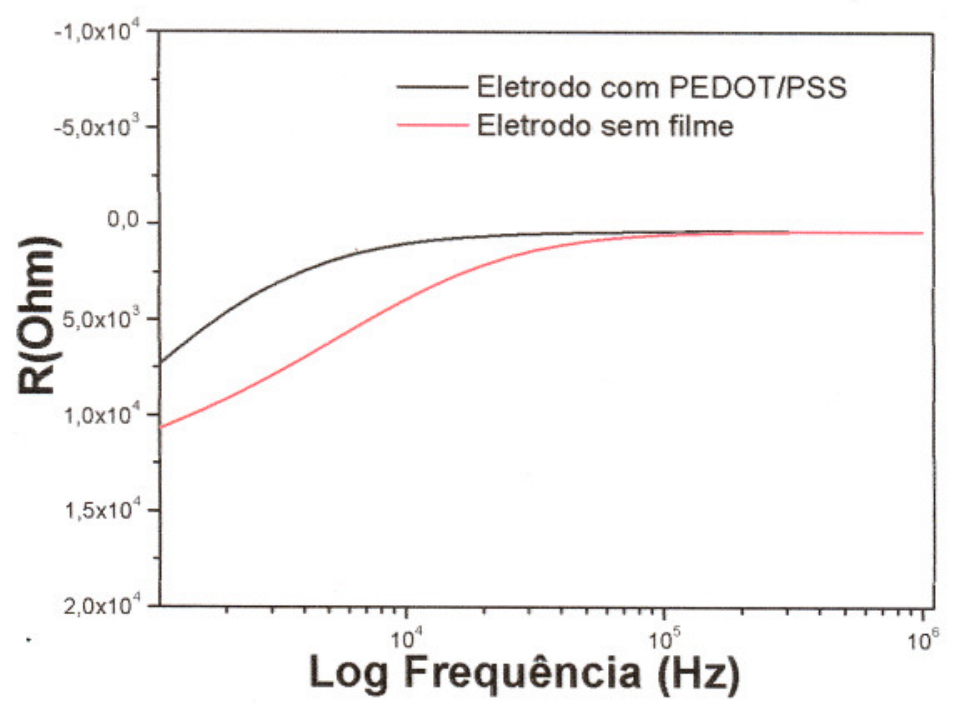

Figura 25. Curva de resistência para um microeletrodo interdigitado sem filme, e para o microeletrodo de PEDOT/PSS depositado com uma camada automontagem.

As respostas de capacitância e resistência elétrica mostram que, em geral, o filme apresenta resposta elétrica diferente em água. Assim como a deposição de apenas uma camada de cada filme automontado sobre um microeletrodo interdigitado apresenta uma resposta elétrica diferenciada ao eletrodo sem filme. 


\section{4- Determinação das Cinéticas de Adsorção dos pesticidas na PANI por UV-Vis}

- Linuron

A Figura 26 apresenta os espectros de UV-Vis do pesticida linuron em solução nas concentrações de 2, 4, 6, 8 e $10 \mu \mathrm{g} \mathrm{mL}^{-1}$.

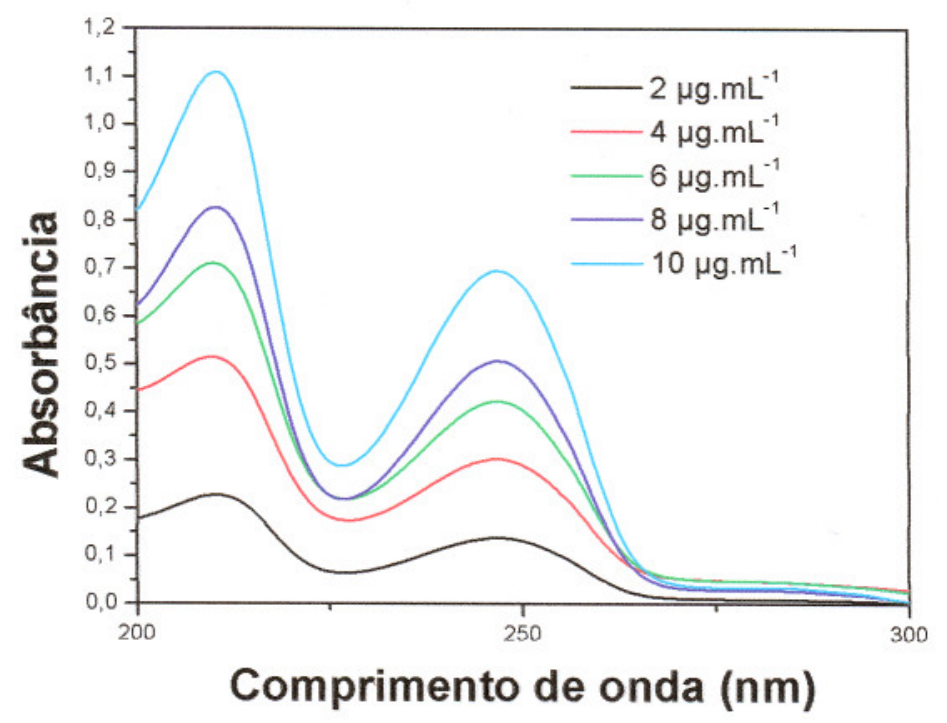

Figura 26. Espectro de Absorção do Linuron em diversas concentrações.

Observam-se duas bandas de absorção, uma em 246 nm, e outra em 225 nm. Utilizando-se a banda em $246 \mathrm{~nm}$, obteve-se uma curva analítica (Figura 27), que possibilta a medida da concentração do pesticida, quando em contato com a PANI. 


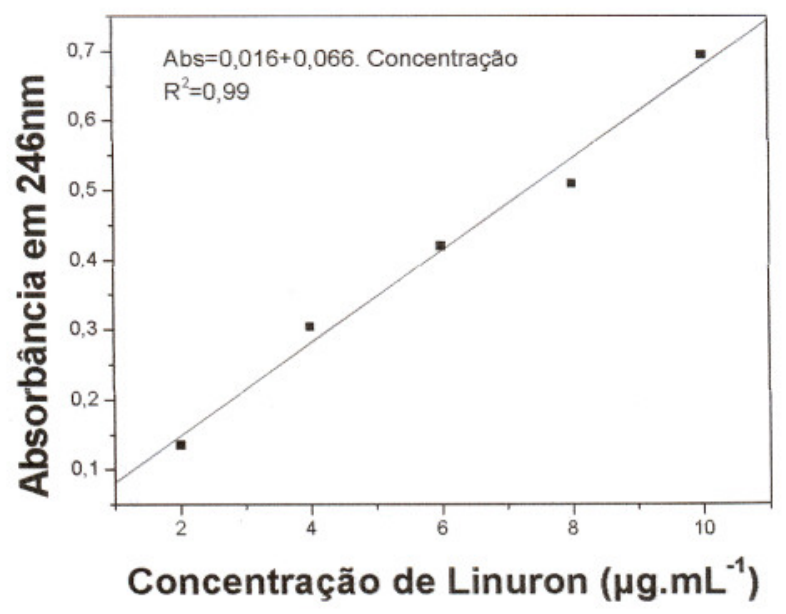

Figura 27. Curva analítica do linuron, obtida por espectrofotometria de UV-Vis, com banda de absorção em $246 \mathrm{~nm}$.

A Figura 28 mostra os espectros de UV-Vis do pesticida linuron juntamente com a polianilina no estado dopado, após 20 minutos, 2, 4, 7, 24, 48, 72 e 96 horas de contato do pesticida com o polímero. Observa-se uma diminuição das bandas de absorção com o aumento do tempo de contato, indicando uma diminuição da concentração do pesticida em solução devido à adsorção do linuron na PANI.

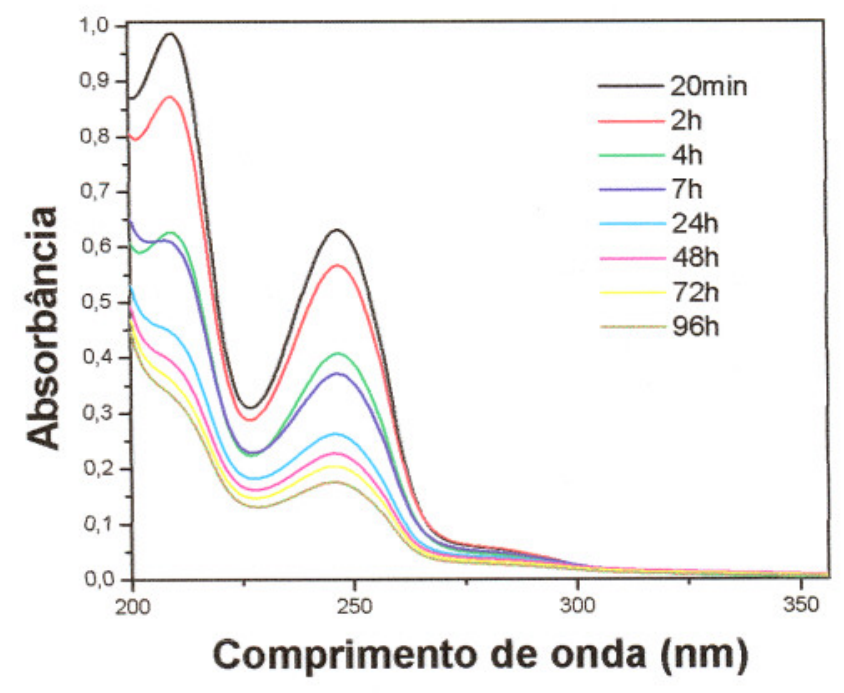

Figura 28. Espectros de UV-Vis do linuron em contato com a PANI dopada em função do tempo. 
Utilizando-se a curva analítica de absorção UV-Vis do linuron (Figura 27) pode-se calcular as quantidades de linuron adsorvida na PANI em função do tempo. Esses dados são apresentados na Tabela 4 e os gráficos das cinéticas de diminuição da concentração em solução e quantidades adsorvidas são apresentados nas Figuras 29 e 30, respectivamente.

Tabela 4. Adsorção do linuron na polianilina dopada. A concentração inicial do linuron na solução foi de $10 \mu \mathrm{g} \mathrm{mL} \mathrm{L}^{-1}$ e a de PANI $10^{-3} \mathrm{~mol} . \mathrm{L}^{-1}$.

\begin{tabular}{|c|c|c|}
\hline Tempo (h) & $\begin{array}{c}\text { Concentração do } \\
\text { sobrenante }\left(\mu \mathrm{g} \mathrm{mL}^{-1}\right)\end{array}$ & $\begin{array}{c}\text { Concentração } \\
\text { Adsorvida }\left(\mu \mathrm{g} \mathrm{mL}^{-1}\right)\end{array}$ \\
\hline 0 & 10 & 0 \\
\hline 20 minutos & 9,21 & 0,79 \\
\hline $2 \mathrm{~h}$ & 8,28 & 1,72 \\
\hline $4 \mathrm{~h}$ & 6,03 & 3,97 \\
\hline $7 \mathrm{~h}$ & 5,44 & 4,56 \\
\hline $24 \mathrm{~h}$ & 3,88 & 6,12 \\
\hline $48 \mathrm{~h}$ & 3,29 & 6,71 \\
\hline $72 \mathrm{~h}$ & 2,95 & 7,05 \\
\hline $96 \mathrm{~h}$ & 2,51 & 7,49 \\
\hline
\end{tabular}

Os comportamentos observados para a diminuição da concentração do linuron (Figura 29) e da quantidade adsorvida com o tempo (Figura 30) podem ser descritos por funções de decaimento exponencial e logarítmica, respectivamente. 0 equilíbrio é atingido após cerca de $24 \mathrm{~h}$ de contato, com uma adsorção máxima de cerca de $75 \%$ do linuron na PANI dopada. 


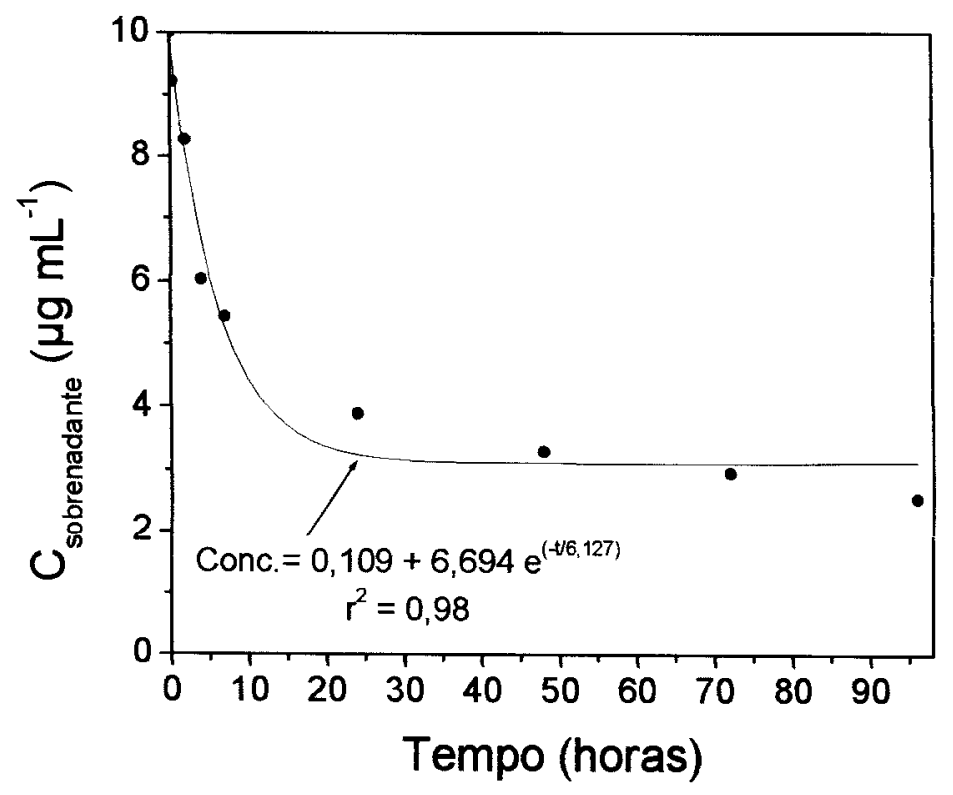

Figura 29. Cinética da concentração do sobrenadante do pesticida linuron com a PANI dopada.

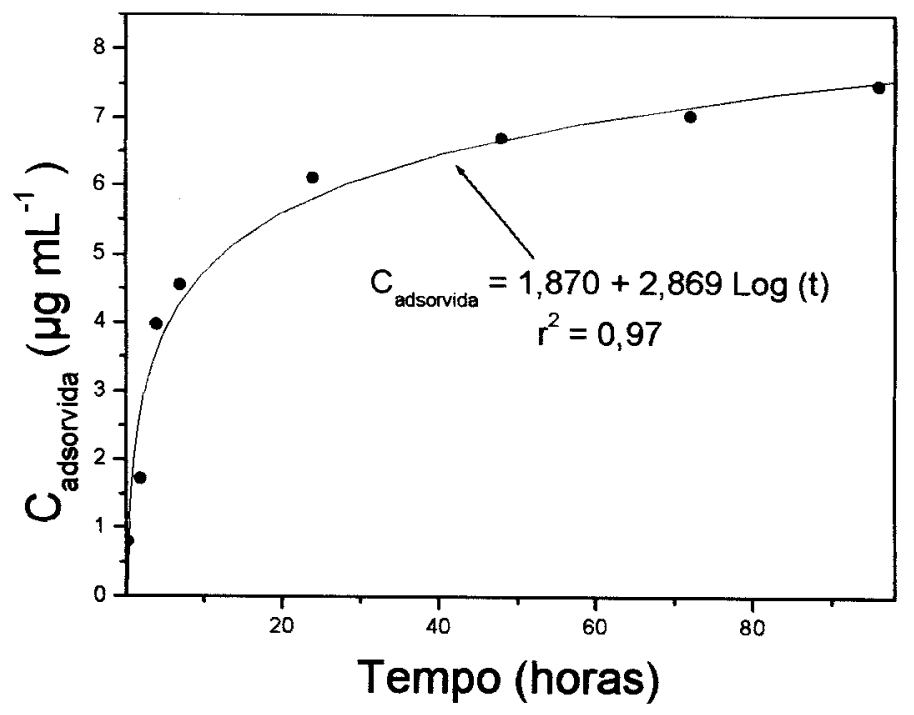

Figura 30. Gráfico da concentração adsorvida do pesticida Linuron com PANI dopada em função do tempo.

A Figura 31 apresenta os espectros de UV-Vis do linuron com a polianilina, desdopada em função do tempo de contato. 


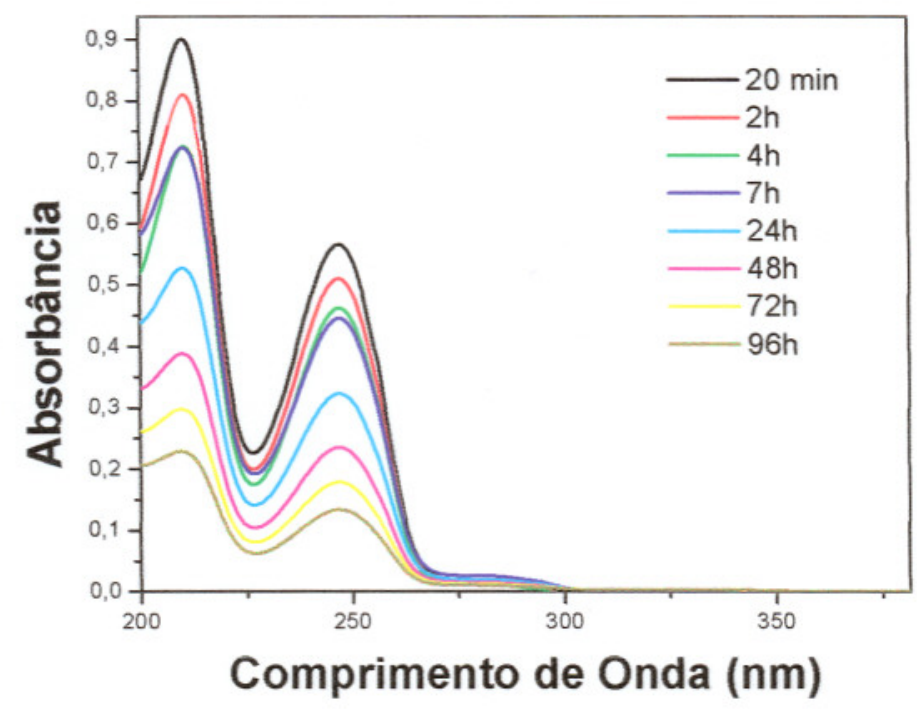

Figura 31. Espectro de UV-Vis do linuron com a PANI desdopada em função do tempo de contato.

A Tabela 5 apresenta os valores de concentração do sobrenadante e das concentrações adsorvidas em função do tempo de contato, obtidos através dos espectros da Figura 31 e da curva analítica (Figura 27). 
Tabela 5. Adsorção do linuron na PANI desdopada. Concentração inicial do linuron $10 \mu \mathrm{g} \mathrm{mL} \mathrm{H}^{-1} \mathrm{e}$ a de PANI $10^{-3} \mathrm{~mol} \mathrm{~L}^{-1}$.

\begin{tabular}{|c|c|c|}
\hline Tempo (h) & $\begin{array}{l}\text { Concentração do } \\
\text { sobrenadante } \\
\left(\mu \mathrm{g} \mathrm{mL}^{-1}\right)\end{array}$ & $\begin{array}{l}\text { Concentração } \\
\text { adsorvida }\left(\mu \mathrm{g} \mathrm{mL}^{-1}\right)\end{array}$ \\
\hline 0 & 10 & 0 \\
\hline 20 minutos & 8,32 & 1,68 \\
\hline $2 \mathrm{~h}$ & 7,55 & 2,45 \\
\hline $4 h$ & 6,87 & 3,13 \\
\hline $7 \mathrm{~h}$ & 6,59 & 3,41 \\
\hline $24 h$ & 4,82 & 5,18 \\
\hline $48 \mathrm{~h}$ & 3,45 & 6,55 \\
\hline $72 h$ & 2,68 & 7,32 \\
\hline $96 \mathrm{~h}$ & 1,95 & 8,05 \\
\hline
\end{tabular}

As Figuras 32 e 33 apresentam as cinéticas das concentrações do sobrenadante e quantidades adsorvidas na PANI desdopada. Observa-se que no caso da PANI desdopada o equilíbrio da adsorção é atingida apenas após 96 horas de contato do linuron com o polimero. Os resultados indicam que o processo de adsorção do linuron na PANI desdopada é mais lento que na PANI dopada, pois após 24 h de contato houve a diminuição de apenas $50 \%$ do herbicida ao passo que no caso da PANI dopada a concentração da solução sofreu uma diminuição maior (60\%) neste mesmo período de tempo. Entretanto, as quantidades adsorvidas após 96h foram similares para as condições dopada e desdopada. 


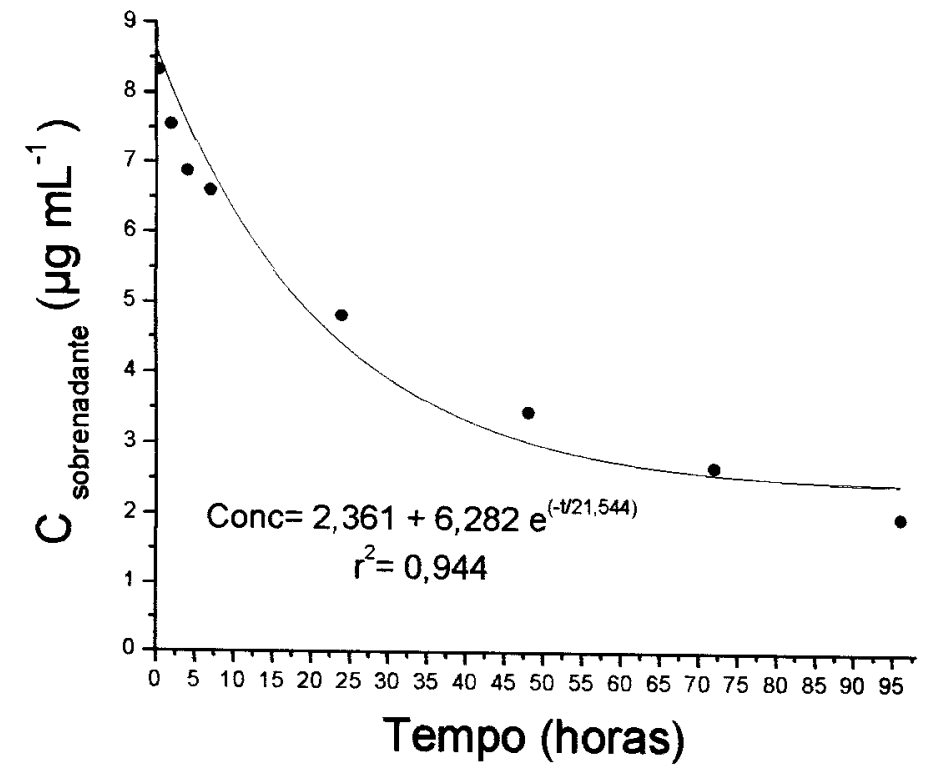

Figura 32. Variação da concentração do linuron em contato com a PANI desdopada no sobrenadante em função do tempo.

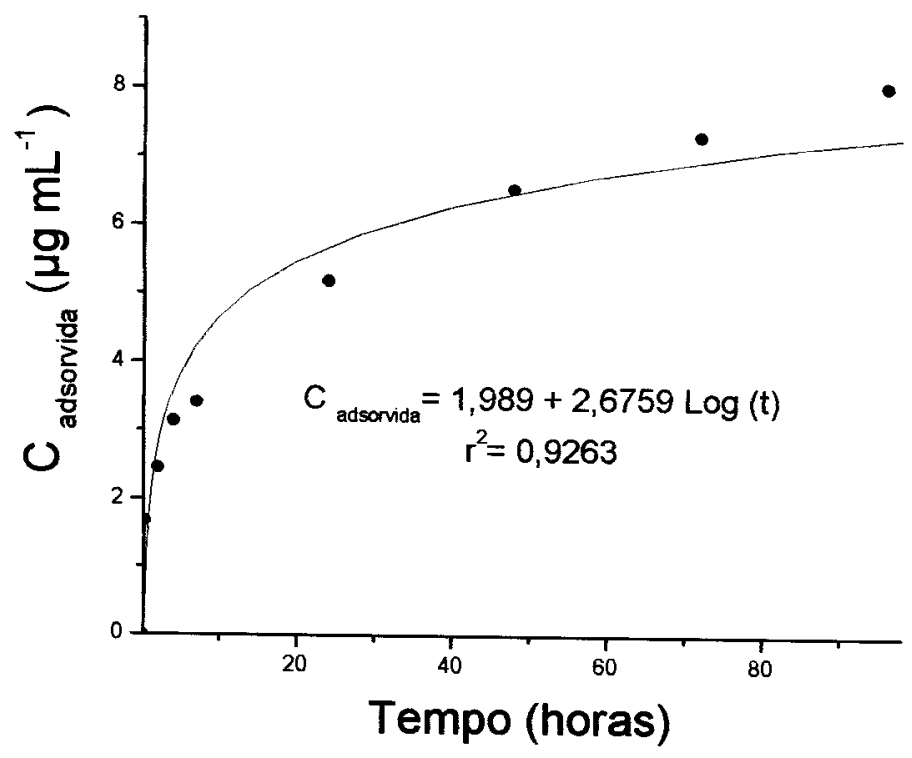

Figura 33. Variação da concentração do linuron adsorvido na PANI desdopada em função do tempo. 


\section{- Metribuzin}

Os espectros de absorção no UV-Vis do herbicida metribuzin em solução aquosa com concentrações crescentes $\left(4,6,8\right.$ e $\left.10 \mu \mathrm{g} \mathrm{mL} \mathrm{m}^{-1}\right)$ são apresentados na Figura 34. Observa-se uma banda principal de absorção em 294 nm e outras duas bandas de absorção para comprimentos de onda abaixo de $250 \mathrm{~nm}$. A banda em 294 nm foi utilizada para a obtenção da curva analítica apresentada na Figura 35.

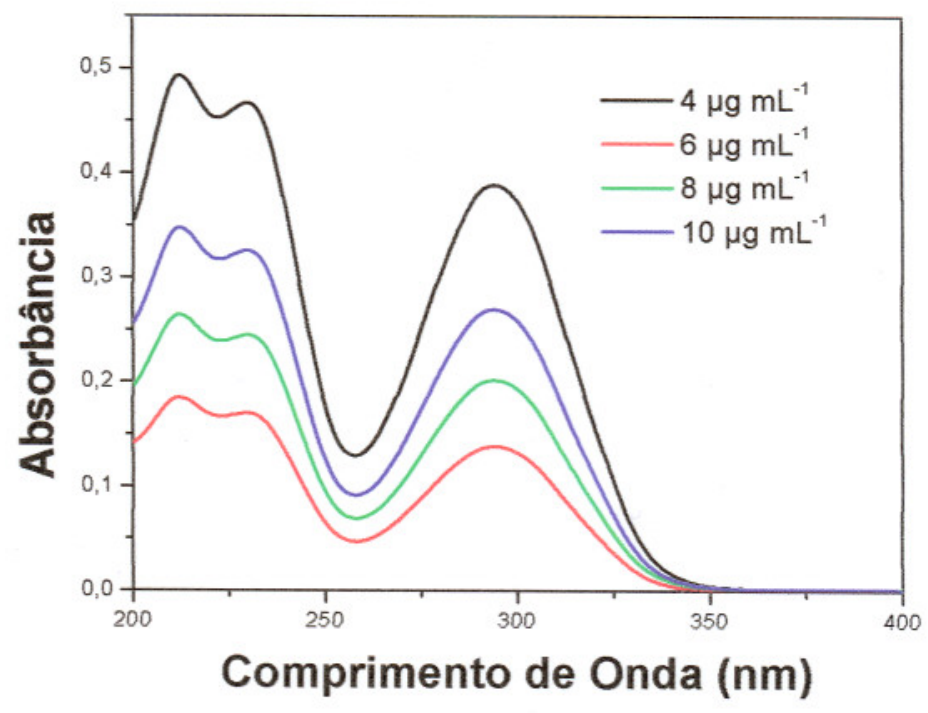

Figura 34. Espectros de UV-Vis do herbicida metribuzin em solução aquosa para várias concentrações.

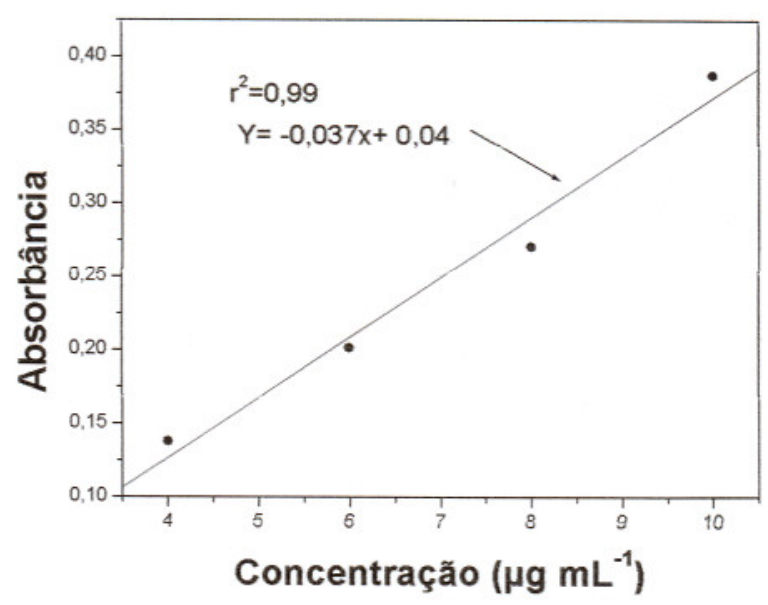

Figura 35. Curva analítica do herbicida metribuzin, obtida dos espectros da Figura 34 com a banda de absorção em $294 \mathrm{~nm}$. 
Os espectros de UV-Vis das soluções contendo metribuzin e PANI dopada são apresentados na Figura 36 , para uma solução de $10 \mathrm{\mu g} \mathrm{mL}^{-1}$ do pesticida e $10^{-3}$ mol L ${ }^{-1}$ de PANI em diversos tempos de contato. Observa-se uma diminuição das bandas de absorção com o aumento do tempo de contato, indicando a ocorrência do processo de adsorção do metribuzin na PANI desdopada.

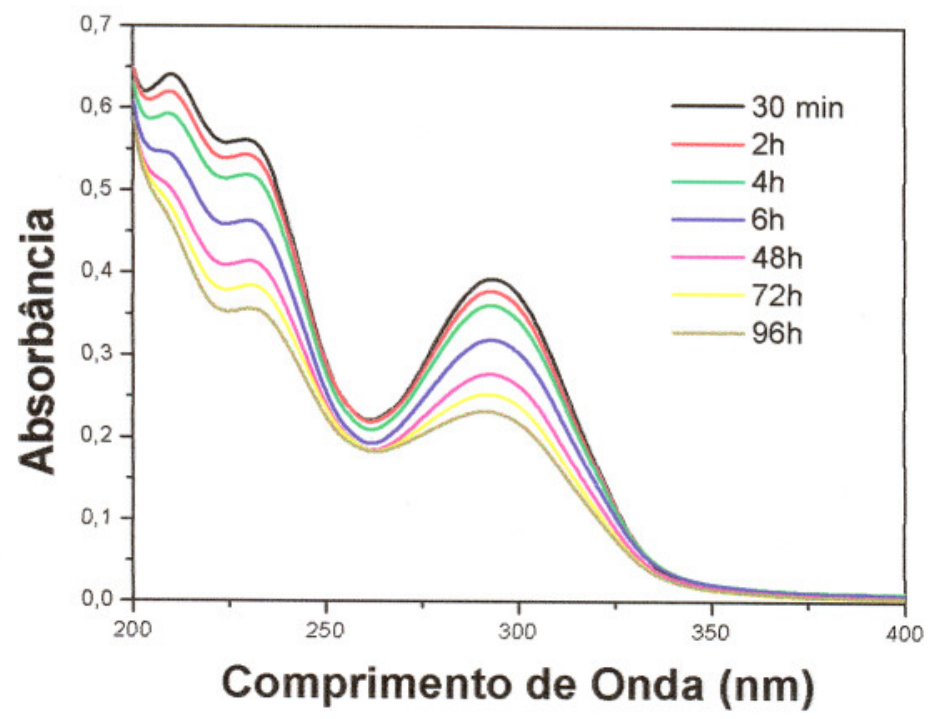

Figura 36. Espectro de UV-Vis do herbicida metribuzin na PANI dopada em função do tempo de contato.

A Tabela 6 apresenta os valores das concentrações do metribuzin no sobrenadante e adsorvida na PANI em função do tempo de contato, obtidos através dos espectros das Figuras 36 e da curva analítica (Figura 35). Comparado com o linuron, observa-se uma adsorção muito menos intensa do metribuzin na PANI dopada. As Figuras 37 e 38 apresentam graficamente as variações das concentrações do sobrenadante e das concentrações adsorvidas em função do tempo. Observa-se também um comportamento de decaimento exponencial e aumento logarítmico das concentrações do sobrenadante e adsorvidas, 
respectivamente, com cerca de $30 \%$ de adsorção após $96 \mathrm{~h}$. Nota-se pela tendência da curva, que o equilíbrio não é atingido no período do experimento.

Tabela 6. Adsorção do herbicida metribuzin na PANI dopada. A concentração inicial de metribuzin foi de $10 \mu \mathrm{gL} \mathrm{L}^{-1} \mathrm{e}$ a de PANI $10^{-3} \mathrm{~mol} \mathrm{~L}^{-1}$.

\begin{tabular}{|c|c|c|}
\hline Tempo $(\mathrm{h})$ & $\begin{array}{l}\text { Concentração do } \\
\text { sobrenadante } \\
\left(\mathrm{mg} \cdot \mathrm{L}^{-1}\right)\end{array}$ & $\begin{array}{c}\text { Concentração } \\
\text { Adsorvida }\left(\mathrm{mg} \cdot \mathrm{L}^{-1}\right)\end{array}$ \\
\hline 0 & 10 & 0 \\
\hline $20 \mathrm{~min}$ & 10 & 0 \\
\hline $2 \mathrm{~h}$ & 10 & 0 \\
\hline $4 \mathrm{~h}$ & 9,71 & 0,29 \\
\hline $6 \mathrm{~h}$ & 8,72 & 1,29 \\
\hline $48 \mathrm{~h}$ & 7,68 & 2,32 \\
\hline $72 \mathrm{~h}$ & 7,12 & 2,88 \\
\hline $96 \mathrm{~h}$ & 6,63 & 3,37 \\
\hline
\end{tabular}

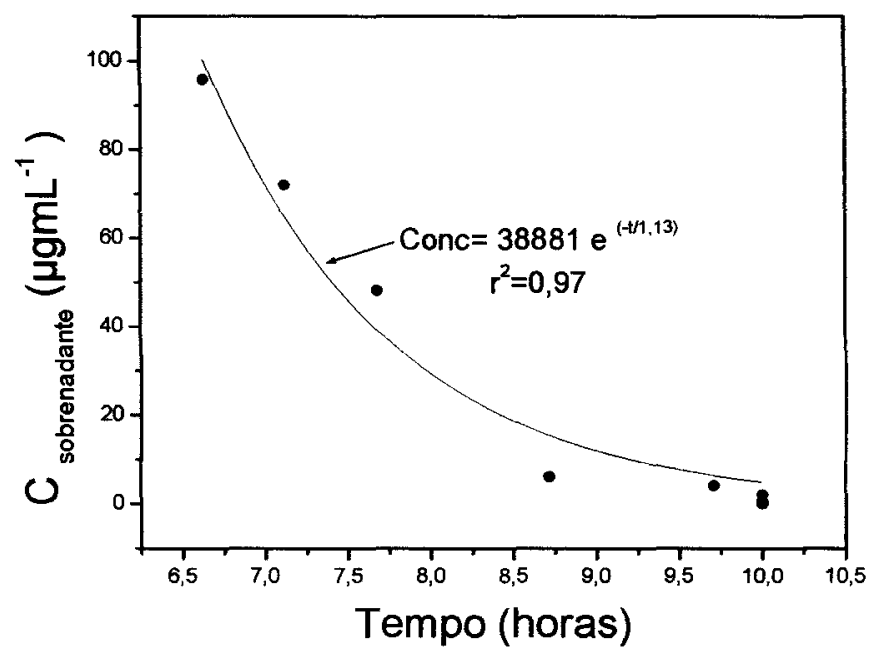

Figura 37. Variação da concentração do metribuzin em contato com a PANI dopada no sobrenadante em função do tempo. 


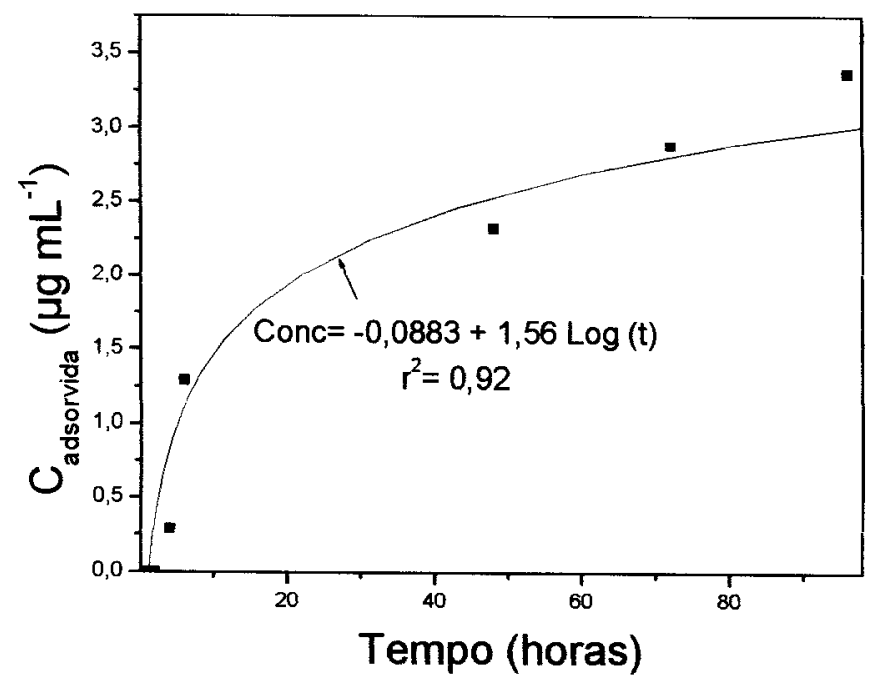

Figura 38. Cinética da concentração adsorvida do pesticida metribuzin com a PANI dopada.

A Figura 39 apresenta os espectros de UV-Vis do metribuzin com a PANI desdopada em função do tempo de contato. Na Tabela 7, e nas Figuras 40 e 41 são apresentados os dados da cinética de adsorção. Observa-se, neste caso, uma adsorção ainda menor, com apenas $9 \%$ do pesticida adsorvido após 96 horas de contato, quando comparado com a cinética do metribuzin na PANI dopada.

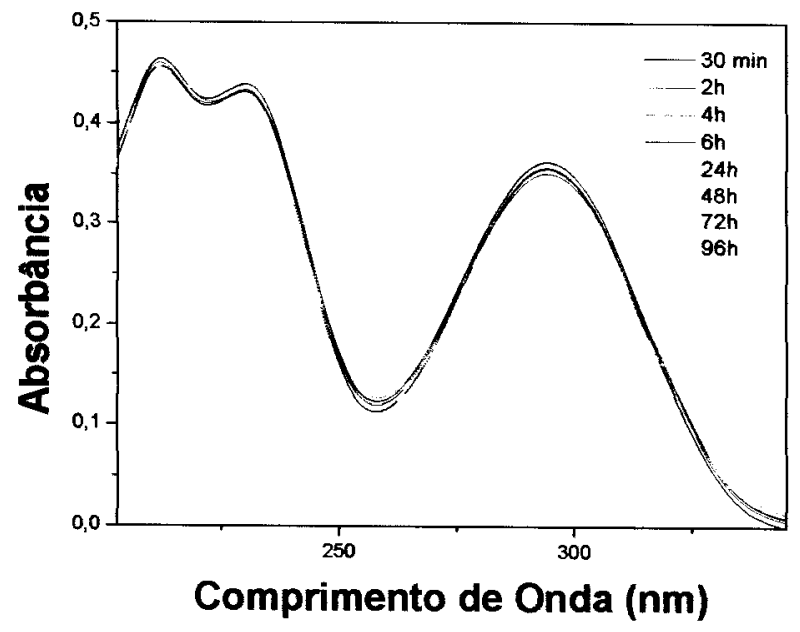

Figura 39. Espectro de UV-Vis do herbicida metribuzin com a PANI desdopada em função do tempo de contato. 
Tabela 7. Adsorção do herbicida metribuzin na PANI desdopada. A concentração inicial de metribuzin foi de $10 \mu \mathrm{gL}^{-1}$ e a de PANI $10^{-3} \mathrm{~mol} \mathrm{~L}^{-1}$.

\begin{tabular}{|c|c|c|}
\hline Tempo (horas) & $\begin{array}{c}\text { Concentração do } \\
\text { sobrenadante } \\
\left(\mu \mathrm{gL}^{-1}\right)\end{array}$ & $\begin{array}{c}\text { Concentração } \\
\text { Adsorvida }\left(\mu \mathrm{gL}^{-1}\right)\end{array}$ \\
\hline 0 & 9,91 & 0,09 \\
\hline 0,5 & 9,91 & 0,09 \\
\hline 2 & 9,91 & 0,09 \\
\hline 4 & 9,83 & 0,17 \\
\hline 6 & 9,83 & 0,17 \\
\hline 24 & 9,55 & 0,45 \\
\hline 48 & 9,55 & 0,45 \\
\hline 72 & 9,36 & 0,87 \\
\hline 96 & 9,13 & \\
\hline
\end{tabular}

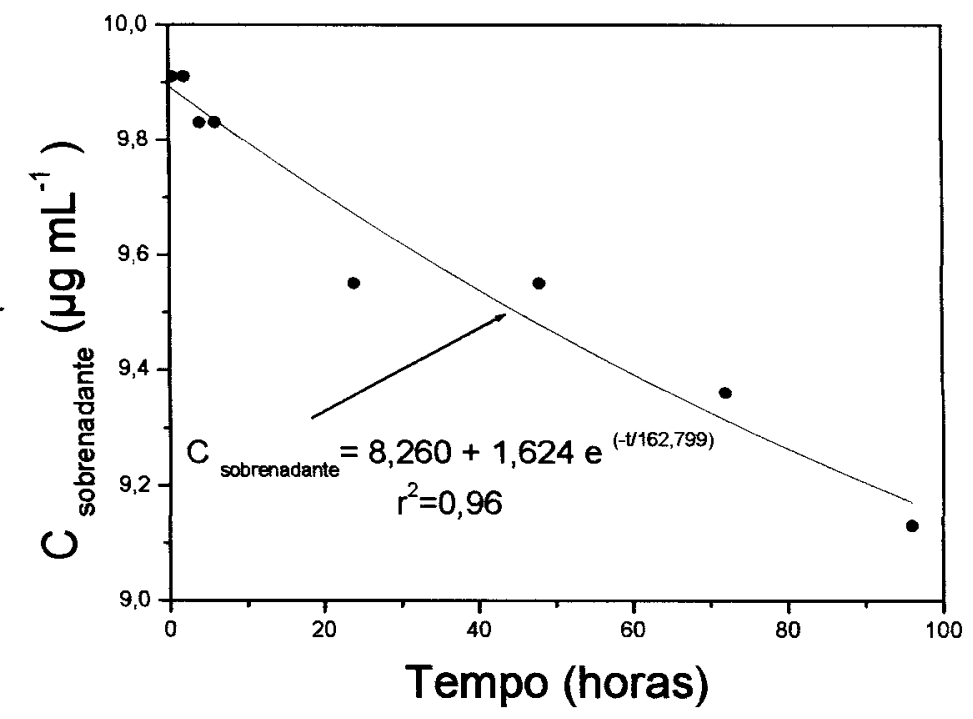

Figura 40. Variação da concentração do metribuzin em contato com a PANI desdopada em função do tempo. 


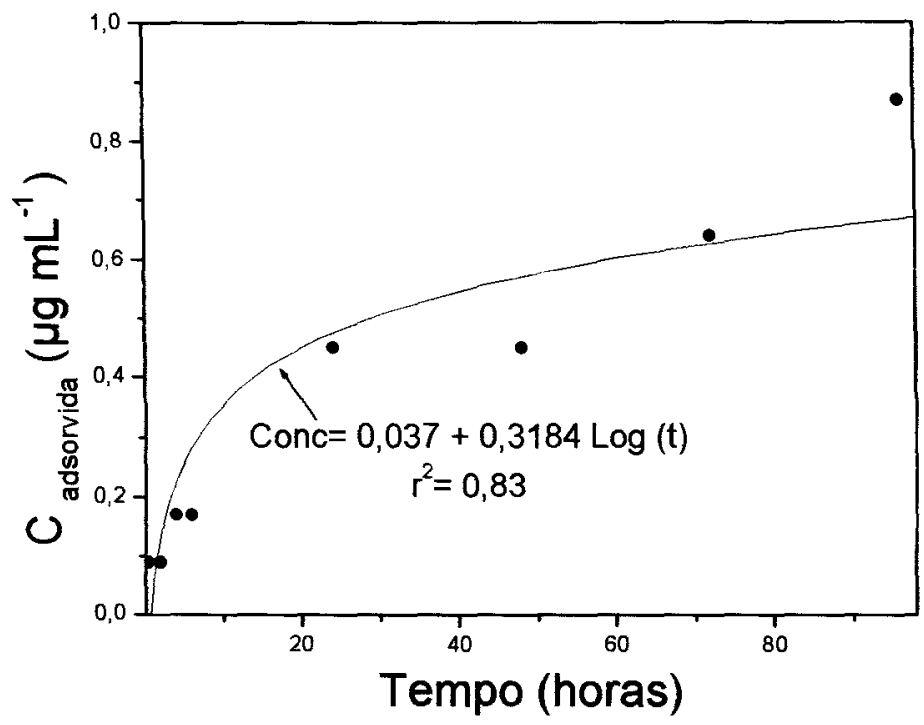

Figura 41. Variação da concentração do metribuzin adsorvido na PANI desdopada em função do tempo.

\section{5- Caracterização elétrica dos microeletrodos interdigitados}

São apresentadas nas Figuras 42 e 43 a caracterização elétrica dos microeletrodos interdigitados de ouro que foram selecionados para compor as unidades sensoriais da "língua eletrônica" utilizada neste trabalho. As Figuras 42 e 43 apresentam a varredura de freqüência de 1 a $1 \mathrm{MHz}$, e dentro destas Figuras encontra-se a região que será utilizada nos estudos com a "língua eletrônica", de 100 a $10 \mathrm{KHz}$. Estes microeletrodos interdigitados de ouro foram caracterizados sem a deposição dos filmes finos poliméricos, em água destilada. Nota-se que cada microeletrodo possui uma resposta elétrica própria. É possível observar que não existe nenhum microeletrodo igual ao outro, porém todos eles seguem o mesmo comportamento. 


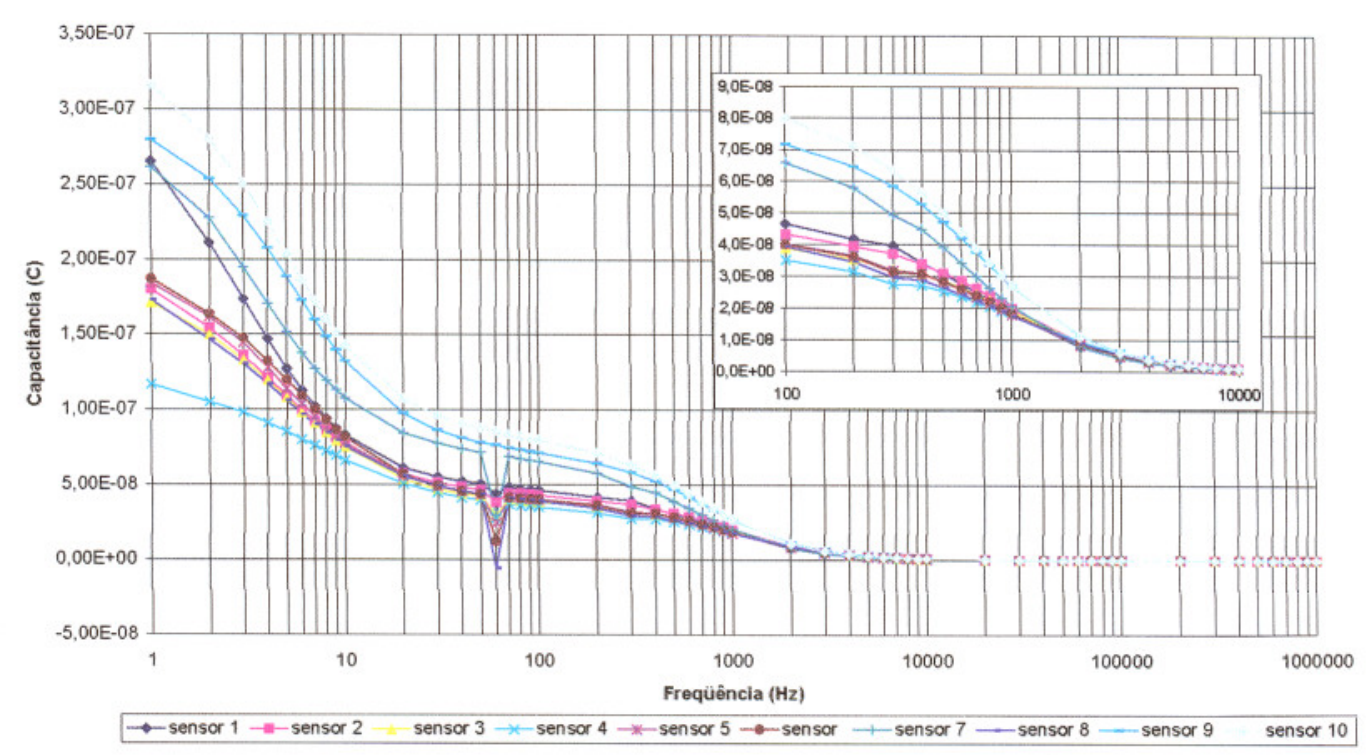

Figura 42. Espectro da Capacitância versus Freqüência para os dez microeletrodos interdigitados de ouro.

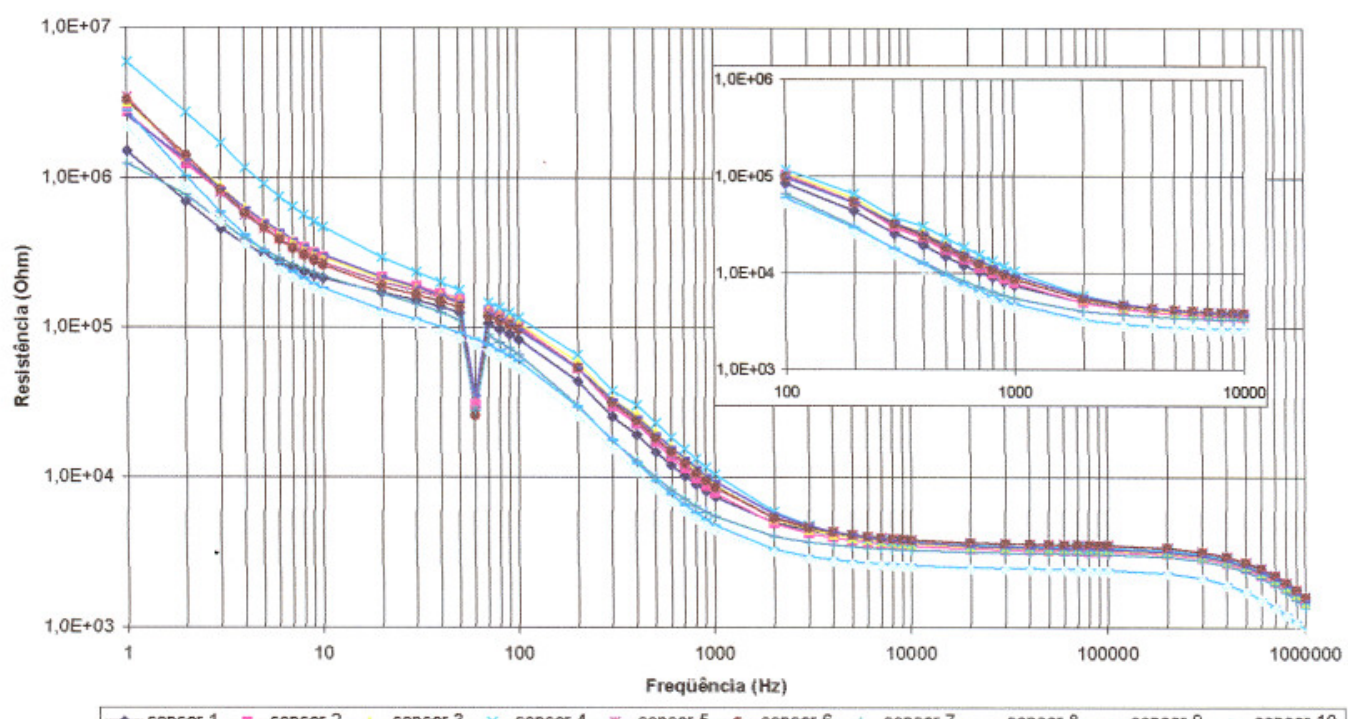

Figura 43. Espectro da Resistência versus Freqüência para os dez microeletrodos interdigitados de ouro. 


\section{6- Análise dos pesticidas com os microeletrodos}

\section{interdigitados ("língua eletrônica")}

Após a deposição dos polímeros, conforme indicado na Tabela 2 (item 2.2.10), foram feitas medidas de capacitância em função da freqüência de $100 \mathrm{~Hz}$ a $1 \mathrm{MHz}$, em água destilada e posteriormente no pesticida em estudo. No final, após a lavagem dos microeletrodos foram feitas novamente medidas na água destilada para avaliar possíveis efeitos de contaminação nas unidades sensoriais.

A Figura 44 e 45 apresentam as respostas de capacitância e resistência em função da freqüência para os dez microeletrodos com polímeros depositados imersos na água destilada.

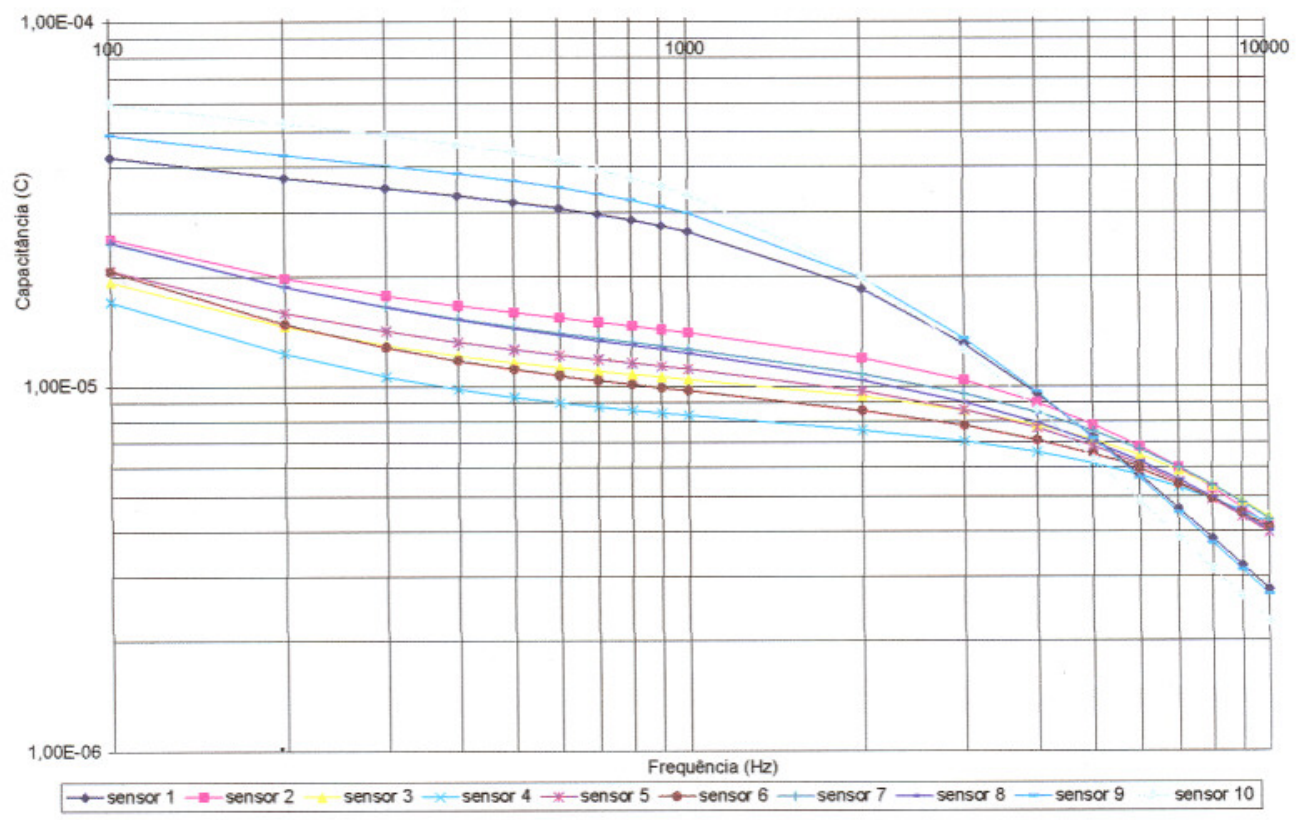

Figura 44. Espectro da Capacitância versus Freqüência para os dez microeletrodos interdigitados de ouro após a deposição dos polímeros. 


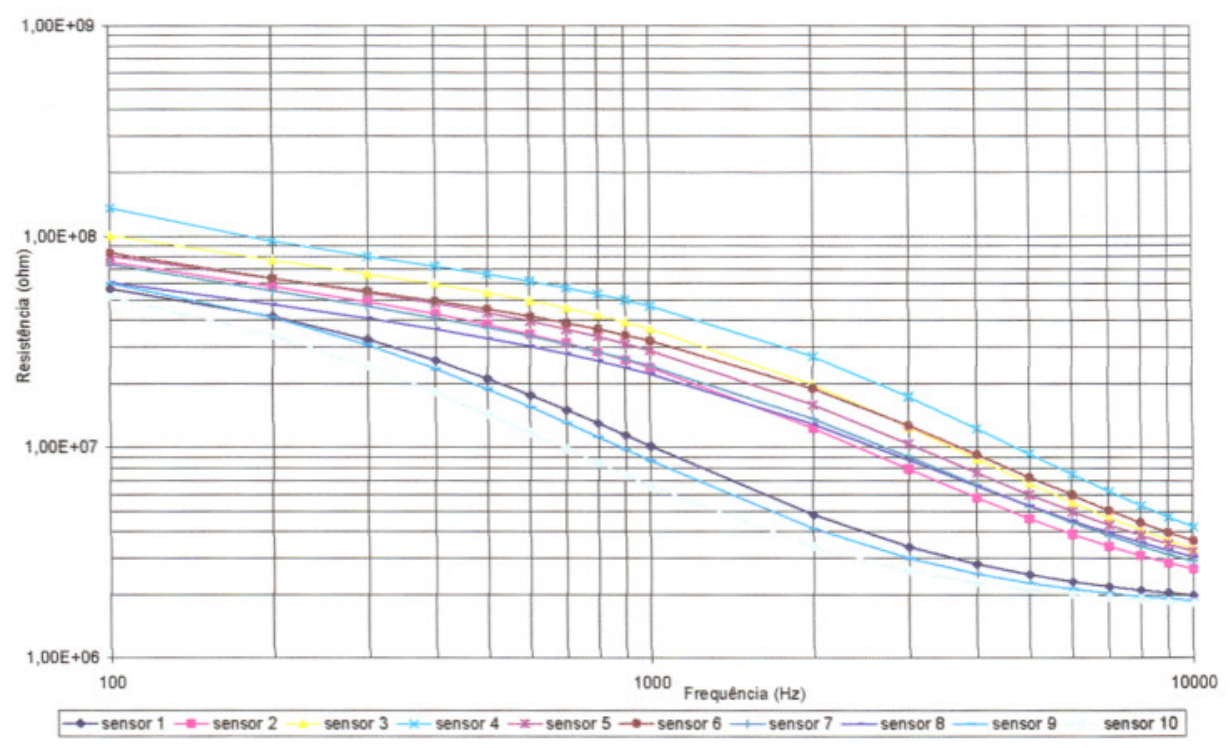

Figura 45. Espectro da Resistência versus Freqüência para os dez microeletrodos interdigitados de ouro após a deposição dos polímeros.

Os sensores de 2 a 7 foram preparados com POEA, com variação do número de camadas depositadas e os sensores 9 e 10 foram preparados com uma camada de PANI, ou seja, são repetições.

Outro aspecto avaliado foi a reprodutibilidade, a qual foi verificada por meio das medidas realizadas em água antes e depois do contato com os pesticidas. A Figura 46 apresenta uma comparação direta das medidas em água antes e depois, para todos os sensores. 


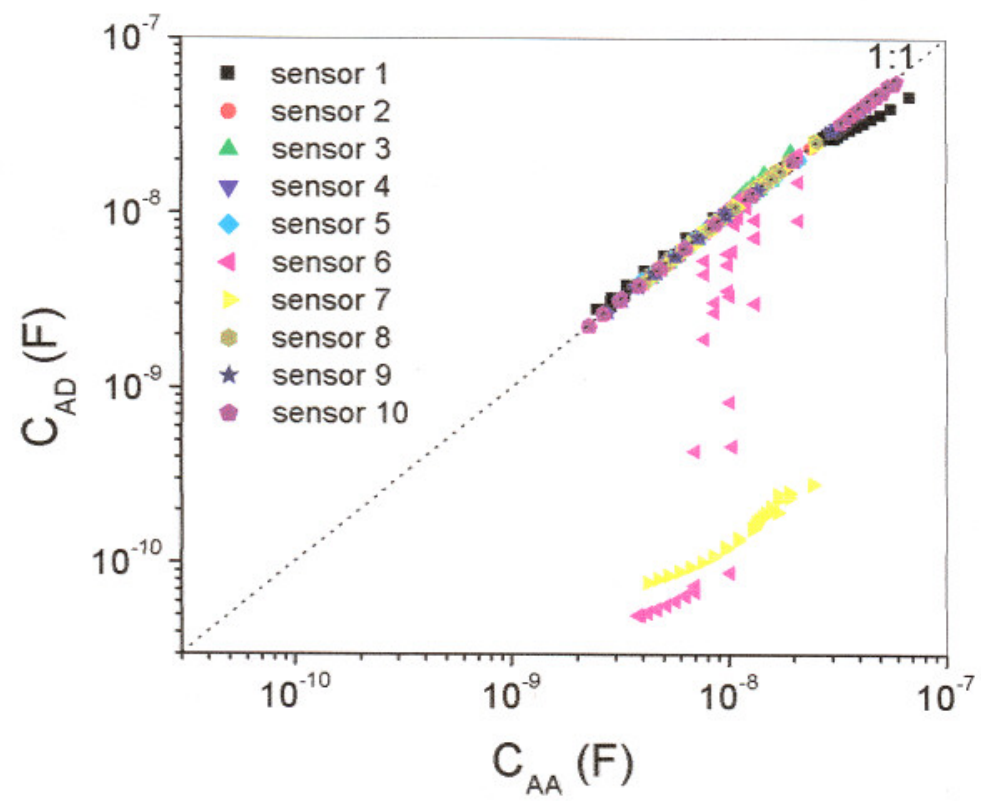

Figura 46. Comparação da variação das capacitâncias das águas antes da imersão na água contaminada com os pesticidas (AA) e após a lavagem realizada depois da imersão na solução dos pesticidas para os dez sensores (AD).

Observa-se para todos eles, com exceção dos sensores 6 e 7, uma boa reprodutibilidade, pois as medidas realizadas em água antes e após o contato com os pesticidas foram muito próximas. Em função dos resultados apresentados na Figura 46, descartou-se os sensores 6 e 7 para as medidas posteriores. Essa inconsistência observada para os sensores 6 e 7 deve ter sido, provavelmente, devido a problemas de maus contatos, ou danificação dos dígitos. 

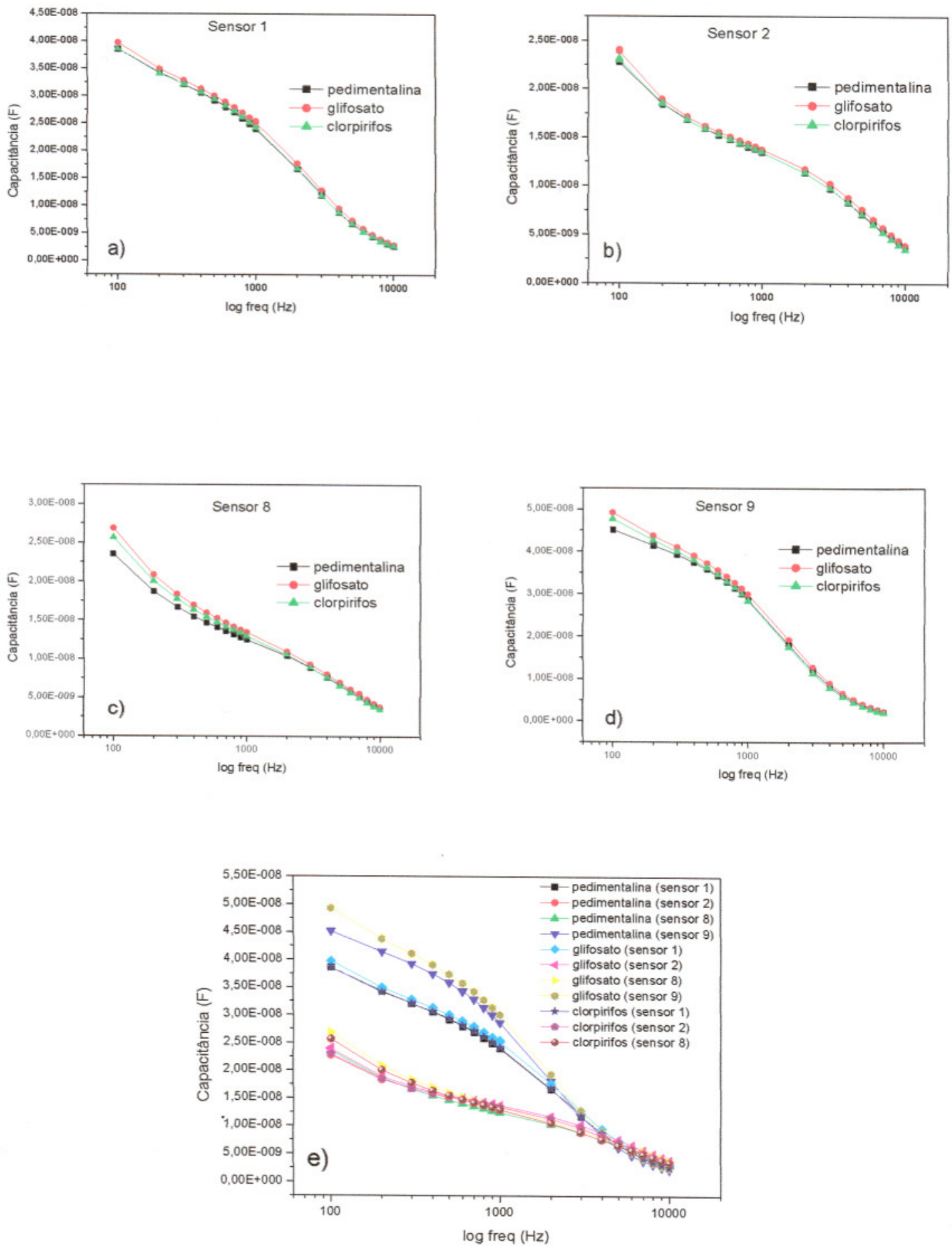

Figura 47. Variação da capacitância em função da freqüência para os sensores $1,2,8$ e 9 .

A Figura 47 apresenta a resposta da capacitância dos sensores 1(Figura 47a), 2 (Figura 47b), 8 (Figura 47c) e 9 (Figura 47d) para os três pesticidas. De um 
modo geral, observa-se pouca diferença entre as respostas para os diferentes pesticidas, mas isso se deve à forma de visualização dos dados no formato logarítmico. Entretanto, entre diferentes sensores observa-se diferenças significativas, o que está relacionado primeiramente às variações naturais de resposta entre cada microeletrodo, e principalmente, devido aos polímeros utilizados. Deste modo, para se visualizar melhor as diferenças e similaridades das respostas com as unidades sensoriais da "língua eletrônica", tem-se utilizado a Análise de Componentes Principais (PCA).

A Figura 48 mostra o resultado de uma PCA para uma freqüência de $1 \mathrm{kHz}$, que pode ser considerada uma boa escolha baseada no critério de se evitar trabalhar com valores de freqüência onde há efeitos de dupla camada elétrica (que ocorre em baixas freqüências) e efeitos de capacitância geométrica (que ocorre em altas freqüências). Neste caso, observa-se que não há uma boa diferenciação das medidas dos pesticidas e águas. 


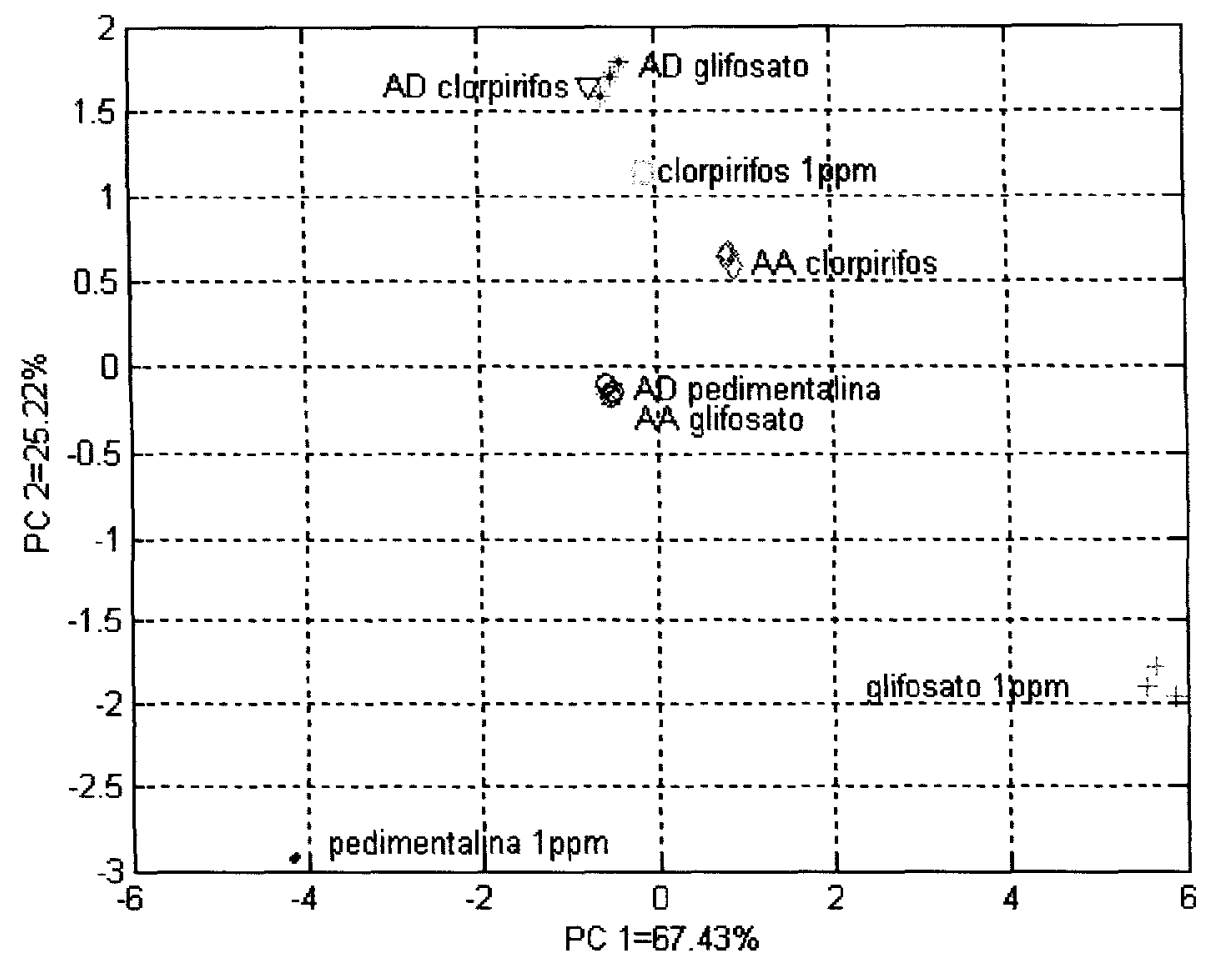

Figura 48. Análise de componentes principais de capacitância elétrica, utilizando-se as unidades sensoriais $1,2,8$ e 9 em medidas com água antes (AA) e depois (AD) do contato com amostras contendo $1 \mu \mathrm{g} \mathrm{mL} \mathrm{L}^{-1}$ de pedimentalina, glifosato $\mathrm{e}$ clorpirifos.

Com relação à escolha da frequência, a experiência do grupo na utilização da "língua eletrônica" em diversos tipos de bebidas, tem mostrado a necessidade de uma otimização, considerando a melhor freqüência, que proporciona a melhor separação dos dados na PCA, e foi validado em análises de bebidas, com bons resultados $^{63}$.

A Tabela 8 apresenta as melhores freqüências obtidas para cada uma das unidades sensoriais. Essas freqüências foram obtidas a partir de um tratamento de dados realizados com base em um fator de correção que está sendo desenvolvido pelo grupo. Nota-se a ausência dos sensores 6 e 7, que danificaram-se durante 0 uso e não foram utilizado nas avaliações que serão apresentadas a seguir. 
Tabela 8. Melhores freqüências para as unidades sensoriais da "língua eletrônica", para a determinação de pesticidas.

\begin{tabular}{|c|c|}
\hline Sensor & Melhor Freqüência $(\mathrm{Hz})$ \\
\hline 1 (SF) & 500 \\
\hline 2 (POEA1) & 6000 \\
\hline 3 (POEA 2) & 10000 \\
\hline 4 (POEA 2) & 10000 \\
\hline 5 (POEA 2) & 10000 \\
\hline 8 (PEDOT/POEA) & 6000 \\
\hline 9 (PANI) & 6000 \\
\hline 10 (PANI) & 6000 \\
\hline
\end{tabular}

A Figura 49 apresenta a Análise de Componentes Principais utilizando a resposta de capacitância para os sensores de números 1,2,8 e 9, ou seja, para um microeletrodo sem filme, e para os microeletrodos depositados com cada um dos polímeros estudados (POEA- sensor 2; PEDOT/PSS- sensor 8 e PANI sensor 9). São avaliadas as respostas para as águas antes (AA) e depois (AD) do contato com os pesticidas, além das respostas de águas contaminadas com $1 \mu \mathrm{g} \mathrm{mL}^{-1}$ dos pesticidas clorpirifos, glifosato e pedimentalina. 


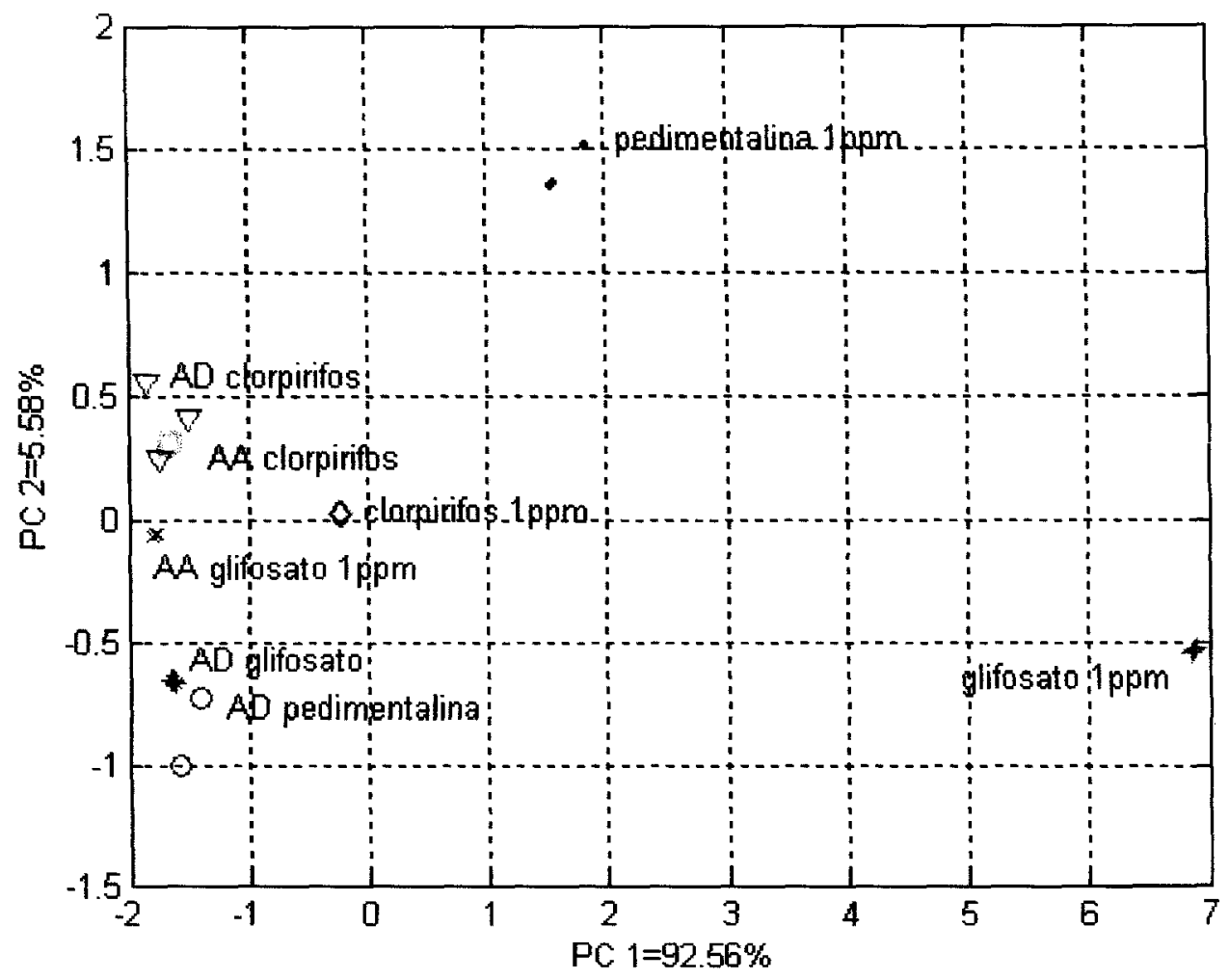

Figura 49. Análise de Componentes Principais da capacitância dos sensores em água destilada (AA), no pesticida ( $1 \mu \mathrm{g} \mathrm{mL}^{-1}$ ) e novamente na água (AD), utilizandose o procedimento de seleção da resposta na melhor freqüência (Tabela 8 ).

Observa-se que a Primeira Componente Principal (PC1) possui 92,6\% das informações mais importantes, e a Segunda Componente Principal (PC2) possui apenas $5,6 \%$ das informações mais importantes. Verifica-se que o conjunto de medidas na água destilada apresenta respostas bem próximas e as águas contaminadas com os pesticidas a $1 \mu \mathrm{g} \mathrm{mL}^{-1}$ foram significativamente diferentes das águas destiladas. Desta forma, pode-se dizer que é possível diferenciar as amostras de águas contaminadas, das não contaminadas, e que o processo de limpeza dos microeletrodos com água destilada em agitação por 30 minutos é eficiente.

As diferenças observadas entre os pesticidas estão relacionadas às interações entre pesticidas e polímeros e às características físico-química dos 
mesmos. Dentre esses aspectos pode-se destacar as baixas solubilidades do clorpirifos e pedimentalina em água, comparado com o glifosato (Tabela 1), que possui uma solubilidade em água mil vezes maior que a da pedimentalina e do clorpirifos. Outro aspecto é que o glifosato é conhecido como um pesticida com uma alta capacidade de sorção nos minerais e colóides do solo. Estudos de interação do glifosato em polianilina eletrodepositada em eletrodo de carbono ${ }^{64}$, mostraram uma alta afinidade do glifosato com a PANI, quando comparado com outros pesticidas, o que pode estar contribuindo para a separação do sinal na PCA. 


\section{Capítulo IV}

\section{Conclusões}

Os resultados apresentados nesta dissertação nos permite concluir que a maioria dos pesticidas estudados possui algum tipo de interação com os polímeros condutores POEA, PANI e PEDOT/PSS, e isto permite uma diferenciação dos mesmos quando comparados com a água pura na análise de PCA dos valores de capacitância dos sensores por espectroscopia de impedância elétrica.

Os estudos realizados com lâminas de vidro com o polímero PANI depositado "in situ" via síntese química, demonstraram que forma um filme esverdeado na lâmina, com morfologia granular e irregular. Quando esta lâmina entra em contato, por um periodo curto de tempo, com os pesticidas clorpirifos, imazaquin e metribuzin, nota-se uma mudança de coloração da lâmina, que passa de verde para azul, e também observa-se um deslocamento no comprimento de onda do espectro de UV-Vis de aproximadamente $200 \mathrm{~nm}$ no espectro, relativo ao estado de dopagem do polimero.

Os estudos de cinética de adsorção foram realizados com a PANI e os pesticidas linuron e metribuzin, em um intervalo de tempo de 96 horas. Para a solução do pesticida linuron nota-se que a velocidade de adsorção entre a mesma e 
o polímero PANI em sua forma base esmeraldina (desdopada) é maior do que na forma sal de esmeraldina (dopada). Consolin Filho ${ }^{2}$ mostra, em sua tese de doutorado, esta mesma tendência com relação ao pesticida imazaquin, que, provavelmente, devido ao maior grau de ionização de seus grupos funcionais, tende a adsorver e interagir mais com as polianilinas. $O$ gráfico de concentração adsorvida do pesticida linuron com a PANI dopada em função do tempo mostra uma tendência similar ao gráfico de concentração adsorvida do pesticida linuron com a PANI desdopada; observa-se que as quantidades do pesticida adsorvidas são crescentes até um certo ponto, e depois tende a ocorrer uma estabilização. Já para o o pesticida metribuzin, não foi observado o mesmo comportamento, sendo as quantidades do pesticida adsorvidas bem menores, se comparado com o linuron, e houve uma maior, embora ainda pequena, adsorção do pesticida metribuzin com a PANI dopada. Consolin Filho ${ }^{2}$ também realizou este estudo com o pesticida atrazina, e notou que há uma menor velocidade de adsorção para a atrazina, tanto em PANI dopada como desdopada, com relação ao imazaquin.

Estudou-se filmes do polímero PEDOT/PSS depositados em lâminas de vidro a partir de duas técnicas diferentes: "coating" e automontagem. Concluiu-se que a melhor técnica é a de automontagem, uma vez que superfícies mais homogêneas de filme são obtidas, quando comparado ao método "coating". O estudo espectroscópico de impedância elétrica comprovou que é possível a formação de um filme fino no microeletrodo, e que o mesmo responde eletricamente.

A caracterização elétrica dos microeletrodos que fizeram parte das unidades sensoriais da "língua eletrônica" utilizada para a detecção de pesticidas na água mostrou que cada microeletrodo possui característica própria, ou seja não há nenhum microeletrodo com resposta idêntica ao outro. 
A "língua eletrônica" utilizada neste trabalho foi bastante eficiente na detecção de pesticidas em águas. A "língua eletrônica", através de medidas de capacitância elétrica, consegue distinguir entre conjunto de águas não contaminadas e contaminadas com pesticidas, mesmo quando os mesmos encontram-se em concentrações baixas, como $1 \mu \mathrm{g} \mathrm{mL}$. As Componentes Principais obtidas, após a determinação das melhores freqüências para cada unidade sensorial, foram bem altas, com a PC1 chegando a $92.6 \%$, o que permite a análise em apenas uma dimensão, o que seria bastante interessante para um futuro possivel sistema prático para medir águas contaminadas em rios e lagos. Serão necessários, entretanto, estudos da reprodutibilidade de dados a partir da língua eletrônica em diferentes dias e condições experimentais.

Além dos resultados aqui apresentados, foram realizadas também uma série de outras medidas como estudos de UV-Vis e voltamétricos com a POEA, objetivando-se a avaliação da interação dos pesticidas com este polímero. Entretanto, como esses estudos apresentaram alguns problemas, não foram aqui apresentados. No caso dos estudos de UV-Vis, os estudos foram realizados para observar o deslocamento da banda polarônica do polímero POEA em diversas concentrações, de diversos tipos de pesticidas, porém observou-se que o deslocamento da banda polarônica das triplicatas de medidas estava dentro do erro experimental. Tentou-se observar possíveis interações entre a POEA e os pesticidas através de voltametria de pulso diferencial com eletrodo de mercúrio gotejante, porém ocorreram algumas incoerências nos voltamogramas, devido à mudanças de POEA (sintetizadas posteriormente), degradação de pesticidas, entre outros. Outro problema encontrado foi que vários pesticidas importados acabaram durante os inúmeros experimentos realizados, e portanto não foi possível a utilização em todas as etapas do trabalho. 
Apesar das dificuldades encontradas, pode-se dizer que os resultados trazem uma grande contribuição cientifica, pois são apresentados uma série de resultados ainda não encontrados em literatura, que podem ajudar o estudo de trabalhos futuros, visando o monitoramento ambiental. 


\section{Trabalhos Futuros}

Serão apresentados sugestões de temas de possiveis trabalhos para a continuação deste projeto.

1) Estudo de outros tipos de pesticidas presentes no mercado com a finalidade de se aplicar a tecnologia da "língua eletrônica" no desenvolvimento de um protótipo;

2) Investigação de outros materiais utilizados para fabricação das unidades sensoriais para análise de contaminantes em águas , como a utilização de outros polímeros como o polipirrol(PPy) e a lignina sulfonada;

3) Caracterização estrutural e morfológica de novos filmes automontados por análise de espectrofotometria de UV-Vis, infravermelho (FTIR), microscopia eletrônica de varredura (MEV) e microscopia de força atômica (MFA);

4) Estudo de outros tipos de águas naturais com a "língua eletrônica" a fim de se obter uma resposta elétrica mais próxima da realidade. 


\section{Referências Bibliográficas}

1- KHAN, U. S. Pesticides in the Soil Environment, Elsevier Scientific Publishing Company, Amsterdam-Oxford-New York, 1980.

2- CONSOLIN FILHO, N. Desenvolvimento de Novos Materiais para a Detecção de Pesticidas. São Carlos, SP, 2003. Tese (Doutorado) - Instituto de Física de São Carlos. Ciência e Engenharia de Materiais. Universidade de São Paulo USP.

3- Disponível em : http:/lepa.gov/pesticides/about/types.htm; visualizado em $03 / 07 / 03$ às $11: 00 \mathrm{~h}$

4- Disponível

em:

http://igm.pt/edicoes online/diversos/agua subterranea/poluicao.htm; visualizado em 14/10/04 às 9:00h.

5- Disponível em: http://www.jornalexpress.com.br/noticias/detalhes.php?id jornal=8341\&id notici $a=204$; visualizado em 26/01/05 às $11: 42 \mathrm{~h}$.

6- SPADOTTO, C. A. Modelagem do Movimento de Herbicidas no Solo. Comitê de Meio Ambiente, Sociedade Brasileira da Ciência das Plantas Daninhas, 2002.

7- Disponivel em: http://uww.cetesb.sp.gov.br/Agua/agua geral.asp; visualizado 26/01/05 às 9:40h.

8- ZHANG, Z.; HUANG, J.;YU, G.; HONG, H. Occurrence of PAHs, PCBs and organochorine pesticides in the Tonghui River of Beijing, China. Environmental Pollution, vol. 130, p. 249-261, 2004.

9- IVANOV, A. N.; EVTUGYN, G. A.; GYURCSÁNYI, R. E.; TÓTH, K.; BUDNIKOV, H. C. Comparative investigation of electrochemical cholinesterase biosensors for pesticide determination. Analytica Chimica Acta, vol. 4004-1, p. 55-65, 2000.

10-KRANTZ-RÜLCKER, C.; STENBERG, M.; WINQUIST, F.; LUNDSTRÖM, I. Electronic tongues for environmental monitoring based on sensor arrays and pattern recognition: a review. Analytica Chimica Acta, vol. 426-2, p. 217-226, 2001.

11-FIRMINO, A. Desenvolvimento de Materiais para Aplicação em Sensores de Café, Dissertação de Mestrado em Ciência e Engenharia de Materiais, Instituto de Física de São Carlos, USP, p.69-70, 2002.

12-BORATO, E. Estudo de filmes poliméricos ultrafinos de polianilinas para aplicação em sensores, Dissertação de Mestrado em Ciência e Engenharia de Materiais, Instituto de Física de São Carlos, USP, 2002.

13-BORATO, E.; RIUL JR., A.; FERREIRA, M.; OLIVEIRA JR., O. N.; MATTOSO, L. H. C. Exploiting the Versatility of Taste Sensors base on Impedance 
Spectroscopy. Instrumentation Science and Techonology, vol. 32, n. 1, p. 21-30, 2004.

14- MANO, E. B.; MENDES, L. C. Introdução a Polímeros, Segunda edição revisada e ampliada, Editora Edgard Blücher Itda, p. 3, 1999.

15-CALLISTER J.; WILLIAM D. C. Ciência e Engenharia de Materiais: Uma Introdução, sexta edição, editora LTC, p.309-324, 2002.

16-PATERNO, L. G.; MATTOSO, L. H. C.; OLIVEIRA JR., O. N. Filmes Poliméricos Ultrafinos Produzidos Pela Técnica De Automontagem: Preparação, Propriedades e Aplicações. Química Nova, Vol. 24, No 2, p.228-235, 2001.

17-GUISEPPI-ELIE, A.; WALLCE, G. G.; MATSUE, T. Chemical and Biological Sensors based on Electrically Conducting Polymers, In Handbook of Conducting Polymers, 2ed. New York, Marcel Decker, cap. 34, 1998.

18- MALTA, M.; GONZALEZ, E. R.; TORRESI, R. M. Electrochemical and chromogenic relaxation processes in polyaniline films. Polymer, 43, p.5895$5901,2002$.

19-GHOSH, S., INGANÃS, O. Self-assembly of a conducting polymer nanostructure by physical crosslinking: applications to conducting blends and modified electrodes. Synthetic Metals, 101, p.413-416, 1999.

20- MONTHEO, A. J., SANTOS, J. R., VENANCIO, E. C., MATTOSO, L. H. C. Influence of different types of acidic dopant on the electrodeposition and properties of polyaniline films. Polymer, Vol. 39, No 26, p.6977-6982, 1998.

21-MATTOSO, L. H. C. Polianilinas: Sintese, Estrutura e Propriedades. Química Nova, Vol. 19, No 4, p.388-399, 1996.

22-MACDIARMID, A. G. Polyaniline and polypirrole: where are we headed? Synthetic Metals, Vol. 84, p. 27-34, 1997.

23-DHAWAN, S. K; TRIVEDI, D. C. Synthetic Metals, 60, p.67-71, 1993.

24-LOUWET, F.; GROENENDAAL, L.; DHAEN, J.; MANCA, J.; VAN LUPPEN, J.; VERDONCK, E.; LEENDERS, L. PEDOT/PSS: synthesis, characterization, properties and applications. Synthetic Metals, 135-136, p.115-117, 2003.

25- LANGMUIR, I. J. Am. Chem. Soc., 39, p.1848-1906, 1917.

26- BLODGETT, K. B. J. Am. Chem. Soc., 57, p.1007-1022, 1935.

27-RIUL JR., A.; DOS SANTOS, D. S.; WOHNRATH, K.; DI TOMMAZO, R.; CARVALHO, A. C. P. L. F.; FONSECA, F. J.; OLIVEIRA, O. N.; TAYLOR, D. M.; MATTOSO, L. H. C. Artificial Taste Sensor: Efficient Combination of Sensors Made From Langmuir-Blodgett Films of Conducting Polymers and a Ruthenium Complex and Self-Assembled Films of an Azobenzene Containing Polymer. Langmuir, vol. 18, p. 239-245, 2002.

28-DECHER, G. ; HONG, J. D. ; SCHMITT, J. Buildup of ultrathin multilayer films by a self-assembly process: III. Consecutively alternating adsorption of anionic and cationic polyelectrolytes on charged surfaces. Thin Solid Films, Vol. 210-211, Part 2, p. 831-835, 1992.

29-RIBEIRO, M. Revolução em pequena escala, Revista Pesquisa Fapesp, No 90 , p.60-65, Ago de 2003.

30-D'AMICO, A.; DI NATALE, C.; PAOLESSE, R. Portraits of gasses and liquids by arrays of nonspecific chemical sensors: trends and perspectives. Sensors and Actuators B, 68, p.324-330, 2000.

31-TOKO, K. Electronic tongue. Biosensor and Bioeletronics, Essex, v. 13, n. 6, p. 701-709, 1998.

32-RIUL JR., A.; MALMEGRIM, R. R.; FONSECA, F. J.; MATTOSO, L. H. C. An artificial taste sensor base on conducting polymers. Biosensors and Bioelectronics, vol. 18, no 11, p. 1365-1369, 2003. 
33- TAKEDA, H. H. Estudo da formação de filmes de poli(o-etoxianilina) visando a sua aplicação em Língua Eletrônica. Dissertação de Mestrado em Ciência e Engenharia de Materiais, Instituto de Física de São Carlos, USP, 2004.

34- GREEN, M. B.; HARTLEY, G. S.; WEST, T. F. Chemicals for Crop Improvement and Pest Management, Third Edition, Pergamon Press, p. 9-10, 1987.

35- Disponivel em:http://www.parl.gc.ca/InfoComDoc/36/2/ENVI/Studies/Reports/envi01/10ch3-e.html; visualizado em 14/10/04 às 10:01h.

36-SOIL SCIENCE SOCIETY OF AMERICA. Pesticides in Soil and Water. W. D. Guenzi Editor, 1974.

37-Disponivel em: http://www.tierramerica.net/2002/1201/pconectate.shtml; visualizado em 03/07/03 às 11:30h.

38-SANTOS, F. F.; REZENDE, M. O. Influência do meio reacional no comportamento fotoquímico do inseticida paration etílico. Química Nova, Vol. 25, No 1, p. 53-58, 2002.

39-DORES, E. F. G. C.; DE-LAMONICA-FREIRE, E. M. Contaminação Do Ambiente Aquático Por Pesticidas. Estudo de Caso: Águas Usadas Para Consumo Humano Em Primavera Do Leste, Mato Grosso - Análise Preliminar. Química Nova, Vol. 24, No 1, p.27-36, 2001.

40-TURGUT, C. The contamination with organoclhorine pesticides and heavy metals in surface water in Küçuk Menderes River in Turkey. Environmental International, vol. 29-1, p. 29-32, 2003.

41-FILIZOLA, H. F.; FERRACINI, V. L.; SANS, L. M. A.; GOMES, M. A. F.; FERREIRA, C. J. A. Monitoramento e avaliação do risco de contaminação por pesticidas em água superficial e subterrânea na região de Guairá. Pesquisa Agropecuária Brasileira, vol. 37, n 5, 2002.

42-LAABS V.; AMELUNG, W.; PINTO, A. A.; WANTZEN, M.; DA SILVA, C. J.; ZECH, W. Pesticides in surface water, sediment, and rainfall of the northeastern Pantanal basin. Journal of Environmental Quality, vol. 31-5, p. 1636-1648, 2002.

43- LECHNER, A. Pesquisador aposta na educação em massa. Jornal Primeira Pagina de São Carlos, p. A8, 23 de março de 2003.

44-DOBRINAS, S.; BIRGHILA, S.; COATU, V.; STOICA, A. I.; BAIULESCU, G. E. Contamination of black sea coast by polycyclic aromatic hydrocarbons and organochorine pesticides. Revista de Chimie, vol. 55-7, p. 483-487, 2004.

45-PICER, M.; PICER, N. Hazards posed by petroleum oil and some chorinated hydrocarbons to aquatic ecosystem in Croatian Karst during 1991-1995 war in Croatia. Periodicum Biologorum, vol. 105-3, p. 345-354, 2003.

46-MORALES-RIFFO, J. J.; RICHTER, P. Rapid determination of inorganic elements in airbone particulate matter by using acidified subcritical water extraction and inductively-couple plasma-optical-emission spectrometry. Analytical and Bioanalytical Chemistry, vol. 380-1, p. 129-134, 2004.

47-MACDIARMID, A. G.; CHIANG, J. C.; RICHTER, A. F.; SOMASIRI, N. L. D.; EPSTEIN, A. J. Conducting Polymers, In: Alcacer, L.. Ed.; Reidel Pub. Dordrecht: Holland, 105, 1987.

48-MATTOSO, L. H. C.; MANOHAR, S. K.; MACDIARMID, A. G.; EPSTEIN, A. J. Journal of Polymer Science: Part A: Polymer Chemistry, Vol. 33, p.1227-1234, 1995.

49- MACDIARMID, A. G.; YANG, L. S.; HANG, W. S.; HUMPHREY, B. D. Polyaniline: electrochemistry and application to rechargeable batteries. Synthetic Metals, Vol. 18, p.393, 1987.

50-DOS SANTOS, F. Utilização de lignossulfonatos na preparação de resinas fenólicas tipo novolaca e pós moldagem fenólicos, Dissertação de Mestrado em 


\section{PCA (Principal Component Analysis)}

Krantz-Rulcker et al. (2001), Riul Jr. et al.(2003) e Kiyoshi Toko et al.(1998) em seus estudos ${ }^{10,27,31}$ utilizam, e explicam a PCA, como sendo uma ferramenta matemática e estatística que é utilizada para explicar a variância nos dados experimentais. Os dados da matriz consistem em um número de experimentos, cada um com um número de variáveis. A PCA decompõe os dados da matriz em variáveis latentes com o maior número de variâncias possíveis. Os "loading vectors", descrevem a direção da componente principal em relação às variáveis originais, ou seja, são os vetores descritores. Já os "score vectors", descrevem a direção da componente principal em relação às observações, seriam os vetores amostra ${ }^{65,10}$.

Será descrito, a seguir, como funciona a PCA, e como são gerados os gráficos, a partir de um exemplo prático de dados experimentais ${ }^{66}$. Na prática, os cálculos de autovalores e autovetores são feitos através de softwares computacionais, mas a fim de ilustrar como isso é feito, será apresentado um cálculo de dados bivariados, passo a passo.

A PCA envolve rotação e transformação de $n$ eixos originais em novos eixos, e isto é realizado de modo que os novos eixos sigam a direção da variância máxima dos dados, com a limitação dos eixos serem ortogonais. Normalmente, o número de novas variáveis, $p$, necessárias para descrever a maioria das variâncias dos dados das amostras é menor que n. A PCA fornece um método de redução da dimensionalidade do parâmetro espaço, e pode revelar variáveis ou conjunto de variáveis que determinam alguma estrutura no espaço, e que podem ser interpretadas através de termos químicos ou físico-químicos.

A Primeira Componente Principal é a combinação linear com a maior variância (desvio quadrático médio da média), com coeficientes normalizados aplicados às variáveis usadas nas combinaçōes lineares. Uma vez determinada a Primeira Componente Principal, o procedimento é continuado, até que todas as componentes principais estejam calculadas. Neste ponto $p=n$.

A Tabela 9 a seguir apresenta os principais valores de 11 determinações da concentração de cada um dos 13 traços de metais de 17 amostras diferentes de tecidos sanguíneos. 
Tabela 9. Dados de traços de metal em tecido sanguíneos do coração ${ }^{66}$.

\begin{tabular}{|c|c|c|c|c|c|c|c|c|c|c|c|c|c|}
\hline & $\mathrm{Cu}$ & $M n$ & Mo & $\mathrm{Zn}$ & $\mathrm{Cr}$ & $\mathrm{Ni}$ & Cs & $\mathrm{Ba}$ & Sr & $\mathrm{Cd}$ & Al & Sn & $\mathrm{Pb}$ \\
\hline $1 \mathrm{AO}$ & 38,4 & 5,1 & 1,9 & 300 & 2,3 & 1,8 & 3,9 & 9,9 & 5,4 & 7,1 & 31,0 & 15,2 & 8,8 \\
\hline 2 MPA & 47,6 & 3,8 & 2,1 & 774 & 1,2 & 1,7 & 2,3 & 4,0 & 3,7 & 9,7 & 13,7 & 15,9 & 8,8 \\
\hline $3 \mathrm{RSCV}$ & 112,0 & 9,8 & 4,6 & 521 & 3,0 & 3,9 & 4,9 & 7,3 & 4,4 & 11,8 & 35,9 & 32,8 & 20,1 \\
\hline $4 \mathrm{TV}$ & 52,7 & 3,7 & 3,2 & 358 & 3,0 & 2,7 & 3,7 & 6,6 & 3,6 & 17,6 & 28,6 & 18,5 & 25,2 \\
\hline $5 \mathrm{MV}$ & 42,0 & 3,6 & 3,2 & 327 & 2,1 & 3,5 & 3,1 & 5,1 & 3,7 & 9,7 & 22,0 & 15,4 & 15,1 \\
\hline $6 \overline{\mathrm{PV}}$ & 102,0 & 21,9 & 5,9 & 744 & 7,6 & 8,4 & 47,3 & 54,4 & 16,4 & 33,9 & 280,0 & 36,9 & 55,0 \\
\hline $7 \mathrm{AV}$ & 61,2 & 12,8 & 4,2 & 224 & 5,7 & 5,2 & 21,9 & 31,7 & 7,8 & 13,8 & 126,0 & 25,2 & 32,5 \\
\hline 8RA & 140,0 & 6,4 & 3,3 & 429 & 2,2 & 2,8 & 2,0 & 2,3 & 2,3 & 7,5 & 5,0 & 33,9 & 12,2 \\
\hline 9 LAA & 137,0 & 7,9 & 3,2 & 353 & 0,7 & 2,8 & 1,1 & 0,7 & 1,2 & 7,9 & 6,5 & 33,5 & 9,5 \\
\hline $10 \mathrm{RV}$ & 163,0 & 6,7 & 3,8 & 433 & 2,0 & 2,2 & 0,8 & 0,7 & 1,6 & 7,5 & 6,3 & 38,9 & 6,7 \\
\hline $11 \mathrm{LV}$ & 171,0 & 7,2 & 4,6 & 396 & 1,7 & 2,8 & 0,7 & 0,8 & 1,5 & 7,3 & 6,4 & 44,2 & 7,6 \\
\hline $12 \mathrm{LV}-\mathrm{PM}$ & 170,0 & 7,8 & 5,3 & 330 & 1,8 & 2,6 & 0,9 & 0,8 & 2,1 & 6,8 & 7,6 & 41,6 & 9,3 \\
\hline $13 \mathrm{IVS}$ & 171,0 & 6,8 & 4,6 & 248 & 1,1 & 2,8 & 1,4 & 0,9 & 1,5 & 7,0 & 9,5 & 39,6 & 10,3 \\
\hline $14 \mathrm{CR}$ & 160,0 & 6,9 & 4,1 & 493 & 1,5 & 2,9 & 1,3 & 1,6 & 1,9 & 7,7 & 17,8 & 35,6 & 12,5 \\
\hline $15 \mathrm{SN}$ & 145,0 & 6,6 & 4,2 & 548 & 1,7 & 2,9 & 1,1 & 1,5 & 2,2 & 7,7, & 8,6 & 31,5 & 12,4 \\
\hline $\begin{array}{l}16 \mathrm{AVN} \\
+\mathrm{R}\end{array}$ & 144,0 & 6,5 & 4,2 & 284 & 1,3 & 2,5 & 1,3 & 1,3 & 3,3 & 6,5 & 5,4 & 32,8 & 7,5 \\
\hline 17 LBB & 164,0 & 6,7 & 5,4 & 449 & 1,5 & 2,8 & 1,5 & 1,2 & 2,1 & 7,6 & 12,8 & 39,7 & 12,6 \\
\hline
\end{tabular}

$A O=A o r t a ; M P A=$ artéria pulmonar principal; $R S C V=$ veia cava superior direita; $T V=$ Válvula tricúspide; $M V=$ válvula mitral; $P V=$ válvula pulmonar; $A V=$ válvula aórtica; $R A=$ átrio direito; $L A A=$ átrio esquerdo; $R V=$ ventrículo direito; $L V=$ ventrículo esquerdo; LV-PM= ventrículo esquerdo-músculo; IVS= septo interventricular; $C R=$ crista supraventricular; $S N=$ nodo sinusal $; A V N+B=$ nodo do átrio ventricular ; $L B B=$ ramo esquerdo de nervos.

A variância da concentração do cromo é 3,07 e a variância da concentração do níquel é 2,43 , e suas variâncias 2,47 . Esta estrutura variância-covariância pode ser representada na forma de uma matriz variância-covariância, como apresentado a seguir:

$$
\operatorname{Cov} \times 1, \times 2=\begin{array}{ccc} 
& \times 1 & \times 2 \\
\times 1 & 3,07 & 2,47 \\
\times 2 & 2,47 & 2,43
\end{array}
$$

Esses resultados podem ainda ser representados na forma de gráfico, como mostrado na Figura 50. 


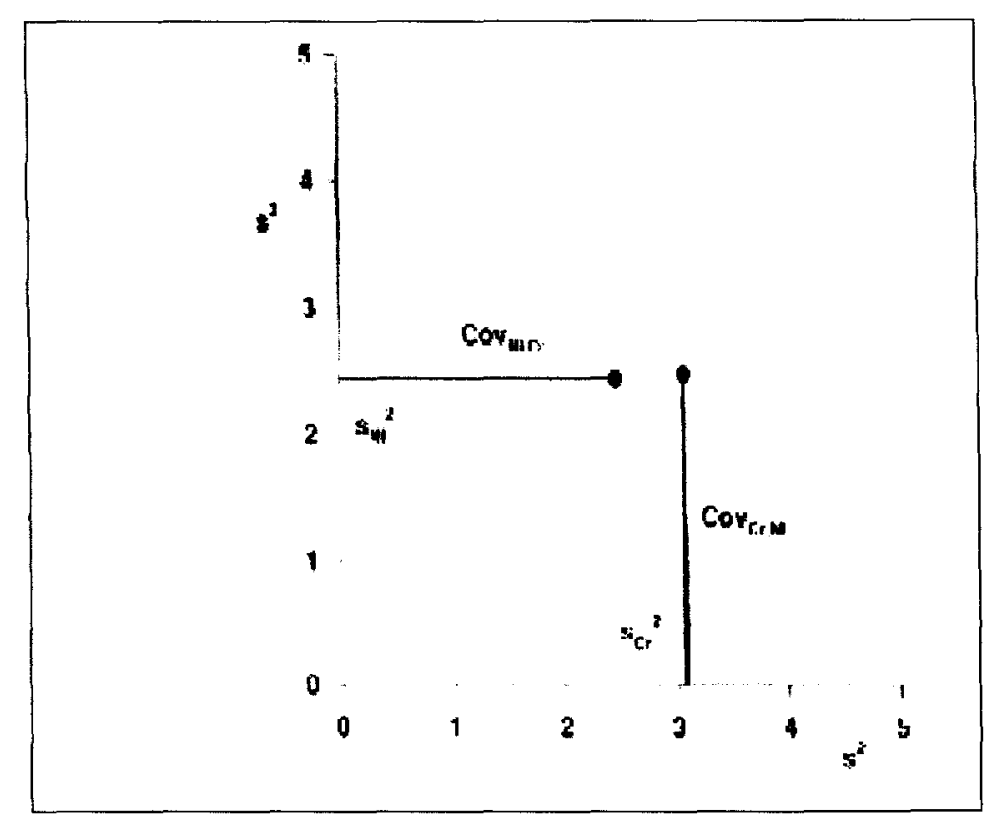

Figura 50. Gráfico da matriz variância-covariância ${ }^{66}$.

A variância dos dados do cromo é representada na Figura 50 por uma linha ao longo do eixo $X 1$ com comprimento igual à variância de $X 1$. Desde que a concentração do cromo é correlacionada com a do níquel, valores $X 1$ variam com o eixo $X 2$ variável. $O$ comprimento desta linha é igual à covariância de $X 1$ com $X 2$, e representa o grau de interação ou colinearidade entre as variáveis. Assim, a variância e a covariância de $X 2$ são desenhadas ao longo do segundo eixo. Para uma matriz quadrada (2x2), estes elementos de matriz variância-covariância representam o limite de uma elipse, onde o centro da mesma representa a origem do sistema co-ordenado. A inclinação do eixo principal é o autovetor associado com a Primeira Componente Principal, e seu autovalor correspondente é o comprimento do eixo principal, como se observa na Figura 51. 


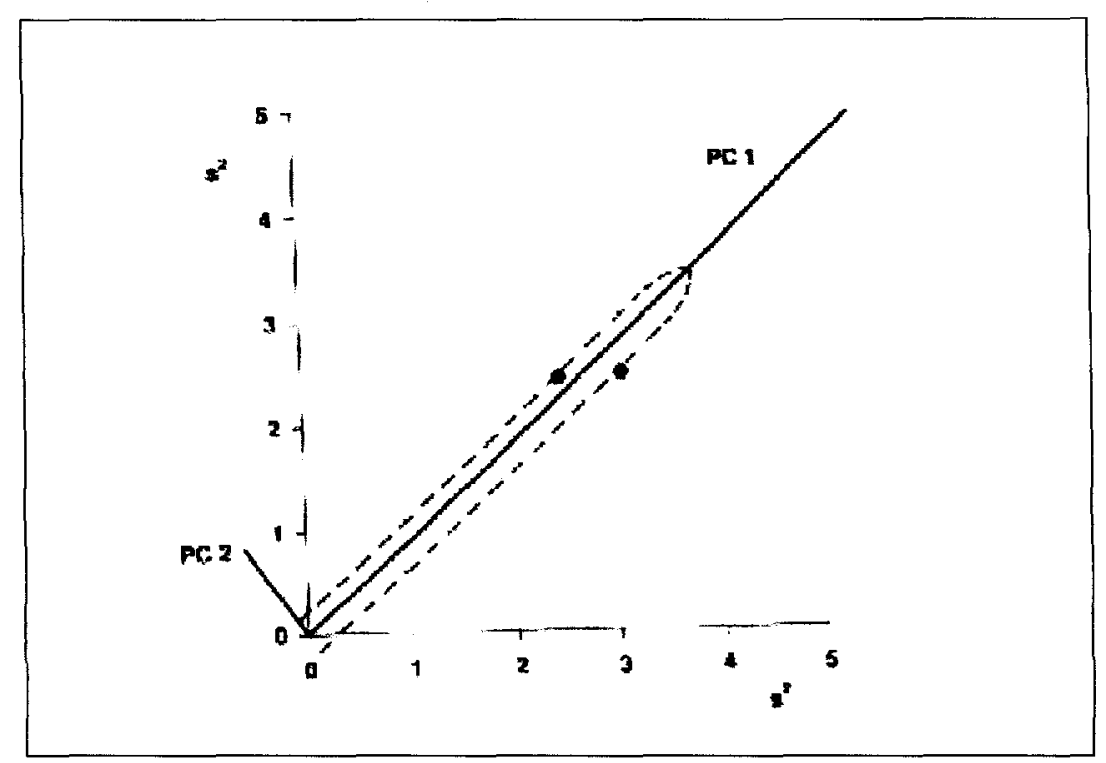

Figura 51. Elementos de uma matriz variância-covariância que definem uma elipse ${ }^{66}$.

A Segunda Componente Principal é definida pelo segundo autovetor e autovalor, e é representada pelo menor eixo da elipse, além de ser ortogonal a Primeira Componente Principal.

Quando a matriz variância-covariância é $3 \times 3$, os elementos representam a superfície de um elipsóide tri-dimensional, e para matrizes maiores, formas elípticas de maiores dimensões são apenas imaginadas. Com o auxílio de operações matemáticas, essas componentes podem ser definidas em uma mesma dimensionalidade.

Ou seja, a componente principal pode ser definida como os autovetores da matriz variância-covariância, que formecem a direção dos novos eixos em que os dados podem ser projetados. O tamanho ou comprimento desses novos eixos contendo os dados projetados é proporcional à variância da nova variável.

Calcularemos, então, com finalidade ilustrativa, os autovetores e autovalores de dados bivariados.

Consideremos o conjunto de equações, expresso matricialmente:

A. $x=\ell$. $x$, onde: $A=$ matriz, $x=$ vetor, $\ell=$ autovalor [1]

Para determinar estes autovalores, reescreve-se a equação acima como:

A. $x-\ell . x=0$ ou $(A-\ell .1) x=0$ [2], onde: I é a matriz identidade

Se $x$ é diferente de 0 , então:

$$
|A-\ell . I|=0 \quad[3]
$$

Com os dados experimentais de cromo e níquel teremos: 


$$
|\operatorname{Cov}-\ell .1|=\left|\begin{array}{cc}
S_{x 1}{ }^{2}-\ell & \operatorname{Cov} \\
\operatorname{Cov} & S_{x 2}{ }^{2}-\ell
\end{array}\right|=0[4]
$$

onde: X1 e X2 são concentrações de cromo e níquel, Cov= covariância entre X1 e X2.

Expandindo a equação 3 , teremos:

$$
(S \times 12-\ell)(S \times 22-\ell)-\operatorname{Cov} 2=0 \text { [5] }
$$

Substituindo valores de cromo e níquel:

$$
(3,07-\ell)(2,43-\ell)-2,472=0 \quad[6]
$$

Simplificando:

$$
\ell 2-5,5 \ell+1,36=0[7]
$$

Desta equação 7, quadrática simples, temos dois autovalores: $\ell 1=5,24$ e $\ell 2=0,26$.

Associado a cada autovalor, tem-se um autovetor característico, v=[v1,v2] definindo a inclinação do eixo. Os autovalores, $\ell$, foram definidos como surgindo de um conjunto de equações simultâneas [equação 2], que podem ser expressas como uma matriz 2x2:

$$
\left[\begin{array}{ll}
A_{11}-\ell_{1} & A_{12} \\
A_{21} & A_{12}-\ell_{1}
\end{array}\right]\left[\begin{array}{l}
X_{1} \\
X_{2}
\end{array}\right]=\left[\begin{array}{l}
0 \\
0
\end{array}\right]_{[8]}
$$

Substituindo os valores dos dados da variância-covariância do Ni-Cr, temos:

$$
\begin{aligned}
& {\left[\begin{array}{cc}
S_{x 1}{ }^{2}-\ell_{1} & C o v \\
\operatorname{Cov} & S_{x 2}{ }^{2}-\ell_{1}
\end{array}\right] \cdot\left[\begin{array}{l}
v 1_{1} \\
v 2_{2}
\end{array}\right]=0 \quad[9]} \\
& {\left[\begin{array}{cc}
S_{x 1}{ }^{2}-\ell_{2} & \operatorname{Cov} \\
\operatorname{Cov} & S_{x 2}{ }^{2}-\ell_{2}
\end{array}\right]\left[\begin{array}{l}
v 1_{1} \\
v 2_{2}
\end{array}\right]=0 \quad[10]}
\end{aligned}
$$

Resolvendo:

$$
\begin{aligned}
& V 1=[0,751 ; 0,660] \\
& V 2=[-0,660 ; 0,751]
\end{aligned}
$$

Tendo determinado os eixos ortogonais de nossos dados bivariados, então temos a Primeira Componente Principal PC1:

$$
P C 1 i=0,751 \times 1 i+0,660 \times 2 i
$$

E para a Segunda Componente Principal PC2:

$$
P C 2 i=-0,660 \times 1 i+0,751 \times 2 i
$$


Então, os elementos dos autovetores tornam-se coeficientes requeridos para as variáveis originais, e são ditos "loadings". Os elementos individuais das variáveis PC1 e PC2 são derivados de X1 e X2 e são denominados "scores".

A Tabela 10 mostra os scores das concentrações de cromo e níquel.

Tabela 10. PC "scores" das concentrações de cromo e níquel ${ }^{66}$.

\begin{tabular}{|l|l|l|}
\hline Amostra & PC1 & PC2 \\
\hline AO & 2,91 & $-0,17$ \\
\hline MPA & 2,02 & 0,48 \\
\hline RSCV & 4,82 & 0,94 \\
\hline TV & 4,03 & 0,04 \\
\hline MV & 3,89 & 1,24 \\
\hline PV & 11,25 & 1,28 \\
\hline AV & 7,71 & 0,14 \\
\hline RA & 3,50 & 0,65 \\
\hline LAA & 2,37 & 1,64 \\
\hline RV & 2,95 & 0,33 \\
\hline LV & 3,12 & 0,98 \\
\hline LV-PM & 3,06 & 0,76 \\
\hline IVS & 2,67 & 1,37 \\
\hline CR & 3,04 & 1,18 \\
\hline SN & 3,19 & 1,05 \\
\hline AVN+B & 2,62 & 1,02 \\
\hline LBB & 2,97 & 1,11 \\
\hline
\end{tabular}

A variância total dos dados originais é $5,5(3,07+2,43)$, sendo $56 \%$ a contribuição de $X 1$ e $44 \%$ a contribuição de $X 2$. Os autovalores calculados são os comprimentos dos dois eixos principais, e representam a variância associada com cada nova variável PC1 e PC2. Mais de 95\% da variância total é encontrada na Primeira Componente Principal, e menos de 5\% na Segunda Componente Principal.

Assim, pode-se aplicar a análise de componentes principais na matriz inteira, apresentada na Tabela 9. A mesma técnica utilizada no exemplo para extrair autovalores e autovetores para duas variáveis é extendido para multivariáveis, neste caso com auxílio de um software adequado, já que os cálculos começam a ficar complexos.

Finalizando o exemplo, a fim de facilitar os cálculos, os dados foram transformados em escala logarítimica, e os resultados da PCA são apresentados na Tabela 11. 
Tabela 11. Resultados da Análise de Componente Principal nos logarítimos dos dados de concentração dos metais ${ }^{66}$.

\begin{tabular}{|c|c|c|c|c|c|c|c|c|c|c|c|c|c|}
\hline \multicolumn{14}{|c|}{ autovalores } \\
\hline & & PC1 & $\mathrm{PC2}$ & $\mathrm{PC3}$ & $\mathrm{PC4}_{4}$ & $\mathrm{PC6}$ & PC7 & $\mathrm{PC} 8$ & PC9 & $\mathrm{PC} 10$ & PC11 & PC12 & $\mathrm{PC} 13$ \\
\hline Variâr & & 7,49 & 3,47 & 0,99 & 0,38 & 0,15 & 0,09 & 0,08 & 0,05 & 0,02 & 0,01 & 0,000 & 0,001 \\
\hline $\begin{array}{l}\% \\
\text { Variâr }\end{array}$ & & 57.7 & 26,7 & 7,7 & 2,9 & 1,2 & 0,7 & 0,6 & 0,4 & 0,1 & 0,1 & 0,0 & 0,0 \\
\hline $\begin{array}{l}\text { \%con } \\
\text { ção } \\
\text { cumu }\end{array}$ & ibui & 57,7 & 84,4 & 92,1 & 95,0 & 98,0 & 98,7 & 99,4 & 99,8 & 99,9 & 100 & 100 & 100 \\
\hline \multicolumn{14}{|c|}{ autovetores } \\
\hline & $\mathrm{PC1}$ & PC2 & $\mathrm{PC} 3$ & PC4 & PC5 & PC6 & PC7 & PC8 & PC9 & PC10 & PC11 & PC12 & $\mathrm{PC} 13$ \\
\hline $\begin{array}{l}\mathrm{Log} \\
\mathrm{Cu}\end{array}$ & $-0,17$ & 0,47 & 0,08 & 0,08 & 0,07 & 0,16 & $-0,07$ & $-0,17$ & 0,35 & 0,47 & $-0,43$ & $-0,22$ & 0,35 \\
\hline $\begin{array}{l}\text { Log } \\
\mathrm{Mn}\end{array}$ & 0,20 & 0,39 & $-0,05$ & 0,57 & $-0,30$ & 0,12 & 0,14 & 0,27 & $-0,16$ & $-0,54$ & $-0,17$ & 0,001 & 0,13 \\
\hline $\begin{array}{l}\text { Log } \\
\text { Mo }\end{array}$ & 0,63 & 0,49 & $-0,04$ & $-0,33$ & 0,26 & $-0,52$ & 0,36 & $-0,009$ & 0,03 & $-0,30$ & 0,20 & 0,02 & 0,26 \\
\hline $\begin{array}{l}\log \\
\mathrm{Zn}\end{array}$ & 0,10 & 0,01 & 0,95 & $\overline{0,10}$ & 0,12 & $-0,11$ & \begin{tabular}{|l|}
$-0,11$ \\
\end{tabular} & 0,10 & $-0,08$ & $-0,03$ & 0,08 & $-0,05$ & $-0,006$ \\
\hline $\begin{array}{l}\mathrm{Log} \\
\mathrm{Cr}\end{array}$ & 0,33 & 0,04 & $-0,19$ & $-0,03$ & 0,74 & 0,26 & $-0,30$ & 0,20 & $-0,23$ & $-0,08$ & $-0,006$ & $-0,21$ & 0,01 \\
\hline $\begin{array}{l}\log \\
\mathrm{Ni}\end{array}$ & 0,29 & 0,27 & $-0,05$ & $-0,24$ & $-0,30$ & $-0,26$ & $-0,50$ & $-0,26$ & $-0,45$ & 0,28 & $-0,06$ & $-0,002$ & $-0,08$ \\
\hline $\begin{array}{l}\mathrm{Log} \\
\mathrm{Cs}\end{array}$ & 0,36 & $-0,04$ & $-0,07$ & 0,15 & $-0,20$ & 0,002 & $-0,05$ & $-0,12$ & 0,35 & 0,11 & 0,58 & $-0,55$ & 0,10 \\
\hline $\begin{array}{l}\mathrm{Log} \\
\mathrm{Ba}\end{array}$ & 0,35 & $-0,14$ & $-0,03$ & 0,17 & 0,04 & $-0,05$ & $-0,16$ & 0,08 & 0,19 & 0,19 & 0,14 & 0,68 & 0,48 \\
\hline $\begin{array}{l}\mathrm{Log} \\
\mathrm{Sr}\end{array}$ & 0,34 & $-0,11$ & $-0,01$ & 0,33 & 0,27 & $-0,31$ & 0,24 & $-0,50$ & 0,19 & 0,10 & $-0,32$ & 0,04 & $-0,36$ \\
\hline $\begin{array}{l}\mathrm{Log} \\
\mathrm{Cd}\end{array}$ & 0,33 & 0,19 & $0, \overline{17}$ & $-0,36$ & $-0,07$ & 0,59 & 0,41 & $-0,38$ & $-0,17$ & 0,005 & $-0,02$ & 0,07 & 0,16 \\
\hline $\begin{array}{l}\text { Log } \\
\text { Al }\end{array}$ & 0,35 & $-0,03$ & $-0,05$ & 0,06 & $-0,18$ & $-0,11$ & 0,44 & 0,63 & $-0,21$ & 0,38 & $-0,14$ & $-0,09$ & $-0,11$ \\
\hline $\begin{array}{l}\mathrm{Log} \\
\mathrm{Sn}\end{array}$ & $-0,09$ & 0,51 & 0,01 & 0,14 & 0,08 & 0,26 & 0,38 & 0,05 & 0,08 & 0,22 & 0,42 & \begin{tabular}{|l|}
0,34 \\
\end{tabular} & $-0,53$ \\
\hline $\begin{array}{l}\log \\
\mathrm{Pb}\end{array}$ & 0,34 & 0,07 & 0,04 & $-0,41$ & $-0,15$ & 0,06 & $-0,22$ & 0,26 & 0,55 & $-0,31$ & $-0,26$ & 0,07 & $-0,29$ \\
\hline
\end{tabular}

Graficamente, podemos observar na Figura 52, a transformação das 13 variáveis originais em duas novas combinaçōes lineares, que reduziram bastante os dados, mas mantiveram muito das informações originais ${ }^{66}$. 


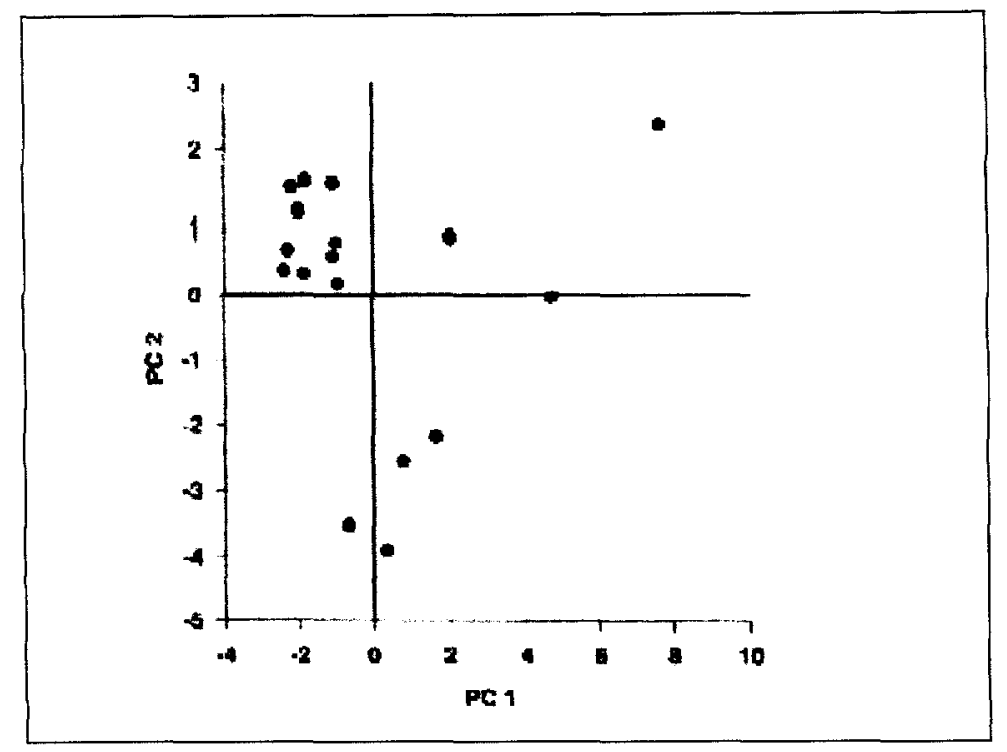

Figura 52. PCA dos dados de traços de metais nos tecidos do coração ${ }^{66}$.

Os princípios da interpretação de uma PCA podem ser brevemente descritos como:

- Uma proximidade maior ou menor entre dois pontos-variáveis no plano traduz uma correlação maior ou menor entre essas variáveis;

- a proximidade entre dois pontos-amostra indica similaridade entre as mesmas ${ }^{65}$

A partir da PCA ilustrada na Figura 52 obtem-se informações tais como: três tecidos, a válvula pulmonar, válvula aórtica e a veia cava superior direita, formam um grupo bem distinto dos outros; a aorta, artéria pulmonar principal, mitral, e válvulas tricúspides constituem um conjunto de quatro tipos de tecidos; e existe um grupo de dez tecidos derivados do miocárdio. Niedermeier et al. fez uma análise completa destes dados, que foram aqui apresentados como uma ilustração ${ }^{66}$. 